\title{
Etiquetagem do Português Clássico Baseada em Corpus
}

\author{
Carlos Daniel Chacur Alves ${ }^{1}$
}

\author{
DISSERTAÇÃO APRESENTADA \\ $\mathrm{AO}$ \\ INSTITUTO DE MATEMÁTICA E ESTATÍSTICA \\ DA \\ UNIVERSIDADE DE SÃO PAULO \\ PARA \\ OBTENÇÃO DO GRAU DE MESTRE \\ EM \\ MATEMÁTICA APLICADA
}

\begin{abstract}
Área de Concentração: Ciência da Computação
Orientador: Prof. Dr. Marcelo Finger
\end{abstract}

29 de julho de 1999

\footnotetext{
${ }^{1}$ Durante a elaboração desse trabalho o autor recebeu apoio financeiro da CAPES e FAPESP (processo 97/12986-3).
} 


\title{
Etiquetagem do Português Clássico Baseada em Corpus
}

\author{
Uma Investigação do
}

Método de Aprendizado de Transformações

Dirigido por Erros

Este exemplar corresponde à redação final da dissertação devidamente corrigida e defendida por Carlos Daniel Chacur Alves e aprovada pela comissão julgadora.

São Paulo, 26 se setembro de 1999.

Banca Examinadora:

- Prof. Dr. Marcelo Finger (Orientador) - IME-USP

- Profa. Dra. Sandra Maria Aluisio - ICMSC-USP

- Prof. Dr. Flávio Soares Corrêa da Silva - IME-USP 
Aos meus pais, a minha irmã, à Rose e à esperança. 


\section{Agradecimentos}

Talvez a parte mais difícil de escrever dessa dissertação seja a dos agradecimentos. Por essa razão, antecipo-me e peço desculpas pelas injustiças que cometerei ao me esquecer de citar algumas pessoas que foram importantes para que esse trabalho pudesse ser realizado.

Aproveito essa ocasião para expressar a minha profunda gratidão aos meus pais Carlos Alberto e Lêda Mari... nă ó por terem sido fundamentais para a elaboração desse projeto, mas principalmente peia treciosa convivência que me fez ser quem hoje sou. À Dani, minha irmã, pelo carinho e constante incentivo. À Rose, que fez os momentos mais dificeis possíveis e transformou os mais simpies en especiais. Ao tio-amigo-quase-irmão Douglas, pela grande pessoa que é. Agradeço também a todos os meus parentes que acreditam na família.

Ao Prof. Dr. Marcelo Finger, não só pela orientação que tornou esse trabalho viável mas sobretudo pelas qualidades que me fazem considerá-lo um amigo. Durante todo o projeto aprendi muitas coisas que fogem do escopo desse trabalho, e que nem por isso são menos importantes do que as que nele se encontram.

Aos amigos: Pil e Mário, colegas em mais essa empreitada; Sandro, Clemente e Litos, por mostrarem que diversão e trabalho podem conviver harmoniosamente; Cláudio, pelo bom humor mesmo nas piores tempestades; ao Lymber, pelas dicas sobre LATEX; e a todos os outros para quem a amizade é algo mais do que uma simples palavra.

Por fim, agradeço à CAPES e à FAPESP (processo 97/12986-3) pelo auxílio financeiro que me foi concedido durante o período em que esse trabalho foi feito. 


\section{Resumo}

A construção do Corpus Tycho Brahe do português histórico motivou a criação de ferramentas automáticas para a etiquetagem morfo-sintática de palavras de um texto. Para esse fim, selecionamos o método de etiquetagem de Brill por ser um dos que apresenta os melhores resultados na anotação do inglês e por ser um método de aprendizagem automática que representa o conhecimento explicitamente, sob a forma de regras claras e, portanto, de fácil compreensão.

No entanto, mostramos teórica e experimentamente que tal método não é apropriado para línguas com a riqueza morfológica do português, que requerem um grande número de etiquetas para codificação de tais informações. Para aumentar a eficiência do aprendizado das regras, propomos uma extensão ao método de Brill que impõe uma estrutura ao conjunto de etiquetas utilizado e adiciona uma fase de refinamento ao método original. Este refinamento pode ser feita de forma eficiente por não utilizar aprendizado.

Apresentamos medidas e resultados obtidos com a versão atual do Corpus Tycho Brahe e discutimos os diversos problemas encontrados no desenvolvimento de nossa abordagem. Além disso, mostramos, através de uma série de experimentos, como um etiquetador morfo-sintático pode ser uma importante ferramenta para o estudo de uma língua. 


\begin{abstract}
The construction of the Tycho Brahe Corpus of Historical Portuguese motivated the development of automatic tools for part-of-speech tagging. For this purpose, the transformation-based error-driven learning method proposed by Eric Brill was chosen. This method was chosed due to its good results in tagging English texts and its use of an explicit representation of linguistic knowledge by means rules that are easy to understand.

However, we have shown theoretically and experimentally that this method is not appropriate for languages that are morphologically rich, like Portuguese, and therefore need a large number of tags to capture this richness. To avoid such a problem, we proposed an extension to Brill's method that adds an inner structure to the tags used for annotating the texts and introduces a new phase in the tagging process called refinement. We show that this refinement can be done efficiently without using any kind of automated learning technique.

We present the results obtained so far using the latest version of the corpus and discuss some problems that have arisen during the development of the new method. We also discuss how a part-of-speech tagger can be used as a power tool for studying a language.
\end{abstract}




\section{Sumário}

1 Introdução $\quad 9$

1.1 Histórico da Lingüística Computacional Empírica . . . . . . . . . . . . . 9

1.2 o Corpus Tycho Brahe . . . . . . . . . . . . . . . . . 11

1.3 Etiquetadores Morfo-sintáticos Baseados em Regras . . . . . . . . . . . . . . 13

1.4 Etiquetadores Baseados Em Regras vs. Etiquetadores

Estocásticos . . . . . . . . . . . . . . . . . . . . 14

2 A Etiquetagem Baseada em Regras 17

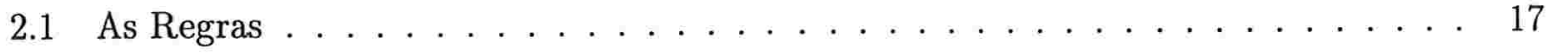

2.1.1 As Regras para Etiquetagem de Palavras Desconhecidas . . . . . . . . 18

2.1 .2 As Regras Contextuais . . . . . . . . . . . . . . . . . . 20

2.2 O Aprendizado de Regras Contextuais . . . . . . . . . . . . . . . . 21

2.2 .1 O Algoritmo de Aprendizado . . . . . . . . . . . 25

2.2.2 Análise do Algoritmo de Aprendizado . . . . . . . . . . . . . 26

2.3 A Etiquetagem . . . . . . . . . . . . . . . . . 31

2.3 .1 O Algoritmo de Etiquetagem . . . . . . . . . . . . . . 31

3 A Etiquetagem em Fases 34

3.1 Introdução . . . . . . . . . . . . . . . . . . . . . . . . . . 34 
3.2 o Refinamento das Etiquetas . . . . . . . . . . . . . . . 34

3.3 o Algoritmo de Refinamento . . . . . . . . . . . . . . . 38

3.4 Análise do Algoritmo de Refinamento . . . . . . . . . . . . . . 38

4 O Sistema 40

4.1 A Arquitetura do Sistema . . . . . . . . . . . . . . . . . 40

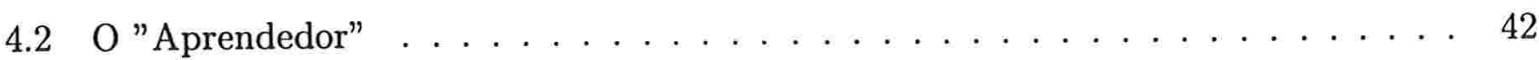

4.2.1 O "Aprendedor" de Regras para Etiquetagem de Palavras Desconhecidas 42

4.3 o "Aprendedor" de Regras Contextuais . . . . . . . . . . . . . . . 47

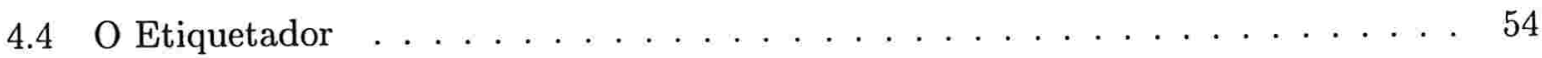

$4.4 .1 \quad \mathrm{o}$ Etiquetador Inicial $\ldots \ldots \ldots \ldots \ldots \ldots$

4.4 .2 o Etiquetador Final $\ldots \ldots \ldots \ldots \ldots$

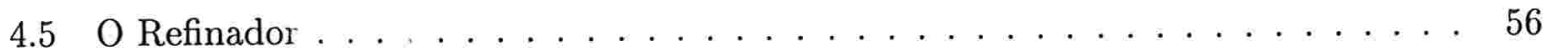

4.6 Ferramentas Auxliares . . . . . . . . . . . . . . . 56

4.6 .1 checker $\operatorname{prl} \ldots \ldots \ldots \ldots \ldots \ldots$

4.6 .2 format.prl ........................... 57

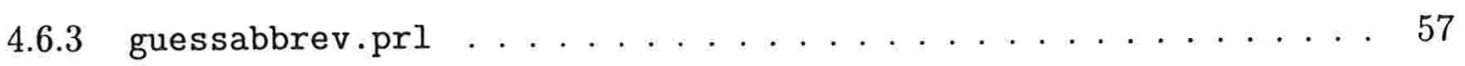

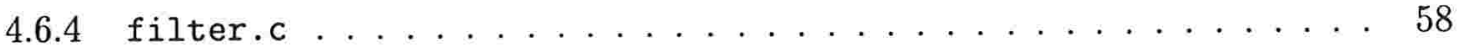

4.6 .5 generator $\operatorname{prl} \ldots \ldots \ldots \ldots \ldots \ldots \ldots \ldots$

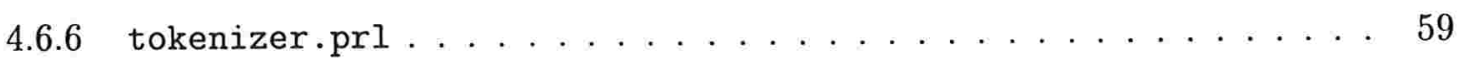

4.6 .7 extractcompl.prl . . . . . . . . . . . . . 59

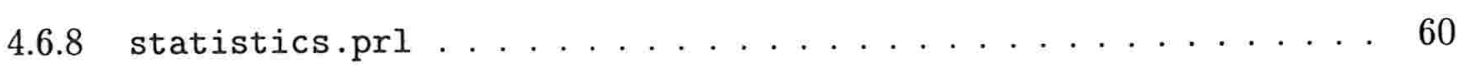

5 Refinando as Etiquetas do Corpus Tycho Brahe $\quad 61$

5.1 o Refinamento . . . . . . . . . . . . . . . . . . 61 
5.1.1 Comentários Sobre a Notação Utilizada . . . . . . . . . . . . . . . 61

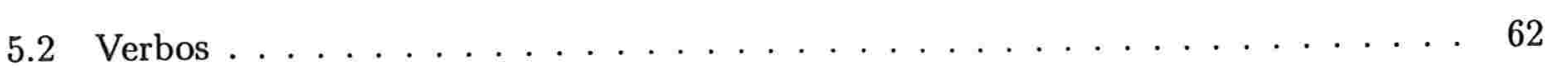

5.2 .1 Verbos Ser e Haver . . . . . . . . . . . . . . . . 63

5.2 .2 Verbos Estar e Ter . . . . . . . . . . . . . . . . 64

5.2 .3 Demais Verbos . . . . . . . . . . . . . . . . 65

5.2 .4 Adjetivos . . . . . . . . . . . . . . . . 65

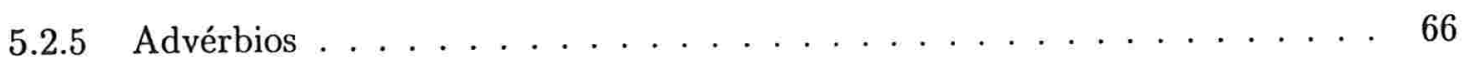

5.2 .6 Flexão de Gênero . . . . . . . . . . . . . . . . . . 67

5.2 .7 Flexão de Número . . . . . . . . . . . . . . . . . 67

5.2 .8 Flexões de Gênero e Número . . . . . . . . . . . . . . . . . 68

5.2 .9 Contrações . . . . . . . . . . . . . . . . . . 69

5.2 .10 Locuções . . . . . . . . . . . . . . . . . . . . . 69

5.2 .11 Etiquetas Sem Complemento . . . . . . . . . . . . . . . 69

5.3 Tratando as Ambigüidades . . . . . . . . . . . . . 70

6 Os Experimentos Realizados $\quad 72$

6.1 Resultados da Etiquetagem . . . . . . . . . . . . . . . . . 72

6.1 .1 Os Dados Utilizados . . . . . . . . . . . . . . . . . . . 72

6.1 .2 As Medidas Realizadas . . . . . . . . . . . . . . . 73

6.1 .3 Os Resultados Obtidos . . . . . . . . . . . . . . . . . 74

6.1 .4 Conclusões sobre os Resultados . . . . . . . . . . . . . . 75

6.2 Número de Regras Geradas vs. Número de Etiquetas . . . . . . . . . . . . 76

6.2 .1 Os Dados Utilizados . . . . . . . . . . . . . . . . . . . 77

6.2 .2 Os Resultados Obtidos . . . . . . . . . . . . . . . . 78

6.2 .3 Conclusões sobre os Resultados . . . . . . . . . . . . . . 78 
6.3 Distribuição das Regras vs. Valores da Constante MíniMO . . . . . . . . . . . 79

6.3 .1 Os Dados Utilizados . . . . . . . . . . . . . . . . . . . . . 79

6.3 .2 Os Resultados Obtidos . . . . . . . . . . . . . . . . . . . . . 80

6.3 .3 Conclusões sobre os Resultados . . . . . . . . . . . . . . . . 80

6.4 Acerto na Etiquetagem vs. Valores da Constante MíNIMO . . . . . . . . . 80

6.4 .1 Os Resultados Obtidos . . . . . . . . . . . . . . . . . . . 85

6.4 .2 Conclusões sobre os Resultados . . . . . . . . . . . . . . . 86

6.5 Paralelização das Regras . . . . . . . . . . . . . . . . . . . 87

6.5 .1 Os Dados Utilizados . . . . . . . . . . . . . . . . . . . . 90

6.5 .2 Os Resultados Obtidos . . . . . . . . . . . . . . . . . . . . 90

6.5 .3 Conclusões sobre os Resultados . . . . . . . . . . . . . . . . 91

7 Conclusões 93

7.1 Conclusões sobre o Trabalho Realizado . . . . . . . . . . . . . . . . . 93

7.2 O Etiquetador como uma Ferramenta para a Construção do Corpus . . . . . . . 94

7.3 Sobre o Método proposto por Brill . . . . . . . . . . . . . 95

7.4 Investigações Futuras . . . . . . . . . . . . . . . . . 95

A Manual de Etiquetagem do Corpus Tycho Brahe $\quad 97$

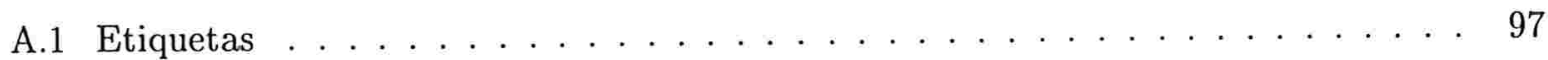

A.1.1 Verbos em Geral . . . . . . . . . . . . . . . . . . . . 98

A.1.2 Nomes . . . . . . . . . . . . . . . . . . . . 98

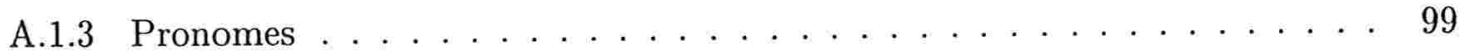

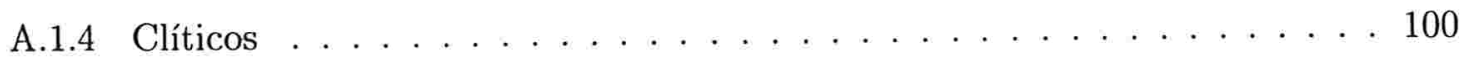

A.1.5 Determinantes . . . . . . . . . . . . . . . . 100 
A.1.6 Adjetivos . . . . . . . . . . . . . . . . . 101

A.1.7 Advérbios . . . . . . . . . . . . . . . . . . 101

A.1.8 Quantificadores . . . . . . . . . . . . . . . . 102

A.1.9 Conjunções Coordenativas e Subordinativas . . . . . . . . . . . . . . 102

A.1.10 Interrogativas Diretas e Indiretas/Relativas/Exclamativas . . . . . . . 103

A.1.11 Preposições e Contrações . . . . . . . . . . . . . . . . . . 103

A.1.12 Locuções . . . . . . . . . . . . . . . . . . . . . . . . . 103

A.1.13 Numerais . . . . . . . . . . . . . . . . . . . . . . 104

A.1.14 Negações . . . . . . . . . . . . . . . . . . . . . . . 104

A.1.15 Interjeições . . . . . . . . . . . . . . . . . . . . 105

A.1.16 Palavras Estrangeiras e Palavras Desconhecidas . . . . . . . . . . . 105

A.1.17 Sinais de Pontuação . . . . . . . . . . . . . . . . . 105

A.2 Marcações Extra-lingüísticas . . . . . . . . . . . . . . . 105

B Manual do Sistema 107

B.1 O Aprendizado de Regras para Etiquetagem de Palavras Desconhecidas . . . . 107

B.2 O Aprendizado de Regras Contextuais . . . . . . . . . . . . . . . 109

B.3 Etiquetagem $\operatorname{dos}$ Textos . . . . . . . . . . . . . . . . 110

B.4 Refinamento das Etiquetas . . . . . . . . . . . . . . . 112

B.5 Ferramentas Auxiliares . . . . . . . . . . . . . . . 113

B.5.1 divide-in-two-rand.prl . . . . . . . . . . . . 113

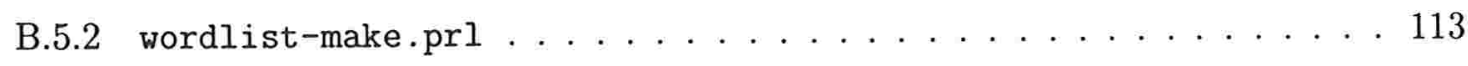

B.5.3 word-tag-count.prl . . . . . . . . . . . . . 113

B.5.4 bigram-generate.prl . . . . . . . . . . . . . . . . 114

B.5.5 make-restricted-lexicon.prl ................... 114 
B.5.6 tagged-to-untagged.prl. . . . . . . . . . . . . . . 114

B.5.7 comparitor prl . . . . . . . . . . . . . . . . 114 


\section{Lista de Figuras}

1.1 Etiquetagem Baseada em Regras ou por Transformações Sucessivas . . . . . . . . 14

1.2 Comparação dos Diferentes Métodos na Etiquetagem sem Palavras Desconhecidas 16

2.1 Aprendizado de Transformações Dirigido por Erros . . . . . . . . . . . . . 22

2.2 Um Exemplo do Método Brill de Aprendizado . . . . . . . . . . . . . . . . 23

2.3 Um Exemplo do Processo de Aprendizado de Transformações . . . . . . . . . . . 27

2.4 Um Exemplo de Etiquetagem de um Corpus . . . . . . . . . . . . . . . . 33

3.1 Algumas Etiquetas do Corpus WSJ Penn Treebank . . . . . . . . . . . . . 37

3.2 Algumas Etiquetas do Corpus Tycho Brahe . . . . . . . . . . . . . 37

4.1 Arquitetura do Sistema que desenvolvemos . . . . . . . . . . . . . 41

4.2 Arquitetura do Sistema proposto por Brill . . . . . . . . . . . . . . 41

4.3 Regras para Etiquetagem de Palavras Desconhecidas . . . . . . . . . . . . 48

4.4 Alguns Exemplos de Regras Contextuais . . . . . . . . . . . . . . . . . . 53

6.1 Divisão do Corpus para Aprendizado e Experimentos . . . . . . . . . . . . . . 74

6.2 Distribuição das REPDs, Núcleos das Etiquetas . . . . . . . . . . . . . . 81

6.3 Distribuição das REPDs, Etiquetas Completas . . . . . . . . . . . . . . 82

6.4 Distribuição das RCs, Núcleos das Etiquetas . . . . . . . . . . . . . . . . . 83 
6.5 Distribuição das RCs, Etiquetas Completas . . . . . . . . . . . . . . . . 84

6.6 Exemplo de Cluster $\ldots \ldots \ldots \ldots \ldots \ldots \ldots \ldots \ldots$

6.7 Número de Clusters $\times$ Tamanho do Cluster $\ldots \ldots \ldots \ldots$. . . . . . . . 92 


\section{Capítulo 1}

\section{Introdução}

\subsection{Histórico da Lingüística Computacional Empírica}

Os estudos lingüísticos baseados em corpora, ou seja, o estudo da linguagem com base em exemplos de sua utilização na "vida real", têm se destacado nos últimos anos, após terem sido praticamente esquecidos nas décadas de 50 e 60 . Tal esquecimento ocorreu basicamente devido à publicação de uma série de livros e artigos por Noam Chomsky que, através de críticas contundentes a tal abordagem, mudou os rumos da lingüística do empirismo para o racionalismo. Em outras palavras, estudos que antigamente se baseavam em dados naturais, tipicamente encontrados em textos, passaram a ser feitos com base em textos artificiais (teóricos) e julgamentos introspectivos dos pesquisadores.

Um dos principais argumentos de Chomsky contra o uso de corpora enfatizava que a preocupação do lingüista deveria ser o estudo da competência no uso da linguagem em detrimento da performance. Com isso, ele afirmou que o conhecimento interno (consciência) da linguagem é mais significativo do que sua manifestação externa (utilização propriamente dita, através da fala ou escrita), já que a última poderia ser afetada por fatores como o consumo de bebidas e esquecimento temporário e portanto seria um péssimo "espelho" da performance. Para ele, um lingüista não teria que se preocupar em descrever os aspectos morfológicos, sintáticos e léxicos de uma língua particular, e sim investigar, por exemplo, o que é conhecido como gramática universal, ou seja, as características comuns entre as diversas línguas. Além disso, Chomsky alegou que não seria possível estudar as características da linguagem através de uma coleção de textos, que consiste em um conjunto finito de sentenças, já que o número destas é sabidamente infinito e, mesmo que esse não fosse o caso, grande parte da linguagem não poderia ser aprendida, já que é inata aos seres humanos. Chomsky também criticou o fato de que grande parte dos 
textos seria composta por sentenças gramaticalmente incorretas, e que portanto não poderiam ser utilizadas como base para o estudos de sintaxe. Sendo assim, um texto poderia levar um lingüista a modelar características da linguagem não-gramaticais como gramaticais.

Segundo Abercrombie (ver [15]), outro fator decisivo na época para que a metodologia baseada em corpus fosse desprezada foi a falta de recursos que permitissem a manipulação de grandes quantidades de dados. Dessa forma, todo o trabalho deveria ser feito manualmente, o que resultava em grande consumo de tempo e em custos que geralmente inviabilizavam sua execução, além de não oferecer grande confiabilidade.

De fato, não é possível estudarmos todas as características de uma língua com base apenas nas informações contidas em um conjunto de textos, por mais abrangentes que esses sejam. Não seria possível, por exemplo, concluir que a sentença

* Ele brilha os livros de Mickey.

é incorreta, supondo que essa sentença (ou alguma similar) não ocorra nos corpora utilizados nos estudos, já que poderíamos encontrar sentenças como

Ele empresta os livros de Mickey.

Ele olha os livros de Mickey.

Ele carrega os livros de Mickey.

Não há nada que possa sugerir que o complemento do verbo brilhar é diferente dos complementos dos verbos emprestar, olhar e carregar, caso não tenhamos visto anteriormente tal verbo. Nesse caso, teríamos que recorrer a um falante nativo da língua ou a estudos introspectivos sobre a teoria gramatical de tal língua.

Contudo, com o passar do tempo e a evolução da lingüística, alguns estudos foram feitos e grande parte das antigas críticas foram se tornando insustentáveis. A utilização de corpora em estudos de fonética e de aquisição de linguagem tornou-se a principal fonte de evidências para essas áreas (não se pode esperar que uma criança de um ano e meio saiba se uma determinada palavra que ela conhece é um substantivo ou um verbo). O fato dos textos abrangerem apenas parte da linguagem já não era mais considerado um grande problema, dado que as sentenças mais utilizadas podiam ser encontradas e, além disso, estes eram a única fonte de informações para o estudo das frequêencias com que as palavras e construções eram aplicadas no cotidiano das pessoas. Além disso, julgamentos introspectivos muitas vezes estudavam construções que jamais seriam utilizadas por um falante (dados artificiais $\times$ dados naturais). Outro ponto importante a favor da utilização de corpora na lingüística é que, ao contrário do que acontece no caso de 
estudos introspectivos, os dados estão disponíveis para quem queira observá-los. Labov, um importante lingüista, mostrou, no final da década de 60, que a grande maioria das sentenças contidas nos textos eram gramaticalmente corretas e que portanto poderiam ser utilizadas em estudos de sintaxe. Por fim, atualmente os computadores têm grande poder de processamento e estão amplamente disponíveis nos mais diversos meios.

Além dessas razões, outra motivação muito importante para a utilização de textos no estudo de fenômenos lingüísticos é que, quando o objeto estudado se refere à utilização da linguagem no passado, eles são as únicas fontes de informação. Isso acontece pelo fato de não encontrarmos falantes destas épocas. Assim, os textos são de grande valor para a área conhecida como lingüística diacrônica ou histórica.

Baseados em estudos de corpora, foram desenvolvidos, nos últimos anos, sistemas capazes de fazer correção de erros de grafia que resultam em palavras pertencentes ao léxico [14], sistemas para tradução automática de textos [10], para resolução do problema de ambigüidade de sentenças $[7,9]$, análise sintática $[2,3,5,16]$ e reconhecimento de fala [10], entre outros.

Outro problema que foi abordado com sucesso a partir da utilização de corpora foi a etiquetagem morfo-sintática das palavras de um texto $[6,8,9,17]$, ou seja, a atribuição de um rótulo a cada uma das palavras ${ }^{1}$ que descreva sua classe gramatical. Tais sistemas, como pode ser visto em [10], são importantes ferramentas para o pré-processamento de textos que serão analisados sintaticamente de forma automática.

\subsection{O Corpus Tycho Brahe}

Segundo [13], a palavra corpus vem sendo utilizada recentemente com o sentido de descrever um conjunto de textos naturais que têm como propósito servir como material para estudos de lingüística e que são armazenados eletronicamente, de tal forma que possam ser processados por computadores. Além disso, tais textos devem apresentar máxima representatividade do tipo e estilo dos textos que fazem parte de tal corpus. Em outras palavras, um corpus deve ser uma amostra que reproduza da forma mais fiel possível as características da população que representa.

O primeiro passo ao se pensar em construir um corpus anotado é exatamente qual o tipo de informação que esse corpus deve conter. Isso depende basicamente do propósito para o qual o novo corpus será utilizado. Sendo assim, a escolha dos textos deve ser feita de forma detalhada e criteriosa. Temos que ser cuidadosos para que o corpus possua a maior quantidade de contruções

\footnotetext{
${ }^{1} \mathrm{Na}$ realidade, a cada um dos itens léxicos do texto, que compreendem. além das palavras propriamente ditas, os sinais de pontuação.
} 
presentes no tipo de texto estudado, já que inevitavelmente algumas não serão incluídas ou pelo fato de serem raras, ou por não aparecerem na amostra escolhida ou simplesmente pelo fato do corpus ser finito. Além de reproduzir as construções, é importante que elas apareçam na mesma proporção em que realmente são utilizadas. Em seguida, devemos nos preocupar em determinar uma maneira apropriada para codificar essa informação. Como estamos tratando o problema de etiquetagem morfo-sintática de palavras de um texto, precisamos, em princípio, definir qual será o conjunto de etiquetas a ser utilizado (em outras palavras, temos que determinar quais são as classes gramaticais relevantes para os estudos nos quais o corpus será utilizado). De acordo com [13], ao se projetar as etiquetas, devemos levar em consideração alguns fatores, a seguir: a granularidade da marcação do texto, ou seja, o grau de detalhamento que será utilizado em tal marcação. Isso inclui decisões de se fazer distinção entre gêneros, números, pessoas verbais, etc. (obviamente, as características que devem ser consideradas variam de uma língua para outra). Outro fator que deve ser considerado é a representação do corpus. Para isso, é importante que sejam determinados quais são os fatores essenciais - e que portanto devem ser preservados em relação ao texto original - para se escolher como representar o texto. Por exemplo, caso desejemos utilizar o corpus para estudos de morfologia e sintaxe, devemos nos preocupar apenas com o texto propriamente dito, não considerando aspectos tipográficos como tamanho e tipo da fonte utilizados no documento original. Finalmente, devemos considerar a eficiência computacional decorrente da escolha das etiquetas, isto é a viabilidade de se processar tais informações com a utilização de computadores.

Preocupando-se com esses aspectos, está sendo ${ }^{2}$ criado o Corpus Tycho Brahe ${ }^{3}$, que compreende além de textos do português europeu dos séculos XVI, XVII, XVIII e XIX, uma metodologia de marcação que visa basicamente codificar informações morfológicas e sintáticas a respeito desses textos.

Esse corpus histórico compreende, atualmente, dois tipos de textos:

1. Textos originais, ortograficamente transcritos, com informações sobre as edições, autores, datas e comentários dos editores.

2. Os mesmos textos, com cada palavra marcada morfo-sintaticamente (sem as informações extra-lingüísticas mencionadas acima).

No futuro, o corpus incluirá ainda esses textos com a estrutura sintática anotada.

Ao se escolher os textos, foram utilizados os seguintes critérios filológicos:

\footnotetext{
${ }^{2} \mathrm{O}$ corpus continua em processo de construção depois da conclusão desse trabalho.

${ }^{3}$ Tycho Brahe foi um astrônomo dinamarquês que viveu entre os anos 1546 e 1601, pioneiro na observação e coleta sistemática de dados astronômicos, que mais tarde foram utilizados pelo seu assistente Johannes Kepler para o desenvolvimento das famosas leis que levam seu nome. Detalhes a respeito de seu trabalho podem ser obtidos na URL http://es.rice.edu/ES/humsoc/Galileo/People/tycho_brahe.html.
} 
1. As edições utilizadas foram revistas pelos próprios autores ou foram utilizadas edições baseadas em manuscritos autógrafos.

2. Foram incluídos preferencialmente textos de autores cuja biografia indica poucos e curtos períodos fora de Portugal.

3. Foram selecionados textos com aproximadamente 50.000 palavras cada um.

A lista de autores e textos que foram selecionados para fazerem parte do Corpus Tycho Brahe está disponivel na URL http://www.ime.usp.br/ tycho/what/index.html.

Ressaltamos, ainda, que a construção do Corpus Tycho Brahe faz parte do projeto Rythimic Patterns, Parameter Setting and Language Change, que tem como propósito estudar a evolução do português europeu durante os séculos XVI, XVII, XVII e XIX. Em particular, esse projeto pretende investigar a variação da freqüência do uso de próclises, mesóclises e ênclises no período mencionado. Para isso, além do corpus escrito, será criado também um corpus com gravações para estudos de fonética, que auxiliará na investigação das razões pelas quais as mudanças (se é que existiram) se processaram.

A confecção de um corpus como o Tycho Brahe motiva uma série de atividades. Dentre elas, destacamos a construção de etiquetadores para o português, ferramentas indispensáveis quando se deseja anotar grandes quantidades de textos.

\subsection{Etiquetadores Morfo-sintáticos Baseados em Regras}

Etiquetadores morfo-sintáticos são sistemas que basicamente recebem um texto sem marcação como entrada e marcam cada palavra com uma etiqueta que descreve sua classe gramatical. Esse processo de marcação pode ser feito de diversas maneiras, cada uma de acordo com os objetivos a serem alcançados. Dentre as diversas formas de se etiquetar um texto, destacaremos a que utiliza para tanto um conjunto de regras, também conhecidas na literatura como transformações, que alteram os estados do texto até que um estado final seja atingido. Isso é feito da seguinte forma: o texto, após receber uma marcação inicial (mais detalhes de como isso é feito podem ser encontrados no Capítulo 2), é submetido a cada uma das transformações aprendidas pelo etiquetador, que são aplicadas sucessivamente na ordem em que aparecem na lista, conforme mostra a Figura 1.1.

Há duas fases distintas para que um texto seja marcado: a fase de aprendizado das transformações e a etiquetagem propriamente dita. Note que a primeira etapa é genérica, ou seja, vários textos podem ser etiquetados utilizando-se um mesmo conjunto de regras, enquanto a segunda é particular a cada um dos textos. 


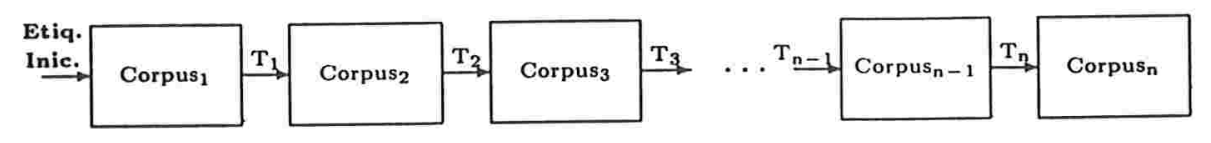

Figura 1.1: Etiquetagem Baseada em Regras ou por Transformações Sucessivas

\subsection{Etiquetadores Baseados Em Regras vs. Etiquetadores Estocásticos}

Conforme dito anteriormente, a técnica de etiquetagem baseada em regras não foi a única desenvolvida para solucionar o problema que pretendemos investigar. Outra abordagem que foi desenvolvida foi a estatística (também conhecida na literatura como estocástica ou markoviana), onde o objetivo é basicamente associar as palavras do texto etiquetas que maximizem a função $\operatorname{Prob}($ palavra $\mid$ etiqueta $) * \operatorname{Prob}($ etiqueta $\mid n$ etiquetas anteriores $)$.

Diferentemente do que acontece no método que faz a marcação dos textos pela aplicação sucessiva de regras proposto por Eric Brill $[3,8]$ (que iremos adotar como base para nosso trabalho), os etiquetadores estocásticos produzem imensas tabelas de probabilidade como resultado da fase de aprendizado. Dessa forma, a informação lingüística é capturada indiretamente, ao contrário do que acontece no método baseado em transformações, que produz um pequeno número de regras bastante claras (saída simbólica), que exprimem as relações entre as palavras de forma objetiva e explícita (mais detalhes sobre tais regras podem ser obtidos nos Capítulos 2 e 4 deste texto).

Outro problema que encontramos em relação a tais tabelas é o espaço gasto para seu armazenamento, que é muito grande devido à quantidade de dados que são gerados na fase de aprendizado. A Figura ${ }^{4} 1.2$ mostra uma comparação entre o número de transformações e o número de informações probabilísticas aprendidas por etiquetadores que implementam cada um dos paradigmas, tendo-se corpora de treinamento ${ }^{5}$ de diferentes tamanhos. Note que, para que a comparação mostrada nessa figura fosse significativa, o mesmo corpus de treinamento foi utilizado por ambos os sistemas, assim como o corpus de testes. Consequentemente, o conjunto de etiquetas manipuladas por ambos os etiquetadores foi o mesmo.

Por fim, mais uma boa razão para adotarmos o paradigma de etiquetagem baseada em regras é que a entrada do léxico para os etiquetadores que o implementam é muito mais simples do que

\footnotetext{
${ }^{4}$ Figura obtida em [8].

${ }^{5}$ Entende-se por corpus de treinamento o texto que será utilizado na fase de aprendizado.
} 
a entrada para etiquetadores estocásticos. Por exemplo, para a palavra half, teríamos a seguinte entrada ${ }^{6}$ para um etiquetador baseado em transformações:

\section{half: CD DT JJ NN PDT RB VB}

A lista acima tem 7 possibilidades de etiquetas para a palavra half. Tais etiquetas foram obtidas a partir do corpus de treinamento ${ }^{7}$, e NN está marcada na lista por ter sido a etiqueta mais freqüente, ou seja, a etiqueta que aparece maior número de vezes associada à palavra em questão. Abaixo, mostramos como seria a entrada para mesma palavra no caso de um etiquetador estocástico:

$$
\begin{gathered}
P(\text { half } \mid C D)=0.000066 \\
P(\text { half } \mid D T)=0.000757 \\
P(\text { half } \mid J J)=0.000092 \\
P(\text { half } \mid N N)=0.000702 \\
P(\text { half } \mid P D T)=0.039945 \\
P(\text { half } \mid R B)=0.000443 \\
P(\text { half } \mid V B)=0.000027
\end{gathered}
$$

Além de o método baseado em transformações apresentar essas vantagens em relação ao método markoviano, os resultados obtidos por este são tão bons ou eventualmente melhores do que os obtidos pelo segundo, conforme ilustra a Figura 1.2.

Mais informações sobre métodos estatísticos utilizados no processamento de linguagem natural podem ser obtidas em [11] e [17].

Outro critério que pode ser utilizado para se fazer a distinção entre etiquetadores é fato de utilizarem ou não textos etiquetados no aprendizado das regras. Os primeiros, ou seja, que utilizam tais textos, são chamados de etiquetadores supervisionados, enquanto os que não utilizam são conhecidos como etiquetadores não-supervisionados. Embora esses últimos apresentem a vantagem de utilizarem apenas o conjunto de etiquetas, um dicionário (arquivo semelhante ao léxico utilizado por um etiquetador baseado em regras supevisionado) e textos não-etiquetados para o aprendizado das regras, os resultados apresentados por esses ainda não são tão bons quanto os obtidos pelos etiquetadores supervisionados (o etiquetador não-supervisionado implementado por Brill foi treinado com aproximadamente 120.000 palavras e obteve um percentual de acerto de $95,1 \%$, enquanto o supervisionado lexicalizado foi treinado

\footnotetext{
${ }^{6}$ Dados obtidos em [8].

${ }^{7}$ Estes resultados foram obtidos de experimentos feitos por Brill utilizando-se como base o Penn Treebank Wall Street Journal Corpus, versão 0.5.
} 


\begin{tabular}{|l|c|c|c|}
\hline \hline Método & $\begin{array}{c}\text { \# de palavras } \\
\mathrm{p} / \text { treinamento }\end{array}$ & $\begin{array}{c}\text { \# de regras ou } \\
\text { inform. probab. }\end{array}$ & $\begin{array}{c}\text { Percentual } \\
\text { de Acerto }\end{array}$ \\
\hline \hline Estocástico & $64 \mathrm{~K}$ & 6.170 & 96.3 \\
\hline Estocástico & $1 \mathrm{M}$ & 10.000 & 96.7 \\
\hline $\begin{array}{c}\text { Baseado em Regras, } \\
\text { Lexicalizado }\end{array}$ & $64 \mathrm{~K}$ & 215 & 96.7 \\
\hline $\begin{array}{c}\text { Baseado em Regras, } \\
\text { Lexicalizado }\end{array}$ & $600 \mathrm{~K}$ & 447 & 97.2 \\
\hline $\begin{array}{c}\text { Baseado em Regras, } \\
\text { Não Lexicalizado }\end{array}$ & $600 \mathrm{~K}$ & 378 & 97.0 \\
\hline \hline
\end{tabular}

Figura 1.2: Comparação dos Diferentes Métodos na Etiquetagem sem Palavras Desconhecidas

com apenas aproximadamente 64.000 palavras e obteve $96,7 \%$ de acerto $^{8}$ ), embora estejam muito próximos, sendo bastante satisfatórios e encorajadores. Além disso, o dicionário utilizado pelos etiquetadores não-supervisionados deve ser feito manualmente ou gerado automaticamente a partir de um texto etiquetado. Brill mostra em [1] um etiquetador baseado em regras não-supervisionado, apresentando maneiras de se combinar o aprendizado supervisionado com o aprendizado não-supervisionado, além de comparar o algoritmo de aprendizado por ele proposto com o algoritmo Baum-Welsh, utilizado por etiquetadores estocásticos não-supervisionados.

No próximo capítulo, explicaremos em detalhes como a paradigma de aprendizado de transformações dirigido por erros é utilizado na construção de etiquetadores baseados em regras, que apresentam as vantagens mencionadas acima.

\footnotetext{
${ }^{8}$ Note que a observação foi feita com base nos resultados obtidos pelos etiquetadores baseados em regras implementados por Eric Brill, que foram obtidos a partir de experimentos feitos com Penn Treebank Wall Street Journal Corpus. Isso significa dizer que, para outros corpora, etiquetadores não-supervisionados podem superar os supervisionados. Além disso, não foram incluídos na comparação etiquetadores estocásticos não supervisionados, já que optamos, pelas razōes mencionadas anteriormente, utilizar os etiquetadores baseados em transformaçōes nesse trabalho.
} 


\section{Capítulo 2}

\section{A Etiquetagem Baseada em Regras}

Conforme mencionado no capítulo anterior, a etiquetagem baseada em regras proposta por Eric Brill apresenta duas fases distintas bem definidas: a de aprendizado das regras e a da etiquetagem propriamente dita.

Nesse capítulo, além de discutir em detalhes como este aprendizado ocorre, mostraremos os algoritmos envolvidos no processo, assim como a complexidade de cada um deles, apresentando a razão pela qual concluímos que o método não se mostra suficientemente eficiente quando um grande número de etiquetas é utilizado. Por fim, ilustraremos o processo de etiquetagem propriamente dito, apresentando o algoritmo e um exemplo de sua utilização.

\section{$2.1 \quad$ As Regras}

As regras (ou transformações) nada mais são do que uma maneira de se codificar as informações lingüísticas que são aprendidas pelo etiquetador. Tais regras, que são geradas a partir de moldes (descritos com detalhes nas Seções 2.1.1 e 2.1.2), são compostas por duas partes: as ações e as condições.

As primeiras são regras que efetivamente atribuem ou alteram a etiqueta de uma palavra, como mostra o exemplo abaixo:

Mude a etiqueta de VERBO para SUBSTANTIVO.

As condições são regras que basicamente descrevem quando uma ação deve ser aplicada (em 
outras palavras, elas descrevem condições que devem ser satisfeitas para o acionamento das regras de reescrita a elas associadas). Alguns exemplos são:

A palavra tem inicial maiúscula.

A palavra anterior é um ARTIGO.

Segundo o paradigma de etiquetagem baseado em transformações, há aprendizado de regras em dois contextos. Inicialmente, são aprendidas regras para etiquetagem de palavras desconhecidas, ou seja, de palavras que não pertencem ao léxico ${ }^{1}$ que será utilizado pelo etiquetador. Há também o aprendizado de regras contextuais, que fazem as alterações nas etiquetas atribuídas pelo etiquetador inicial com o intuito de minimizar o número de erros de marcação.

As seções seguintes vão explicar com mais detalhes o que são estas regras e como elas são geradas.

\subsubsection{As Regras para Etiquetagem de Palavras Desconhecidas}

Conforme dito anteriormente, são regras que têm como propósito determinar etiquetas para as palavras que não aparecem no léxico utilizado na marcação do texto. A aplicação dessas regras é feita na fase de etiquetagem inicial, que é a primeira anotação que o texto recebe para que as regras contextuais, descritas na próxima seção, possam ser aplicadas.

A única maneira de se tentar determinar a etiqueta correta para uma palavra desconhecida é extrair informactavia propriamente dita. Sendo assim, são investigados traços na sua morfol... won , mitito de se obter alguma informação que possa determinar sua classe morfo-sıntática e consecüericinente a etiqueta apropriada para marcá-la. Além disso, pode-se tentar obter pistas a partir da posição relativa da palavra em relação a outras palavras do texto.

Dessa forma, são aprendidas regras que manipulam prefixos e sufixos das palavras, que verificam se um determinado caractere aparece ou não na sua estrutura e que verificam se a palavra aparece com freqüência do lado direito/esquerdo de uma outra palavra. São também aprendidas regras que verificam se a palavra foi gerada pelos mecanismos de derivação prefixal ou sufixal a partir de alguma palavra conhecida. Um exemplo de regra para etiquetagem de palavras desconhecidas é:

Altere a etiqueta da palavra corrente para NUM se ela contém o caractere 0.

\footnotetext{
${ }^{1} \mathrm{O}$ léxico é um arquivo com as palavras e suas possíveis etiquetas, conforme mostrado no Capítulo 1.
} 
Observe que a regra acima faz referência à palavra corrente, que nada mais é do que a palavra que está sendo examinada pelo sistema. Analogamente, a etiqueta corrente é a etiqueta da palavra corrente.

As instâncias de tais regras são geradas a partir de combinações de instâncias dos moldes 1-2 (ações) com os moldes 3-9 (condições) apresentados abaixo, da seguinte maneira:

$$
\left[\text { molde }_{1} \mid \text { molde }_{2}\right] \text { se }\left[\text { molde }_{3}|\cdots| \text { molde }_{9}\right]
$$

1. altere a etiqueta corrente para etiq;

2. altere a etiqueta corrente de $e t i q_{1}$ para $e t i q_{2}$;

3. removendo-se um prefixo pref de comprimento ${ }^{2} 1 / 2 / 3 / 4 / 5$ temos uma palavra conhecida;

4. removendo-se um sufixo suf de comprimento $1 / 2 / 3 / 4 / 5$ temos uma palavra conhecida;

5. a palavra corrente aparece à esquerda da palavra pal;

6. a palavra corrente aparece à direita da palavra pal;

7. a palavra em questão contém o caractere $c$;

8. a palavra contém o prefixo pref de comprimento $1 / 2 / 3 / 4 / 5$;

9. a palavra contém o sufixo suf de comprimento $1 / 2 / 3 / 4 / 5$,

onde $e t i q$, eti $q_{1}$ e $e t i q_{2}$ são variáveis sobre o conjunto de etiquetas utilizado na marcação, pal é uma variável sobre o léxico da linguagem considerada, $c$ é uma variável sobre o alfabeto da linguagem considerada e pref e suf são cadeias de caracteres desse alfabeto.

Os moldes exibidos acima são apenas exemplos. Dependendo da língua que se deseja anotar, novos moldes podem ser criados, enquanto outros podem ser alterados ou simplesmente não utilizados. Há línguas onde os sufixos são muito mais significativos do os prefixos no que se refere à determinação das classes morfo-sintáticas de suas palavras. Nesse caso, é natural que os moldes utilizados para a geração de regras para etiquetagem da palavras desconhecidas dessa língua explorem muito mais seus sufixos do que seus prefixos.

Observe que a eficiência da utilização de regras para etiquetagem de palavras desconhecidas depende da língua que está sendo investigada. Presumivelmente, em línguas onde há regularidade na flexão e formação das palavras, melhores resultados são obtidos. No Capítulo 6 podem ser encontrados os resultados da aplicação de tais regras na etiquetagem de palavras desconhecidas do português europeu dos séculos XVI. XVII, XVII e XIX.

\footnotetext{
${ }^{2}$ Número de letras.
} 


\subsubsection{As Regras Contextuais}

Ao contrário das regras para etiquetagem de palavras desconhecidas, essas regras verificam a posição da palavra no texto com relação às palavras vizinhas e suas etiquetas. Em outras palavras, inspecionam o contexto (ou ambiente) onde a palavra ocorre. As regras que se referem apenas a etiquetas são chamadas de regras não-lexicalizadas. As demais, ou seja, que se referem a palavras (ou palavras e etiquetas), são conhecidas como regras lexicalizadas.

As instâncias das regras não-lexicalizadas são geradas a partir de combinações dos moldes 1-2 (ações) com os moldes 3-8 (condições não-lexicalizadas), enquanto as lexicalizadas são geradas a partir de combinações dos moldes 1-2 (ações) com os moldes 9-15 (condições lexicalizadas) da seguinte forma:

$$
\left[\text { molde }_{1} \mid \text { molde }_{2}\right] \text { se }\left[\text { molde }_{3}|\cdots| \text { molde }_{15}\right]
$$

1. altere a etiqueta corrente para etiq;

2. altere a etiqueta corrente de etiq $q_{1}$ para $e t i q_{2}$;

3. a próxima palavra tem etiqueta etiq;

4. a palavra anterior tem etiqueta $e t i q_{1}$ e a palavra posterior tem etiqueta $e t i q_{2}$;

5. as duas palavras anteriores têm etiquetas $e t i q_{1}$ e $e t i q_{2}$;

6. uma das duas palavras posteriores tem etiqueta etiq;

7. uma das três palavras posteriores tem etiqueta etiq;

8. a palavra a duas posições antes da posição corrente tem etiqueta etiq;

9. a palavra anterior é pal;

10. uma das duas palavras anteriores é pal;

11. a palavra anterior é $\mathrm{pal}_{1}$ e a posterior é $\mathrm{pal}_{2}$;

12. a palavra posterior é $\mathrm{pal}_{1}$ e duas posições depois encontra-se a palavra pal $_{2}$;

13. a palavra corrente é $p a l_{1}$ e a anterior tem etiqueta etiq;

14. a palavra corrente é pal e a palavra anterior é marcada com a etiqueta etiq;

15. a palavra corrente é pal e a próxima palavra é marcada com a etiqueta etiq, 
onde $e t i q$, eti $q_{1}$, e $e t i q_{2}$ são variáveis sobre o conjunto de etiquetas utilizado na marcação e pal, $\mathrm{pal}_{1}$ e $\mathrm{pal}_{2}$ são variáveis sobre o léxico da linguagem considerada.

Mais exemplos de moldes são mostrados no Capítulo 4, quando discutimos a implementação do "aprendedor" de regras contextuais.

Ao se projetar um conjunto de moldes para geração das regras, alguns parâmetros importantes devem ser levados em consideração. Por exemplo, o tamanho da janela que será utilizada, ou seja, o número de palavras/etiquetas que a regra vai analisar. Os moldes acima trabalham com janelas cujos tamanhos variam de 1 a 3 (ou seja, analisam de 1 a 3 palavras/etiquetas para cada lado da palavra/etiqueta corrente). Como pode ser visto na Seção 2.2.2, o tamanho escolhido para a janela tem influência direta na complexidade do algoritmo de aprendizado de regras. Brill e Mangu mostram em [14] como diferentes tamanhos de janelas podem afetar os resultados obtidos por um sistema de correção de erros de grafia que resultam em palavras corretas (ou seja, não introduzem um erro léxico), mas que comprometem o significado das sentenças.

\subsection{O Aprendizado de Regras Contextuais}

Até então, apresentamos os moldes a partir dos quais as regras são geradas, sem mencionar nada sobre como esse processo ocorre. A seguir, descreveremos como as regras são aprendidas pelo sistema. Contudo, antes de descrever o processo em si, vamos explicar quais são os parâmetros que devem ser ajustados para que se possa proceder o aprendizado propriamente dito.

Para definir uma aplicação específica de aprendizado baseado em transformações, deve-se inicialmente especificar os seguintes itens:

- O etiquetador inicial.

- O conjunto de tipos de transformações que são permitidas (ou seja, os moldes para as ações e para as condições).

- A função objetivo que possibilitará que a eficiência de uma transformação seja medida através da comparação do texto a ela submetido com a referência ${ }^{3}$, de tal maneira a determinar se tal transformação deve ou não ser incluída na lista de transformações.

O processo de aprendizado das regras contextuais, ilustrado na Figura ${ }^{4} 2.1$, é feito da seguinte forma: um texto, inicialmente não anotado, é processado pelo etiquetador inicial, que associa

\footnotetext{
${ }^{3}$ Entende-se por referência uma cópia do corpus que foi anotada manualmente, e portanto, livre de erros.

${ }^{4}$ Figura obtida em [8], com pequenas alterações.
} 


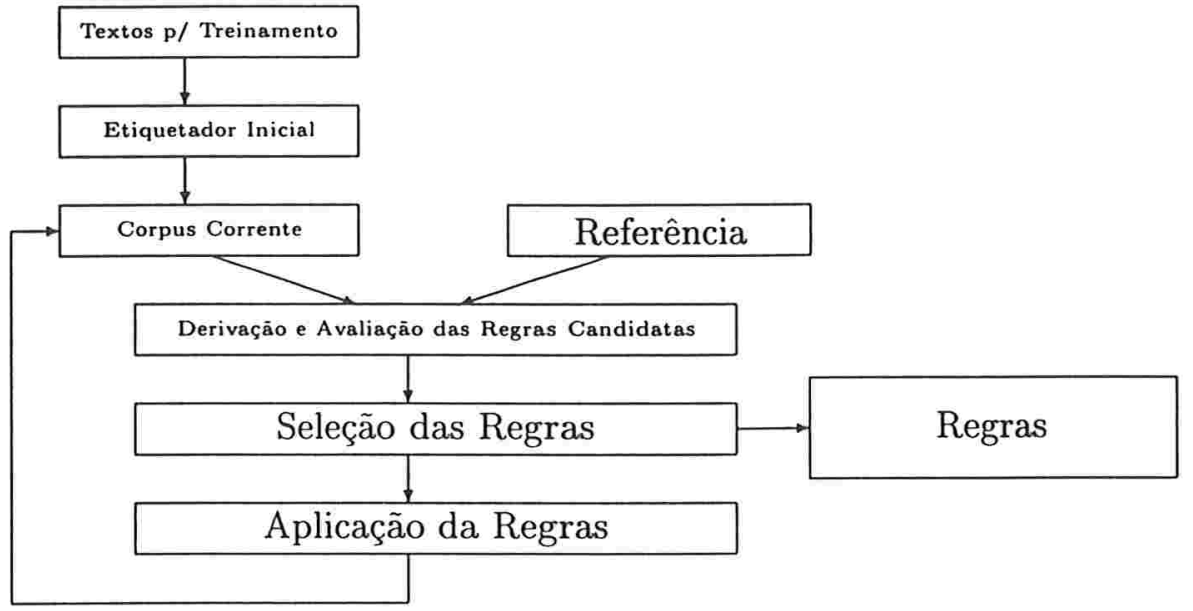

Figura 2.1: Aprendizado de Transformações Dirigido por Erros

a cada uma das palavras uma etiqueta segundo uma determinada estratégia. Tais estratégias podem variar em complexidade, podendo ser bastante simples, como na marcação das palavras com etiquetas aleatórias ou razoavelmente sofisticadas, como a atribuição da etiqueta mais provável a cada uma das palavras do texto. Outra possibilidade é a utilização de um etiquetador estocástico como etiquetador inicial.

Uma vez que o corpus já tem uma marcação inicial, inicia-se a próxima etapa do processo de aprendizado. Nessa etapa, uma série de transformações são aprendidas e aplicadas ao corpus de treinamento, de tal forma que ele se torne o mais similar possível à referência.

Cada iteração do "aprendedor" consiste no seguinte:

1. Geração das possíveis regras contextuais.

2. Para cada uma das transformações geradas:

(a) Aplicar a transformação a uma cópia do corpus.

(b) Aplicar a função objetivo no corpus resultante para medir a eficiência da transformação aplicada.

3. Determinar qual a transformação que obteve o melhor resultado (maximizou ou minimizou a função objetivo, dependendo do caso).

4. Acrescentar tal transformação no final da lista de transformações (observe que a ordem 


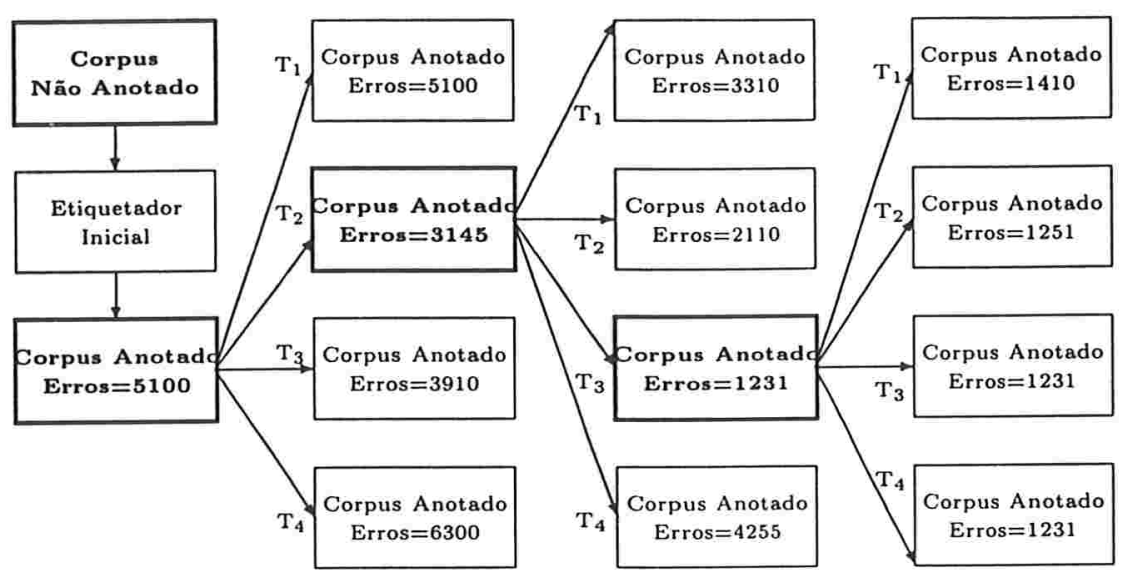

Figura 2.2: Um Exemplo do Método Brill de Aprendizado

das transformações na lista é importante, já que o aprendizado de uma regra depende da aplicação das regras aprendidas anteriormente).

5. Aplicar tal transformação ao corpus para treinamento para atualizá-lo ${ }^{5}$.

6. Retornar ao passo 1 .

A Figura ${ }^{6} 2.2$ exemplifica a execução de tal processo no caso em que há somente 4 transformações e no qual a função objetivo (a ser minimizada) é o número total de erros na marcação. Nesse caso, a lista de transformações aprendida é $\left(\mathrm{T}_{2} ; \mathrm{T}_{3}\right)$.

Há situações nas quais a aplicação de uma transformação num determinado ambiente pode afetar a aplicação da mesma em outro ambiente. Nesse caso, deve ser especificada a ordem em que as transformações são aplicadas e se uma transformação deve ser aplicada imediatamente após sua avaliação ou apenas após a análise de todo o corpus em relação às regras condicionais. Para exemplificar, considere a sequência:

\section{AAAAAA}

e a transformação: altere a etiqueta corrente de $A$ para $B$ se a etiqueta anterior é $A$. Se o efeito da aplicação da transformação não for escrito imediatamente após sua aplicação até que toda

\footnotetext{
${ }^{5} \mathrm{~A}$ cada iteração do processo de aprendizado é utilizada a cópia do corpus de treinamento que foi atualizada mais recentemente, e que portanto é a mais correta com relação à referência.

${ }^{6}$ Figura obtida em [8].
} 
a entrada seja processada, o resultado será $\mathrm{ABBBBB}$, independentemente da ordem em que a transformação foi aplicada. Caso contrário, ou seja, se o resultado da transformação for escrito imediatamente após a sua aplicação, o resultado será $\mathrm{ABABAB}$, caso o processamento seja feito da esquerda para direita; ou $\mathrm{ABBBBB}$, caso o processamento seja feito da direita para esquerda. 


\subsubsection{O Algoritmo de Aprendizado}

Trata-se de um algoritmo "guloso" que, a cada iteração, adiciona a transformação que obteve o melhor resultado (no caso a transformação que corrigiu o maior número de erros no corpus de treinamento da iteração corrente) na lista de transformações. Dessa forma, temos um algoritmo que busca por máximos locais.

Entrada: O corpus de treinamento (referência + texto marcado pelo etiquetador inicial), conjunto de etiquetas, conjunto de moldes para as condições (a única ação é altere a etiqueta corrente de etiq $q_{1}$ para etiq $q_{2}$ ) e a função objetivo.

Saída: A lista de regras contextuais.

O que faz: Constrói a lista de regras contextuais a partir da avaliação de cada uma das possíveis candidatas segundo a função objetivo.

1. enquanto regras ainda podem ser aprendidas

2. $\quad$ para $X \leftarrow e t i q_{1}$ até etiq

3. $\quad$ para $Y \leftarrow e t i q_{1}$ até $e t i q_{t}$

4. $\quad$ para $p o s \leftarrow 1$ até $n$

5. $\quad$ para $M \leftarrow$ molde $_{1}$ até molde $_{m}$

6. $\quad$ para cada $\mathrm{COND}^{7}$ de $\mathrm{M}$

7. avaliar sua performance

8. se esta é a regra com melhor resultado até agora então

9. $\quad$ armazená-la como tal.

10. Se a melhor regra obteve resultado maior ou igual a MÍNIMO $^{8}$ então

11. adicioná-la ao final da lista de regras

12. atualizar o corpus de treinamento

13. senão encerrar o aprendizado 
Observe que não há backtracking, ou seja, uma vez que uma transformação é escolhida, ela é aplicada ao corpus de treinamento e seus efeitos não são desfeitos (podem ser alterados por transformações aprendidas posteroiormente). Além disso, o algoritmo retorna uma lista de regras cuja ordem é importante, já que o aprendizado da $i$-ésima transformação depende das $i-1$ regras aprendidas anteriormente.

\subsubsection{Análise do Algoritmo de Aprendizado}

A seguir, apresentaremos a análise do algoritmo apresentado na Seção 2.2.1. A tabela abaixo mostra quantas vezes cada passagem do algoritmo é executada no pior caso:

\begin{tabular}{|l|l|}
\hline \hline Passagem & \# de execuções \\
\hline \hline 1 & $i$ \\
\hline 2 & $i \cdot t$ \\
\hline 3 & $i \cdot t \cdot t$ \\
\hline 4 & $i \cdot t \cdot t \cdot n$ \\
\hline 5 & $i \cdot t \cdot t \cdot n \cdot m$ \\
\hline 6 & $i \cdot t \cdot t \cdot n \cdot r$ \\
\hline 7 & $i \cdot t \cdot t \cdot n \cdot r$ \\
\hline 8 & $i \cdot t \cdot t \cdot n \cdot r$ \\
\hline 9 & $i \cdot t \cdot t \cdot n \cdot r$ \\
\hline 10 & $i$ \\
\hline 11 & $i-1$ \\
\hline 12 & $i-1$ \\
\hline 13 & 1 \\
\hline
\end{tabular}

onde:

- $i$ é o número de iterações do algoritmo,

- $t$ é o número de etiquetas que serão utilizadas,

- $m$ é o número de moldes,

\footnotetext{
${ }^{7}$ Condição.

${ }^{8}$ MÍNIMO é uma constante que deve ser definida para interromper o aprendizado. Valores altos para esta constante impedem que um determinado número de regras seja aprendido, diminuindo o tempo gasto pela fase de aprendizado. Maiores detalhes podem ser encontrados nos Capítulos 4 e 6 .
} 
Considere a referência e o corpus de treinamento abaixo:

Referência:

Os/D-M-P navegantes/N-P já/ADV sabem/VB-P ./. O/D-M fim/N de/P ano/N e/CONJ o/D-M verão/N acontecem/VB-P em/P Angra/NPR $\operatorname{dos} / \mathrm{P}+\mathrm{D}-\mathrm{P}$ Reis/NRP-P ./.

Corpus de Treinamento:

Os/D-M-P navegantes/NPR - $P^{*}$ já/ADV sabem/VB-P ./. O/D-M fim/N $\mathrm{de} / \mathrm{P}$ ano/N e/CONJ o/D-M verão/N acontecem/VB-P em/P Angra/NPR dos/P+D-P Reis/NPR-P ./.

Considere ainda a seguinte ação e o conjunto de condições:

Ação:

Altere a etiqueta corrente para N-P.

\section{Condição:}

1. Se a palavra anterior tem etiqueta D-M-P.

2. Se a próxima palavra tem etiqueta VB-P.

Como se pode observar, o corpus de treinamento possui apenas uma etiqueta errada, marcada com "*". Após a avaliação das condições, temos que a primeira corrige o erro, enquanto a segunda introduz 2 novos erros no corpus de treinamento. Nesse caso, a regra que será acrescida na lista é altere a etiqueta corrente para $N-P$ se a palavra anterior tem etiqueta $D-M-P$.

Observação: as etiquetas utilizadas seguem o padrão adotado pelo Corpus Tycho Brahe. As condições foram criadas apenas para este exemplo e podem não corresponder as que seriam geradas pelo etiquetador que descreveremos. A função objetivo considerada é a que, dado um texto etiquetado e a respectiva referência, determina o número de erros de tal texto em relação à referência dada. Outra observação importante é que o exemplo mostra o aprendizado em apenas um passo, utilizando as etiquetas completas, diferentemente do que ocorre no nosso sistema.

Figura 2.3: Um Exemplo do Processo de Aprendizado de Transformações 
- $r$ é o número de condições, dado por $\sum_{i=1}^{m} m_{i}$, onde $m_{i}$ é o número de condições que podem ser geradas a partir de molde $_{i} \mathrm{e}$

- $n$ é o tamanho do corpus de treinamento.

Dessa forma, a complexidade do algoritmo é:

$$
O\left(i \cdot t^{2} \cdot r \cdot n\right)
$$

Se chamarmos de $o p$ as operações de troca de etiquetas, dada pelas possíveis instâncias da regra de reescrita altere a etiqueta corrente de $X$ para $Y$, representadas pelos passos 1 e 2 do algoritmo, e de env os ambientes gerados pelas possíveis instâncias das regras condicionais, temos que a complexidade do algoritmo de aprendizado é:

$$
O(i \cdot|o p| \cdot|e n v| \cdot n)
$$

Note que o número de iterações do algoritmo não pode ser previsto, já que depende da anotação inicial, das regras que vão sendo aprendidas durante o processo e da constante MíNIMO que é utilizada no aprendizado. Contudo, como em cada iteração é aprendida uma regra que corrige pelo menos um erro no corpus de treinamento, o número máximo de iterações do algoritmo é $n$ (número de palavras da referência). Entretanto, na prática, o número de iterações do processo de aprendizado é muito menor do que esse limitante teórico devido a otimizações feitas na implementação. Maiores detalhes podem ser obtidos no Capítulo 4, onde discutimos detalhes da implementação do "aprendedor" de regras contextuais. O Capítulo 6 mostra o número de regras aprendidas em alguns experimentos.

Considere, então, um caso prático onde a função objetivo a ser minimizada é a função que, dado um corpus etiquetado e a respectiva referência, retorna o número de etiquetas erradas nesse corpus com relação à referência dada, o único molde para as ações é altere a etiqueta corrente de etiq para $_{\text {etiq }}$ e os moldes para as condições são os seguintes:

1. a palavra anterior tem etiqueta etiq;

2. a próxima palavra tem etiqueta etiq;

3. a palavra anterior tem etiqueta $e t i q_{1}$ e a palavra posterior tem etiqueta etiq 
4. as duas palavras anteriores têm etiquetas $e t i q_{1}$ e $e t i q_{2}$, respectivamente;

5. as duas palavras posteriores têm etiquetas etiq $q_{1}$ e $e t i q_{2}$, respectivamente;

6. uma das duas palavras anteriores tem etiqueta etiq;

7. uma das duas palavras posteriores tem etiqueta etiq;

8. uma das três palavras anteriores tem etiqueta etiq;

9. uma das três palavras posteriores tem etiqueta etiq;

10. a palavra a duas posições antes da posição corrente tem etiqueta etiq,

onde $e t i q$, $e t i q_{1}$ e $e t i q_{2}$ são variáveis sobre o conjunto de etiquetas utilizado.

Desse modo, o número de ambientes de condições (em função do número de etiquetas a serem utilizadas) para cada um dos moldes acima é dado por:

\begin{tabular}{|l|l|}
\hline \hline$R R C$ & \# de ambientes \\
\hline \hline 1 & $t$ \\
\hline 2 & $t$ \\
\hline 3 & $t \cdot t$ \\
\hline 4 & $t \cdot t$ \\
\hline 5 & $t \cdot t$ \\
\hline 6 & $t$ \\
\hline 7 & $t$ \\
\hline 8 & $t$ \\
\hline 9 & $t$ \\
\hline 10 & $t$ \\
\hline \hline
\end{tabular}

Logo, o número total de ambientes para as regras condicionais é:

$$
\begin{aligned}
& t+t+t \cdot t+t \cdot t+t \cdot t+t+t+t+t+t= \\
& 3 \cdot t^{2}+7 \cdot t
\end{aligned}
$$

Conseqüentemente, a complexidade de cada iteração do algoritmo de aprendizado para esse conjunto de moldes em função do número de etiquetas que serão utilizadas é: 


$$
O\left(t^{2} \cdot\left(3 \cdot t^{2}+7 \cdot t\right) \cdot n\right)
$$

ou seja, depende da quarta potência do número de etiquetas.

Em geral, a complexidade de cada iteração de um algoritmo baseado em regras como o mostrado acima é $O\left(t^{2+k} \cdot n\right)$, onde $k$ é o número máximo de posições analisadas nos moldes das regras condicionais.

A seguir, faremos um comparativo entre a eficiência do algoritmo de aprendizado de transformações no caso acima (a medida será feita considerando-se o tempo de processamento do programa que o implementa) para diferentes conjuntos de etiquetas. Mais precisamente, consideraremos o conjunto de etiquetas do Penn Treebank Wall Street Journal Corpus (PTWSJC) e do Corpus Tycho Brahe (CTB) (tais conjuntos de etiquetas podem ser obtidos em [3] e [18], respectivamente).

Para o Penn Treebank Wall Street Corpus ${ }^{9}$, com $36^{10}$ etiquetas, temos:

$$
\begin{aligned}
& \mid \text { op }|\cdot| \text { env } \mid \cdot n= \\
& \quad 36^{2} \cdot\left(3 \cdot 36^{2}+7 \cdot 36\right) \cdot n= \\
& \\
& 1.296 \cdot 4.140 \cdot n= \\
& 5.365 .440 \cdot n
\end{aligned}
$$

Já para o Corpus Tycho Brahe, com 176 etiquetas $^{11}$ etiquetas, temos:

$$
\begin{aligned}
& \mid \text { op }|\cdot| \text { env } \mid \cdot n= \\
& \quad 176^{2} \cdot\left(3 \cdot 176^{2}+7 \cdot 176\right) \cdot n= \\
& 30.976 \cdot 94.160 \cdot n= \\
& 2.916 .700 .160 \cdot n
\end{aligned}
$$

\footnotetext{
${ }^{9} \mathrm{Não}$ estamos nos referindo ao corpus propriamente dito e sim ao conjunto das etiquetas utilizadas em sua marcação.

${ }^{10}$ Esse é o número de etiquetas do corpus sem considerar os sinais de pontuação. Uma lista com essas etiquetas pode ser obtida em [3].

${ }^{11}$ Esse é o número de etiquetas atualmente, sem considerarmos as etiquetas formadas pelas aglutinaçōes dos clíticos, utilizado apenas como ilustração. O número total ultrapassa 250 etiquetas. Tal conjunto ainda não está "fechado", podendo ser alterado no decorrer do processo de construção do corpus.
} 
Comparando, o tempo gasto na fase de aprendizado utilizando-se os conjuntos de etiquetas citados acima, temos que:

$$
\frac{T e m p o(T B)}{\text { Tempo }(P T W S J)}=\frac{2.916 .700 .160 \cdot n}{5.365 .440 \cdot n} \approx 543,
$$

ou seja, para corpora de mesmos tamanhos, o aprendizado regras contextuais, utilizando-se o conjunto de etiquetas do CTB, é aproximadamente 543 vezes mais lento do que o aprendizado utilizando-se o conjunto de etiquetas do PTWSJC.

Segundo Brill [4], a fase de aprendizado de regras contextuais, utilizando-se o conjunto de etiquetas do PTWSJC e um corpus de treinamento com 500.000 palavras leva aproximadamente 1 dia quando é utilizado o valor 15 para a constante MÍNIMO em uma máquina SUN Sparc-10. Sendo assim, utilizando-se um corpus com o mesmo tamanho e uma máquina similar, teríamos, no pior caso, um tempo de treinamento de 543 dias (ou quase 1 ano e meio !!!) ao usar o conjunto de etiquetas do CTB.

Note, mais uma vez, que estamos fazendo apenas uma estimativa dos tempos gastos para o aprendizado das regras, sem considerar a redução do tempo de aprendizado que é proporcionada por otimizações feitas na implementação do algoritmo. Mesmo assim, podemos concluir que utilizar o método Brill "puro" para construir um etiquetador para textos do português baseado nas etiquetas do CTB é computacionalmente inviável.

\subsection{A Etiquetagem}

Mostraremos, a seguir, como um texto é etiquetado tendo-se disponível um conjunto de regras contextuais. Observe que, uma vez que um conjunto de transformações é aprendido, a ordem em que essas transformações são aplicadas é bem definida. Ao contrário, os etiquetadores estocásticos utilizam programação dinâmica para determinar melhor caminho (de maior probabilidade) através de um conjunto de estados, o que dificulta a compreensão do processo de etiquetagem.

\subsubsection{O Algoritmo de Etiquetagem}

Entrada: Lista de regras contextuais, lista de regras para etiquetagem de palavras desconhecidas, etiquetador inicial e texto a ser etiquetado. 
Saída: O texto anotado segundo as regras da lista.

O que faz: Aplica cada uma das regras contextuais da lista ao texto para etiquetá-lo.

1. Submeter o texto ao etiquetador inicial.

2. para $i \leftarrow 1$ até $c$

3. $\quad$ para $p o s \leftarrow 1$ até $n$

4. Aplicar regra[i] a texto[pos $]$

A Figura 2.4 ilustra o processo de etiquetagem de um texto.

Quanto à complexidade, podemos facilmente perceber que o algoritmo leva tempo $O(d \cdot n)+O(c \cdot n)=O(\max \{c, d\} \cdot n)$ para etiquetar um texto, onde $d$ é o número de regras para etiquetagem de palavras desconhecidas, $c$ é o número de regras contextuais utilizadas e $n$ é o tamanho do texto a ser etiquetado. 
Considere o corpus com a etiquetagem inicial abaixo:

Paixão/N pelo/P+D-M mar/N ./. Este/D é/SR-P o/D sentimento/N-S que/WPRO a/D-F Johnson/ $N^{*}$ gosta/VP-P de/PRO* compartilhar/VB com/P você/PRO ./. Por/P isso/PRO fabrica/VB-P motores/N-P de/P popa/N especialmente/ADV desenvolvidos/VB-AN para/PRO* enfrentar/VB as/D-F-P condições/N* mais/ADV-R-F-P adversas/A-F-P de/P uso/N./.

Considere ainda o seguinte conjunto de regras de etiquetagem:

1. altere a etiqueta corrente para $\mathrm{P}$ se a próxima palavra tiver etiqueta VB.

2. altere a etiqueta corrente para N-P se a palavra anterior tem etiqueta D-F-P ou D-P.

3. altere a etiqueta corrente para NPR se a palavra anterior tem etiqueta $D$ ou D-F e a palavra corrente tem inicial maiúscula.

O corpus acima, após ser submetido ao etiquetador, que o altera segundo o conjunto de regras mostrado - as regras são aplicadas na ordem em que aparecem na lista - tem a seguinte marcação (as etiquetas que serão alteradas estão marcadas com “*”):

Paixão/N pelo/P+D-M mar/N ./. Este/D é/SR-P o/D sentimento/N-S que/WPRO a/D-F Johnson/NPR gosta/VP-P de/P compartilhar/VB com $/ \mathrm{P}$ você/PRO ./. Por $/ \mathrm{P}$ isso/PRO fabrica/N motores/N-P $\mathrm{de} / \mathrm{P}$ popa/N especialmente/ADV desenvolvidos/VB-AN para/P enfrentar/VB as/D-F-P condiçōes/N-P mais/ADV-R-F-P adversas/A-F-P de/P uso/N./.

Observação: a etiquetagem inicial acima foi feita com o intuito de exemplificar o método, não seguindo nenhuma estratégia específica. O mesmo acontece com a lista de regras, que foi criada apenas como exemplo.

Figura 2.4: Um Exemplo de Etiquetagem de um Corpus 


\section{Capítulo 3}

\section{A Etiquetagem em Fases}

\subsection{Introdução}

Mostraremos, nesse capítulo, como construir um etiquetador baseado em regras que utiliza um grande número de etiquetas, sem que para isso o tempo de processamento da fase de aprendizado das regras se torne demasiadamente grande.

\subsection{O Refinamento das Etiquetas}

Analisando os fatores que influenciam na complexidade do algoritmo de aprendizado, poderia-se, para tentar tornar esse algoritmo mais eficiente, pensar em alguma das seguintes hipóteses:

1. Diminuir o número de moldes utilizados para a geração das regras e/ou diminuir a janela utilizada nesses moldes.

Essa solução não é boa, já que diminuindo o número de moldes utilizados provavelmente estaríamos perdendo na diversidade de informação lingüística que o sistema seria capaz de capturar. Em outras palavras, existiriam construções que seriam "identificadas" pelas regras geradas a partir dos moldes removidos e não identificadas pelas regras geradas a partir dos restantes (lembre-se que as regras são padrões reconhecidos nos textos). O mesmo aconteceria se a janela utilizada por esses moldes fosse diminuida. Por exemplo, relações de longa distância entre as palavras não seriam mais detectadas pelo sistema.

2. Diminuir o número de etiquetas utilizadas. 
Essa solução também não é boa. Haveria um aumento na granularidade da marcação, o equivale a uma perda do conhecimento lingüístico codificado nos textos.

3. Utilizar menores textos para o aprendizado das regras.

Quanto maior for o tamanho dos textos utilizados, maior será a possibilidade de sistema aprender regras mais genéricas, ou seja, que representam construções mais freqüentes na língua estudada (mais uma vez, lembre que regras nada mais são do que a representação de padrões reconhecidos no texto). Sendo assim, o objetivo é utilizar cada vez textos maiores, e não menores.

Portanto, para resolver o problema apresentado no capítulo anterior, ou seja, diminuir o tempo gasto pelo etiquetador na fase de aprendizado quando o número de etiquetas utilizadas é grande, estendemos o método original para que a nova versão apresentasse maior eficiência computacional $^{1}$.

A solução encontrada foi a seguinte: em vez de utilizarmos etiquetas monolíticas (ou seja, compostas por apenas uma parte), decidimos utilizar etiquetas compostas, onde a classe gramatical seria representada pelo núcleo da etiqueta e os demais traços morfo-sintáticos como número, tempo verbal, gênero, etc. seriam representados por um refinamento deste núcleo. Por exemplo, em vez de termos a etiqueta

\section{DUMFP,}

que é uma etiqueta que representa um artigo indefinido, feminino, no plural (ex.: umas), temos a etiqueta composta

\section{D-UM-F-P.}

Essa alteração na estrutura das etiquetas nos induziu a acrescentar uma fase no processo de etiquetagem dos textos, já que, em vez de utilizarmos a etiqueta completa na fase de aprendizado, utilizaremos apenas os núcleos, diminuindo a quantidade de etiquetas envolvidas no processo de aprendizado de 176 para 36 (observe que esse é o número de etiquetas do Penn Treebank Wall Street Journal Corpus sem os sinais de pontuação, utilizado por Brill em parte de seus experimentos. Como o número de etiquetas do PTWSJC é próximo ao número de núcleos das etiquetas do CTB, esperamos que o tempo que gasto no aprendizado de regras utilizando-se

\footnotetext{
${ }^{1} \mathrm{O}$ método apresentado a seguir texto não altera a complexidade computacional do algoritmo de aprendizado. Contudo, o tempo de processamento esperado é menor do que seria se utilizássemos o método sem modificaçōes. Os resultados das experiências realizadas podem ser observados no Capítulo 6.
} 
cada um dos corpus será bastante próximo. Assim sendo, poderemos comparar o tempo gasto pelo método que estamos propondo com os resultados obtidos por Brill e com uma estimativa do tempo que seria gasto caso não alterássemos o método.). Note que o número de etiquetas utilizadas na marcação não foi reduzido e que portanto não houve perda de informação.

Portanto, após a aplicação das regras aprendidas, haverá uma nova fase na etiquetagem que terá como objetivo exatamente fazer o refinamento dos núcleos para que o texto resultante esteja marcado com as etiquetas completas.

Dessa forma, a etiquetagem de um texto apresentará 3 fases:

Fase I. O texto recebe uma marcação inicial na qual apenas os núcleos das etiquetas serão utilizados. O processo de etiquetagem inicial é o mesmo que o proposto por Brill.

Fase II. Através da aplicação das regras contextuais aprendidas anteriormente, a marcação inicial é alterada para que melhores resultados sejam obtidos (observe que, assim como ocorre na fase anterior, apenas os núcleos das etiquetas serão utilizados). Esta fase também é idêntica à proposta por Brill.

Fase III. É feito um refinamento da marcação de cada uma das palavras (quando for o caso, já que algumas etiquetas não podem ser refinadas) para completar as etiquetas. Como será mostrado a seguir, esse processo não envolve aprendizagem.

As Figuras 3.1 e 3.2 apresentam algumas etiquetas do CTB e do PTWSJC, respectivamente. Note a diferença estrutural no formato das etiquetas de cada um dos corpora.

A seguir, mostraremos como esse refinamento pode ser feito de forma eficiente, isto é, sem comprometer a performance dos processos de aprendizado e etiquetagem. 


\begin{tabular}{|l|l|}
\hline \hline Etiqueta & Classe Gramatical \\
\hline \hline CC & Conjunção Coordenativa \\
\hline CD & Número Cardinal \\
\hline DT & Determinante \\
\hline EX & "there" existencial \\
\hline FW & Palavra Estrangeira \\
\hline IN & Preposição ou Conjunção Subordinativa \\
\hline JJ & Adjetivo \\
\hline JJR & Adjetivo, Comparativo \\
\hline JJS & Adjetivo, Superlativo \\
\hline MD & Modal \\
\hline \hline
\end{tabular}

Figura 3.1: Algumas Etiquetas do Corpus WSJ Penn Treebank

\begin{tabular}{|l|l|}
\hline \hline Etiqueta & Classe Gramatical \\
\hline \hline SR & Verbo Ser, Infinitivo \\
\hline HV & Verbo Haver, Infinitivo \\
\hline ET & Verbo Estar, Infinitivo \\
\hline TR & Verbo Ter, Infinitivo \\
\hline VB-PP & Verbo, Particípio Passado \\
\hline NPR-P & Nome Próprio, Plural \\
\hline PRO\$-F-P & Pronome Possessivo, Feminino, Plural \\
\hline ADJ-R & Adjetivo Comparativo/Consecutivo de Grau \\
\hline ADV-S & Advérbio Superlativo \\
\hline Q & Quantificadores \\
\hline CONJ & Conjunções Coordenativas \\
\hline WADV & Completiva Interrogativa Indireta \\
\hline P & Preposição \\
\hline NUM & Numeral Cardinal \\
\hline FW & Palavras Estrangeiras \\
\hline \hline
\end{tabular}

Figura 3.2: Algumas Etiquetas do Corpus Tycho Brahe 


\subsection{O Algoritmo de Refinamento}

A seguir, apresentaremos, em pseudo-código, o algoritmo de refinamento das etiquetas. Vale ressaltar que a utilização desse método só tem sentido caso as etiquetas tenham sido projetadas para serem refinadas.

Entrada: Um texto marcado com os núcleos das etiquetas utilizadas.

Saída: O texto de entrada com a etiquetagem completa.

O que faz: Para cada palavra do texto de entrada, verifica se a etiqueta corrente pode ou não ser refinada. Em caso afirmativo, investiga se há alguma característica na palavra que permita a determinação do complemento da etiqueta. Caso não seja encontrada nenhuma tal característica, utiliza um complemento padrão (caso esta etiqueta deva ser necessariamente refinada, pois pode haver casos onde o refinamento não é obrigatório). Se a etiqueta corrente não admitir refinamento, nada é feito.

1. para cada palavra do texto faça

2. determine a etiqueta corrente

3. se a etiqueta pode ser refinada então

4. determine qual o refinamento a ser utilizado

5. $\quad$ etiqueta corrente $\leftarrow$ etiqueta corrente + complemento

6. senão

7. não faça nada

\subsection{Análise do Algoritmo de Refinamento}

Vamos, então, analisar a complexidade do algoritmo mostrado na Seção 3.3. Para tanto, calcularemos o número de iterações de cada uma das passagens do algoritmo no pior caso: 


\begin{tabular}{|l|c|}
\hline \hline Passagem & \# de execuções \\
\hline \hline 1 & $n$ \\
\hline 2 & $n$ \\
\hline 3 & $n$ \\
\hline 4 & $k_{1}$ \\
\hline 5 & $k_{1}$ \\
\hline 6 & $k_{2}$ \\
\hline 7 & $k_{2}$ \\
\hline \hline
\end{tabular}

onde:

- $n$ é o número de palavras do texto a ser etiquetado,

- $k_{1}+k_{2}=n$,

- $k_{1}$ é o número de vezes que o teste da linha 3 do algoritmo sucede, ou seja, o número de palavras cujas etiquetas devem ser refinadas,

- $k_{2}$ é o número de vezes que o teste da linha 3 do algoritmo falha, ou seja, o número de palavras cujas etiquetas não podem ser refinadas.

Sendo assim, a complexidade do algoritmo de refinamento é dada por

$$
O(n)
$$

ou seja, é linear no número de palavras do texto a ser etiquetado.

Observação: as etiquetas, diferentemente do que ocorre com o algoritmo de aprendizado das regras, não fazem parte da entrada do algoritmo de refinamento, já que as regras de refinamento estão codificadas no sistema (ou seja, para cada etiqueta que pode ser refinada, há uma lista com os critérios para que tal refinamento possa der feito). Dessa forma, passo 3 do algoritmo pode ser feito em tempo constante $(O(1))$ pois, dada uma etiqueta, basta verificar se ela se encontra na lista de etiquetas que podem ser refinadas, composta por um número finito e constante de etiquetas. Similarmente, para cada um dos núcleos que podem ser refinados, há um número também finito e constante de possibilidades de refinamento. Logo, o passo 4 do algoritmo acima é feito em tempo constante. O detalhamento de como esse passo é feito no caso das etiquetas do corpus Tycho Brahe é apresentado no Capítulo 5. 


\section{Capítulo 4}

\section{O Sistema}

\subsection{A Arquitetura do Sistema}

Sob o ponto de vista da arquitetura, o sistema que desenvolvemos ${ }^{1}$ pode ser dividido em três partes principais: o "aprendedor", que compreende os módulos responsáveis pelo aprendizado de regras para etiquetagem de palavras desconhecidas (Seção 4.2.1) e regras contextuais (Seção 4.3), o etiquetador, que compreende o etiquetador inicial (Seção 4.4.1) e o etiquetador final (Seção 4.4.2), e o refinador (Seção 4.5). As diferenças entre as arquiteturas de nosso etiquetador e do etiquetador de Eric Brill podem ser observadas nas Figuras 4.1 e 4.2. Nesse capítulo, além de detalhar o funcionamento de cada um desses módulos, discutiremos alguns detalhes de suas implementações.

\footnotetext{
${ }^{1} \mathrm{Na}$ realidade, algumas partes do sistema foram apenas alteradas em relação ao etiquetador original implementado por Eric Brill, cujo código é público.
} 

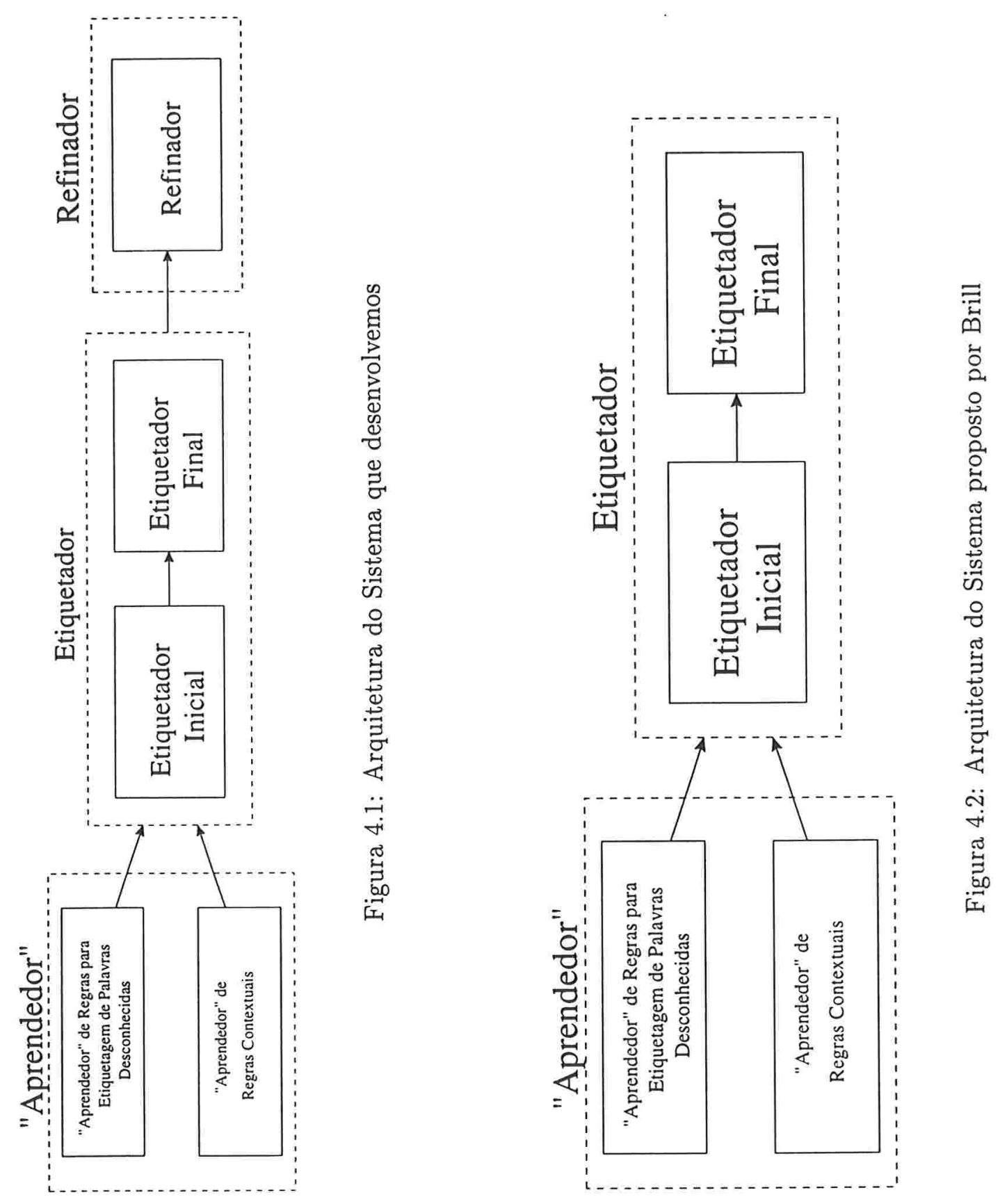


\subsection{O "Aprendedor"}

Nessa seção, descreveremos a parte do sistema responsável pelo aprendizado das regras para etiquetagem de palavras desconhecidas e regras contextuais.

\subsubsection{O "Aprendedor" de Regras para Etiquetagem de Palavras Desconhecidas}

Trata-se do componente do sistema responsável por aprender as regras descritas na Seção 2.1.1. A seguir, descreveremos como o sistema implementa tal aprendizado:

Entrada: arquivos WORDLIST, BIGRAMS, WTC e constante $n$

Saída: arquivo LEXRULEOUTFILE

Mais detalhes sobre os argumentos de entrada desse sistema e sobre a saída podem ser obtidos no Apêndice $B$ desse texto.

1. Leitura do arquivo WORDLIST (com o formato $\langle p a l\rangle$ ), que contém palavras em ordem decrescente de suas ocorrências no corpus de treinamento não-etiquetado, para determinação das $n$ palavras mais freqüentes, ou seja, que aparecem mais vezes em tal corpus. Essas palavras serão utilizadas para seleção dos bigramas ${ }^{2}$. Serão considerados apenas aqueles que tiverem pelo menos uma palavra na lista das $n$ mais freqüentes. Caso seja utilizado um grande valor para $n$, o número de regras que potencialmente serão aprendidas será maior. Por outro lado, pequenos valores para $n$ fazem com que o aprendizado seja mais rápido.

2. Baseado nas palavras de WORDLIST, são determinados os possíveis prefixos e sufixos, com comprimentos ${ }^{3}$ que variam de 1 a 5 . Por exemplo, no caso da palavra abacaxi, seriam gerados os prefixos $a, a b, a b a, a b a c$ e abaca, e os sufixos $i, x i$, axi, caxi e acaxi.

3. Leitura do arquivo WTC (com o formato $\langle p a l\rangle\langle e t i q\rangle\langle f r e q\rangle$, onde freq é o número de vezes que a palavra pal aparece no corpus de treinamento etiquetado marcada com a etiqueta etiq) para determinar quais são as etiquetas mais freqüentemente associadas a palavras, a quantidade de vezes que uma palavra ocorre no corpus de treinamento etiquetado e o número de vezes que uma palavra aparece marcada com uma determinada etiqueta. Para isso, são criadas as tabelas de hashing Freq, indexada pelas palavras, cujas entradas são

\footnotetext{
${ }^{2}$ Bigramas são pares de palavras $\mathrm{p}_{1} \mathrm{p}_{2}$ tais que $\mathrm{p}_{1}$ aparece à esquerda de $\mathrm{p}_{2}$ no corpus de treinamento.

${ }^{3}$ Número de letras.
} 
da forma $\sum$ freq(pal), a tabela PEF, indexada por strings do tipo $\langle p a l\rangle \sqcup^{4}\langle e t i q\rangle$, cujas entradas indicam a frequência com que a palavra pal aparece no corpus de treinamento com a etiqueta etiq e a tabela Etiq, indexada pelas etiquetas que ocorrem no corpus de treinamento, cujas entradas são da forma $\sum$ freq(etiq). O exemplo abaixo ilustra esse processo.

4. Leitura do arquivo BIGRAMS, para seleção e armazenamento dos bigramas.

5. O algoritmo de etiquetagem inicial é aplicado no texto. No caso do programa que desenvolvemos, as palavras com iniciais maiúsculas são marcadas com NPR (nome próprio, singular) e as demais ${ }^{5}$ com $\mathrm{N}$ (nome comum, singular).

6. O potencial $V$ de cada etiqueta é calculado da seguinte forma: para cada entrada $(\langle p a l\rangle \sqcup\langle e t i q\rangle,\langle f r e q\rangle)$ da tabela de hashing PEF, $V($ etiq $)=\sum \frac{\text { freq }}{\text { Freq }[p a l]}$. É criada a lista de etiquetas sortedtags, onde as etiquetas apaarecem em ordem decrescente de potenciais.

Exemplo:

\begin{tabular}{|l|l|l|l|l|}
\hline \hline WORDLIST & Tabela Freq & Tabela PEF & Tabela Etiq & Potencial \\
\hline \hline de P 5 & Freq[de] $=5$ & PEF $($ de $\sqcup$ P $)=5$ & Etiq(P) $=15$ & $V($ P $)=\frac{5}{5}+\frac{10}{30}$ \\
a P 10 & Freq[a] $=30$ & PEF $(\mathrm{a} \sqcup \mathrm{P})=10$ & & \\
a DEM 20 & & PEF $(\mathrm{a} \sqcup \mathrm{DEM})=20$ & Etiq $(\mathrm{DEM})=20$ & $V(\mathrm{DEM})=\frac{20}{30}$ \\
\hline \hline
\end{tabular}

7. Inicia-se, então, o laço de aprendizado das regras. O próximo passo é calcular, para cada uma das etiquetas da lista, a vantagem de se trocar a etiqueta da palavra corrente (palavras de Freq) por tal etiqueta. Dessa forma, em cada iteração são geradas regras para todos os moldes e a melhor delas é escolhida. Cada iteração para geração e avaliação das regras é feita conforme o trecho de código abaixo:

1. bestscore $\leftarrow 0$;

\# Armazena o resultado (score) da melhor transformação.

2. bestguy $\leftarrow \cdots \cdots$;

\# Armazena a melhor transformação.

3. $\operatorname{para}(i \leftarrow 0 ; i \leq \#$ el (sortedtags); $++i)\{$

\# sortedtags é uma lista com as etiquetas que

\# aparecem em PEF em ordem decrescente de

\# potencial

\#

\# \#el(x) é uma função que retorna o número de

\# elementos da estrutura $x$

\footnotetext{
${ }^{4}$ Espaço em branco.

${ }^{5}$ Mais uma vez, estamos nos referindo aos itens léxicos.
} 


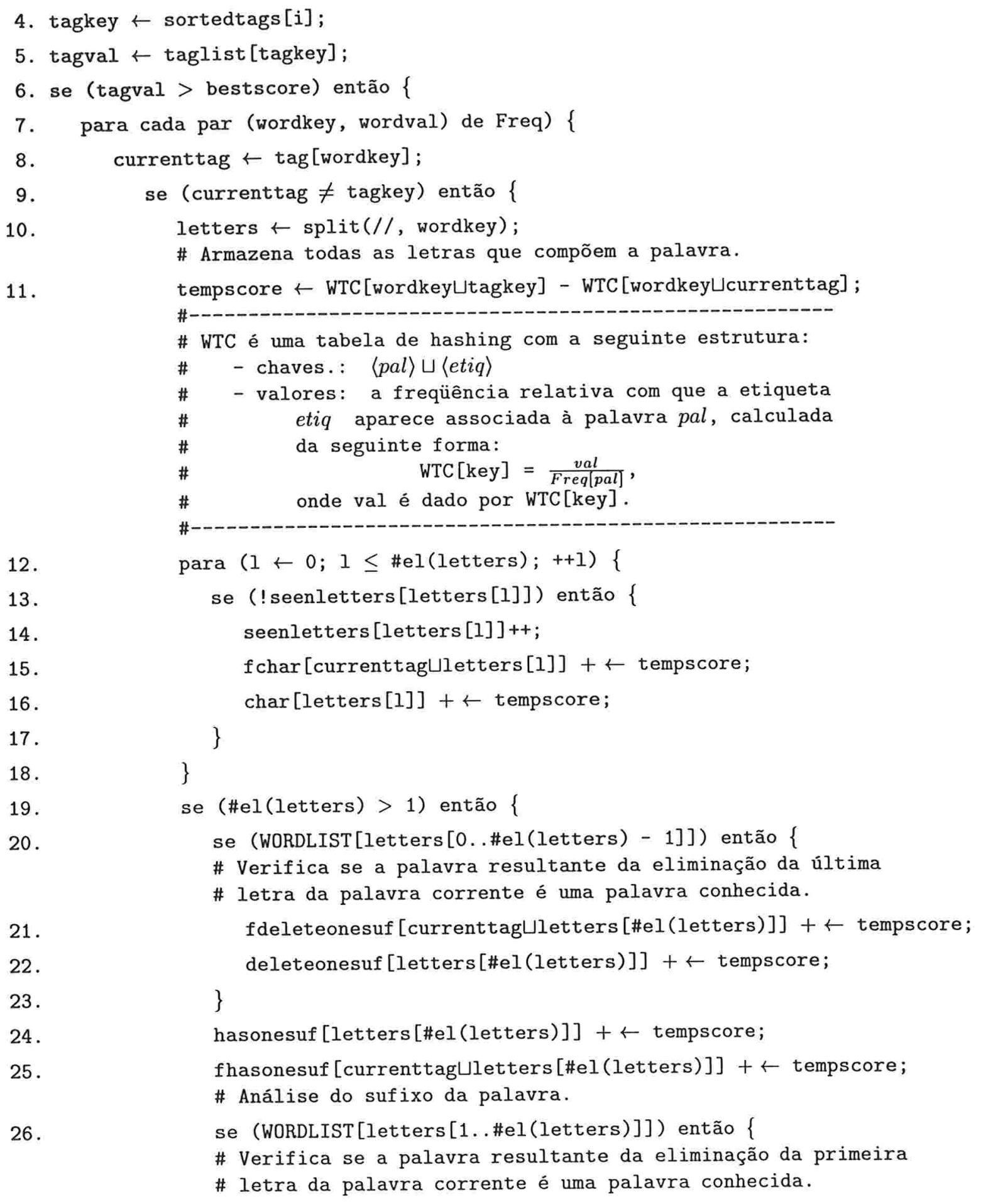


27.

28.

29.

30 .

31.

32.

33.

34.

35.

36.

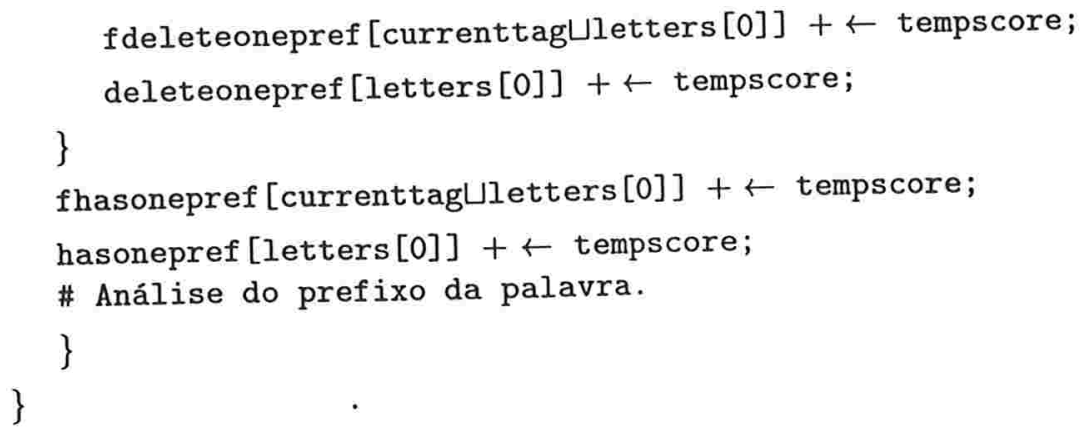

Observe o trecho do código acima que compreende as linhas 19 - 32. Inicialmente, é verificado se a palavra tem comprimento maior que 1 , ou seja, tem pelo menos duas letras. Em caso afirmativo, é verificado se removendo-se a última letra da palavra corrente temos uma palavra conhecida (linha 20). Nesse caso, os vetores fdeleteonesuf e deleteonesuf são atualizados (linhas 21 - 22). Analogamente, as tabelas fhasonepref e hasonepref são atualizados na posição indexada pela primeira letra da palavra (prefixo de comprimento $1)$.

8. A melhor transformação gerada é escolhida (linha 34).

9. Atualização da lista de regras (linha 35).

10. As etiquetas do corpus de treinamento. e lista de regras são atualizadas (linha 36).

11. Retorna ao passo 7.

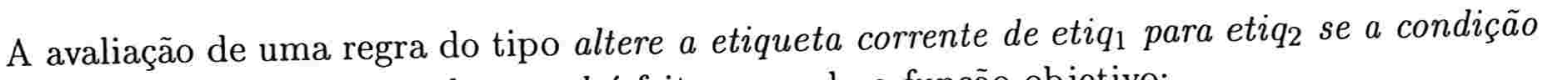
COND é verdadeira para a palavra pal é feita segundo a função objetivo:

$$
\sum_{\substack{\text { pal }=\text { palavras } \\ \text { docorpus } \\ \text { anotado }}} \frac{F r e q\left(p a l, e t i q_{2}\right)-F r e q\left(p a l, e t i q_{1}\right)}{F r e q(p a l)} \times C O N D(p a l) \times \operatorname{etiquetada}\left(\text { pal }, \text { etiq } q_{1}\right)
$$

onde: 


$$
C O N D(p a l)= \begin{cases}1, & \text { se COND é verdadeira para a palavra pal } \\ 0, & \text { caso contrário. }\end{cases}
$$

$$
\text { etiquetada }\left(\text { pal }, e t i q_{1}\right)= \begin{cases}1, & \text { se a palavra pal está anotada com a etiqueta } \text { etiq }_{1} \\ 0, & \text { caso contrário }\end{cases}
$$

Note que, para o aprendizado das regras para etiquetagem de palavras desconhecidas, não é utilizado um corpus. São utilizadas apenas palavras etiquetadas, já que são utilizadas apenas informações intrínsecas as palavras e não informações contextuais que são oferecidas pelos textos.

Os moldes para aprendizado de regras para etiquetagem de palavras desconhecidas implementados no nosso etiquetador são os seguintes:

1. altere a etiqueta corrente de $e t i q_{1}$ para $e t i q_{2}$;

2. altere a etiqueta corrente para etiq;

3. removendo-se um prefixo pref de comprimento $1 / 2 / 3 / 4 / 5$ temos uma palavra conhecida;

4. removendo-se um sufixo suf de comprimento $1 / 2 / 3 / 4 / 5$ temos uma palavra conhecida;

5. a palavra corrente aparece à esquerda da palavra pal;

6. a palavra corrente aparece à direita da palavra pal;

7. a palavra em questão contém o caractere $c$;

8. a palavra contém o prefixo pref de comprimento $1 / 2 / 3 / 4 / 5$;

9. a palavra contém o sufixo suf de comprimento $1 / 2 / 3 / 4 / 5$,

onde etiq, etiq $q_{1}$ e etiq $q_{2}$ são variáveis sobre o conjunto de etiquetas utilizado na marcação, pal é uma variável sobre o léxico da linguagem considerada, $c$ é uma variável sobre o alfabeto da linguagem considerada e pref e suf são cadeias de caracteres desse alfabeto.

Observe que, para cada uma das regras geradas pelos moldes acima, há duas variantes: uma que considera a etiqueta corrente e outra que não. As primeiras são regras que combinam um 
dos moldes de 3 a 9 e o molde 1 . Um exemplo de regra desse tipo é: altere a etiqueta corrente de N-P para NUM se a palavra contém o caractere 0 . A versão desta regra que não considera a etiqueta corrente é altere a etiqueta corrente para NUM se a palavra contém o caractere 0. Regras deste último tipo são geradas por combinações dos moldes 3 a 9 com o molde 2 .

$\mathrm{O}$ arquivo com as regras de etiquetagem de palavras desconhecidas pode ser editado manualmente caso uma regra que se deseja utilizar não esteja nele contida. Para tanto, basta acrescentar no arquivo uma linha com a nova regra. A Figura 4.3 explica o significado de algumas dessas regras. Note que o fato da informação lingüística ser codificada no formato de regras permite que o conhecimento seja armazenado de forma explícita e facilmente compreensível.

Mais uma vez, note a diferença entre haspref/fhaspref, goodright/fgoodright, etc. As regras cujos identificadores começam com "f" são restritas, ou seja, são aplicadas apenas quando a etiqueta corrente é a mesma que a especificada na regra, enquanto as outras regras são aplicadas independentemente desta.

\subsection{O "Aprendedor" de Regras Contextuais}

Trata-se do módulo do sistema que implementa o algoritmo proposto por Brill para o aprendizado de regras contextuais, apresentado na Seção 2.1.2.

O processo de geração dessas regras é o seguinte:

Entrada: arquivos LEXICON, e a referência e esse mesmo texto anotado pelo etiquetador inicial

Saída: arquivos CONTEXTRULEFILE e INFO

Mais detalhes sobre os argumentos de entrada desse sistema e sobre a saída podem ser obtidos no Apêndice B desse texto.

1. Leitura do arquivo com o léxico, com a criação e preenchimento de duas tabelas de hashing: WORDS e SEENTAGGING. A primeira é utilizada para verificar se uma determinada palavra pertence ou não ao léxico da linguagem no momento em que o efeito da aplicação de uma regra é avaliado, conforme mostra o item 5a. A segunda armazenará os pares palavra/etiqueta que ocorrerem na referência. Ela será utilizada posteriormente na verificação se um par palavra/etiqueta é ou não válido no momento que se aplica uma

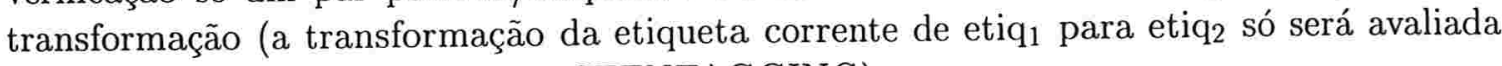
se o par palavra/etiq 2 estiver em SEENTAGGING). 
pref haspref 1 etiq $\mathrm{x}$ se a palavra corrente tem prefixo pref (de comprimento l), marque-a como etiq. Ex.: 0 haspref 1 NUM $\mathrm{x}$.

etiq 1 pref fhaspref 1 etiq $2 \times$ se a palavra corrente tem prefixo pref (de comprimento $l$ ) e tem como etiqueta etiq $_{1}$, alterar a sua etiqueta para etiq $q_{2}$ Ex.: VBN un fhaspref $2 \mathrm{JJ}$ x.

c char etiq $\mathrm{x}$ se o caractere $c$ aparece na palavra corrente, marque-a com etiq. Ex.: 2 char NUM x.

suf hassuf 1 etiq $\mathrm{x}$ se a palavra corrente tem sufixo suf (de comprimento l), marque-a com etiq. Ex.: mos hassuf 3 VB x.

etiq $_{1}$ suf fhassuf 1 etiq 2 xe a palavra corrente tem sufixo suf (de comprimento $l$ ) e tem como etiqueta $e t i q_{1}$, marque-a com $e t i q_{2}$. Ex.: $\mathrm{N}$ da fhassuf $2 \mathrm{VB} \mathrm{x}$.

pref addpref 1 etiq $x$ se adicionarmos o prefixo pref (de comprimento $l$ ) à palavra corrente e a palavra resultante for conhecida, marque-a com etiq. Ex.: mente addsuf 5 ADV x.

suf addsuf 1 etiq $\mathbf{x}$ se adicionarmos o sufixo suf (de comprimento $l$ ) à palavra corrente e a palavra resultante for conhecida, marque-a com etiq. Ex.: d addpref $1 \mathrm{D}$ x.

pal goodright etiq $\mathrm{x}$ se uma palavra aparece sempre à direita da palavra pal, marque-a com etiq. Ex.: tão goodright $\mathrm{ADJ}$ x.

Observação: $0 x$ que aparece na estrutura das regras se refere ao score destas medido no momento em que estas são aprendidas, não sendo importante no momento em que são utilizadas na etiquetagem.

Figura 4.3: Regras para Etiquetagem de Palavras Desconhecidas 
2. Leitura e armazenamento da referência, que é feito em dois vetores: correct_tag_corpus, que armazena as etiquetas e word_corpus, que armazena as palavras propriamente ditas. Tanto as palavras quanto as etiquetas da referência ficam na memória principal durante todo o processo de aprendizado.

3. Leitura do corpus anotado pelo etiquetador inicial e armazenamento de suas etiquetas em guess_tag_corpus. As etiquetas do corpus de treinamento também ficam armazenadas na memória durante todo o aprendizado.

4. É verificado se o número de etiquetas de correct_tag_corpus é o mesmo de guess_tag_corpus. Obviamente, o aprendizado só faz sentido se o número de itens léxicos em ambos os textos for o mesmo.

5. Início da iteração de aprendizado. O laço que controla o aprendizado das transformações tem como condição de parada a comparação do número de erros que ainda podem ser corrigidos com a constante MÍNIMO, que é definida pelo usuário. Caso não seja possível obter alguma regra cuja aplicação resulte na correção de pelo pelo menos MíNIMO erros, o aprendizado deve ser interrompido. Cada iteração de aprendizado consiste no seguinte:

(a) é feita uma comparação entre os vetores correct_tag_corpus e guess_tag_corpus para se verificar quantos são os erros existentes na etiquetagem e de gerar um arquivo com o seguinte formato:

$$
\langle\text { num }\rangle\left\langle e t i q_{1} e t i q_{2}\right\rangle,
$$

onde num é o número de vezes que $e t i q_{1}$ aparece no lugar de $e t i q_{2}$ (em outras palavras, é o número de erros causados pela troca de $e t i q_{2}$ por $e t i q_{1}$ no corpus de treinamento). Para acelerar o processo de aprendizado, é utilizada uma heurística que tem como principal objetivo reduzir o espaço de busca das regras, como explicamos a seguir. Continuando o processo de aprendizado, é gerada a matriz de erros, que armazena os elementos do arquivo mencionado em ordem decrescente do número de erros. Essa ordenação é feita com o objetivo de diminuir o tempo de processamento do sistema de aprendizado de regras contextuais.

Considere uma iteração qualquer do laço de aprendizado. Será verificada, para cada elemento da matriz de erros, qual é a melhor regra contextual (que corrige mais erros) que pode ser gerada utilizando-se esse elemento como ação. Devido ao fato da lista ser ordenada, serão analisados prioritariamente os pares de palavras que podem corrigir o maior número de erros. Seja $\left\langle n u m_{i}\right\rangle\left\langle e t i q_{1}^{i} e t i q_{2}^{i}\right\rangle$ o $i$-ésimo elemento da matriz de erros e $n u m_{i}^{r}$ número de correções da melhor regra gerada a partir de tal elemento da matriz de erros nessa iteração e suponha que $n u m_{i}^{r}>n u m_{j}^{r}$, para todo $j<i$. Seja $\left\langle\right.$ num $\left._{k}\right\rangle\left\langle e t i q_{1}^{k}\right.$ eti $\left.q_{2}^{k}\right\rangle$ o $k$-ésimo elemento da matriz de erros, $k>i$. Se 
$n m_{k}<n u m_{i}^{r}$, então não serão geradas as regras que têm o $k$-ésimo elemento da matriz como regra de reescrita, já que ela não pode corrigir mais do que $n u m_{i}$ erros. Dessa forma, o espaço de busca de regras de reescrita é reduzido, acelerando o processo de aprendizado. Outra otimização é feita quando a matriz de erros é gerada, ja que são selecionados apenas os pares de etiquetas que efetivamente aparecem trocados no corpus de treinamento.

Observe que a aplicação de uma transformação etiq $\rightarrow$ eti $q_{2}$ pode resultar em 3 possibilidades: se $e t i q_{1}$ é a etiqueta correta, o número de erros está sendo aumentado; se $e t i q_{2}$ é a etiqueta correta, o número de erros está sendo diminuido; se nem etiq 1 nem $e t i q_{2}$ são a etiqueta correta, o número de erros permenece o mesmo (observe que necessariamente $e t i q_{1} \neq e t i q_{2}$ ). A seguir, descrevemos cada uma das possibilidades:

Caso 1: a transformação diminui o número de erros: nesse caso, cada uma das tabelas referentes às condições é incrementada na posição relativa à regra que ela representa, conforme mostra o seguinte exemplo: considere uma iteração de aprendizado que não seja a última (ou seja, ainda há uma palavra após a palavra corrente). Nesse caso, a tabela que representa a condição se a próxima etiqueta ou a etiqueta da palavra duas posições depois da palavra corrente será incrementada nas posições referentes à guess_tag_corpus $[i+1]$ e guess_tag_corpus $[i+2]$, onde $i$ é a posição corrente. Isso é feito para todas as condições implementadas no sistema.

Caso 2: a transformação aumenta o número de erros: nesse caso, cada uma das tabelas referentes às condições é decrementada na posição relativa à regra que ela representa, de forma análoga ao que acontece no caso anterior.

Caso 3: a transformação não altera o número de erros. Nada é feito.

(b) A regra selecionada é incluída na lista de regras, o corpus de treinamento é atualizado e uma nova iteração é iniciada.

A avaliação de uma regra do tipo altere a etiqueta corrente de etiq $q_{1}$ para etiq $q_{2}$ se a condição COND é verdadeira para a palavra pal é feita segundo a função objetivo:

$$
\begin{gathered}
{\left[\# \text { Erros corrigidos }\left(e t i q_{1} \rightarrow e t i q_{2}\right)-\# \text { Erros introduzidos }\left(e t i q_{1} \rightarrow e t i q_{2}\right)\right] \times} \\
\operatorname{COND}(\text { pal }) \times \text { etiquetada }\left(\text { pal }, \text { eti } q_{1}\right),
\end{gathered}
$$

onde:

$$
C O N D(\text { pal })= \begin{cases}1, & \text { se COND é verdadeira para a palavra pal } \\ 0, & \text { caso contrário. }\end{cases}
$$


e

etiquetada $\left(\right.$ pal, eti $\left.q_{1}\right)= \begin{cases}1, & \text { se a palavra pal está anotada com a etiqueta etiq } 1 \\ 0, & \text { caso contrário }\end{cases}$

Estão implementados no sistema os seguintes moldes:

1. altere a etiqueta corrente de $e t i q_{1}$ para $e t i q_{2}$;

2. a palavra corrente é pal;

3. a palavra anterior é pal;

4. a próxima palavra é pal;

5. duas posições antes encontra-se a palavra pal;

6. duas posições depois encontra-se a palavra pal;

7. a palavra anterior ou a penúltima palavra é pal;

8. a próxima palavra ou a palavra a duas posições é pal;

9. a palavra corrente é $\mathrm{pal}_{1}$ e a penúltima palavra é $\mathrm{pal}_{2}$;

10. a palavra corrente é $p a l_{1}$ e duas posições depois se encontra a palavra $\mathrm{pal}_{2}$;

11. a palavra corrente é $p a l_{1}$ e aparece à esquerda da palavra $p a l_{2}$;

12. a palavra corrente é $\mathrm{pal}_{1}$ e aparece à direita da palavra $\mathrm{pal}_{2}$;

13. a última palavra é $p a l_{1}$ e a penúltima é $\mathrm{pal}_{2}$;

14. a próxima palavra é pal $_{1}$ e duas posições depois da palavra corrente se encontra a palavra $\mathrm{pal}_{2}$;

15. a palavra anterior tem etiqueta etiq;

16. a próxima palavra tem etiqueta etiq;

17. duas posições antes encontra-se uma palavra marcada com a etiqueta etiq;

18. duas posições depois da palavra corrente encontra-se uma palavra marcada com a etiqueta etiq; 
19. a palavra anterior ou a penúltima palavra é marcada com a etiqueta etiq;

20. a próxima palavra ou a palavra duas posições depois da palavra corrente é marcada com a etiqueta etiq;

21. a palavra anterior, a penúltima ou a antepenúltima palavra é marcada com a etiqueta etiq;

22. a próxima palavra, a palavra duas posições ou a palavra três posições depois da palavra corrente é marcada com a etiqueta etiq;

23. a palavra anterior é marcada com a etiqueta $e t i q_{1}$ e a posterior com a etiqueta $e t i q_{2}$;

24. a palavra corrente é pal e a penúltima palavra é marcada com a etiqueta etiq;

25. a palavra corrente é pal e a palavra duas posições depois é marcada com a etiqueta etiq,

onde etiq, etiq $q_{1}$, e etiq $q_{2}$ são variáveis sobre o conjunto de etiquetas utilizado na marcação e pal, $\mathrm{pal}_{1}$ e $\mathrm{pal}_{2}$ são variáveis sobre o léxico da linguagem considerada.

Esses moldes são os mesmo utilizados originalmente por Eric Brill em seu etiquetador para inglês. Eles podem ser modificados em função da linguagem que se deseja etiquetar.

Observe que há moldes para geração de regras que manipulam palavras além de etiquetas (ex.: $2,3,4,5$, etc.), o que mostra que o etiquetador implementado é lexicalizado.

Assim como acontece em relação às regras para etiquetagem de palavras desconhecidas, podemos acrescentar regras no arquivo das regras contextuais. Tais regras possuem o seguinte formato geral:

$$
\left\langle e t i q_{1}\right\rangle\left\langle e t i q_{2}\right\rangle \text { regra }\left[\left\langle e t i q_{3}\right\rangle \mid\langle p a l\rangle\right]^{6}
$$

O significado de uma regra desse formato é o seguinte: caso uma palavra tenha como etiqueta corrente $e t i q_{1}$ e a condição descrita por regra seja satisfeita em relação a etiq $q_{3}$ (ou pal), etiquetá-la com etiq . A Figura 4.4 mostra alguns exemplos de regras.

Observe que, assim como o que ocorre em relação ao "aprendedor" de regras para etiquetagem de palavras desconhecidas, a saída é simbólica, composta por regras com formato simples e fáceis de serem compreendidas. Isso faz com que o conhecimento lingüístico adquirido seja representado de forma explícita, o que o torna acessível a qualquer pessoa que deseje analisá-lo.

\footnotetext{
${ }^{6}$ Há dois moldes que geram regras com o formato $\left\langle e t i q_{1}\right\rangle\left\langle e t i q_{2}\right\rangle$ regra $\left\langle p a l_{1}\right\rangle\left\langle p a l_{2}\right\rangle$, onde pal $_{1}$ e pal $_{2}$ são palavras do corpus de treinamento. Tais moldes são utilizados para a geração de regras do tipo altere a etiqueto corrente de etiq para etiq $_{2}$ caso a palavra corrente seja pal (pal $_{2}$ ) e a palavra posterior (anterior) seja pal $\left(\right.$ pal $\left._{1}\right)$.
} 
etiq $_{1}$ etiq $_{2}$ PREVTAG etiq 3 altere a etiqueta corrente de $e t i q_{1}$ para $e^{t i q_{2}}$ caso a etiqueta anterior seja etiq. Ex: WPRO C PREVTAG VB.

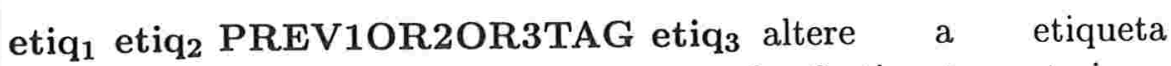
corrente de $e t i q_{1}$ para $e t i q_{2}$ caso uma das 3 etiquetas anteriores seja etiq $_{3}$. Ex.: N VB PREV1OR2OR3TAG VB.

etiq ${ }_{1}$ etiq $_{2}$ WDAND2AFT pal $_{1}$ pal $_{2}$ altere a etiqueta corrente de $e t i q_{1}$ para etiq $q_{2}$ caso a palavra corrente seja pal $_{1}$ e duas palavras depois aparece a palavra $\mathrm{pal}_{2}$. Ex: ADV ADJ WDAND2AFT mais tudo.

etiq $_{1}$ etiq 2 PREV1OR2WD pal altere a etiqueta corrente de etiq $q_{1}$ para eti $_{2}$ caso uma das duas palavras anteriores seja a palavra pal. Ex.: P D PREV1OR2WD mèzinhas.

etiq $_{1}$ etiq $_{2}$ NEXT1OR2WD pal altere a etiqueta corrente de eti $q_{1}$ para $e t i q_{2}$ caso uma das duas palavras posteriores seja a palavra pal. Ex.: NPR N NEXT1OR2WD 1624.

etiq $_{1}$ etiq $_{2}$ LBIGRAM pal pal $_{2}$ altere a etiqueta corrente de etiq 1 para $e t i q_{2}$ caso a palavra corrente seja pal $_{2}$ e a palavra anterior pal $_{1}$. Ex.: N VB LBIGRAM mais falta.

etiq $_{1}$ etiq $_{2}$ RBIGRAM pal pal $_{2}$ altere a etiqueta corrente de etiq $q_{1}$ para $e t i q_{2}$ caso a palavra corrente seja pal $_{1}$ e a próxima pal $_{2}$. Ex.: N P RBIGRAM correio com.

etiq $_{1}$ etiq $_{2}$ PREV1OR2WD pal altere a etiqueta corrente de eti $q_{1}$ para $e t i q_{2}$ caso a próxima palavra seja a palavra pal. Ex.: CONJS CONJ NEXTWD necessário.

etiq $_{1}$ etiq $_{2}$ PREVTAG etiq ${ }_{3}$ altere a etiqueta corrente de etiq para $e t i q_{2}$ caso a palavra anterior esteja marcada com a etiqueta etiq $q_{3}$. Ex.: N VB PREVTAG CL.

Figura 4.4: Alguns Exemplos de Regras Contextuais 


\subsection{O Etiquetador}

Estamos chamando de etiquetador o conjunto formado pelos módulos responsáveis pela etiquetagem dos textos propriamente dita, ou seja, a atribuição de rótulos as palavras. Esse processo, como foi mencionado anteriormente, compreende a etiquetagem inicial do texto e a alteração das etiquetas devido à aplicação das regras contextuais aprendidas. A seguir, descreveremos cada uma dessas etapas.

\subsubsection{O Etiquetador Inicial}

É o módulo do sistema que recebe um texto sem anotação e marca cada uma de suas palavras com uma etiqueta. No sistema que implementamos isso é feito da seguinte forma: inicialmente, todas as palavras são marcadas como nomes. As que têm inicial maiúscula são marcadas como nomes próprios, singular (NPR), enquanto as demais são marcadas como nomes comuns, singular (N). Em seguida, essas etiquetas serão alteradas segundo uma das duas alternativas a seguir: caso a palavra seja conhecida, ou seja, pertence ao léxico que será utilizado pelo etiquetador, ela recebe a etiqueta mais provável a ela associada. A etiqueta mais freqüente de uma palavra é deteminada na construção de léxico pela simples contagem das freqüências de cada uma das etiquetas que aparecem associadas a esta palavra no corpus de treinamento. Caso contrário, isto é, a palavra é desconhecida, sua etiqueta pode ser alterada pela aplicação de alguma das regras de etiquetagem de palavras desconhecidas aprendida. Observe que o fato da palavra ser desconhecida não garante que sua etiqueta será alterada por alguma regra. É exatamente por isso que, inicialmente, todas as palavras devem ser etiquetadas de alguma maneira. 
O algoritmo de etiquetagem inicial, em pseudo-código, é o seguinte:

Entrada: Texto a ser etiquetado, conjunto de regras para etiquetagem de palavras desconhecidas e o léxico.

Saída: O texto de entrada anotado.

O que faz: Marca o texto de entrada de acordo com os critérios descritos acima.

1. para cada palavra pal do texto

2. se a palavra corrente tem inicial maiúscula então

3. marcar pal com NPR

4. senão

5. marcar pal com N

6. para $i \leftarrow 1$ até $d$

7. para cada palavra pal do texto

8. aplicar REPD[i] à pal

9. para cada palavra pal do texto

10. se pal $\in$ LÉXICO então

11. marcá-la com EtiquetaMaisProvável[pal $]$

Note que esse algoritmo leva tempo $O(d \cdot n)$ para fazer a marcação inicial do texto de entrada.

Esse módulo do sistema sofreu as seguintes alterações em relação ao original escrito por Brill:

1. Foram adicionadas as versões que manipulam sufixos e prefixos de comprimento 5 dos moldes $1,2,5$ e 6 , apresentados na Seção 4.2.1. Tais moldes foram adicionados com o intuito de se capturar palavras resultantes da derivação sufixal com base em sufixos como o sufixo adverbial mente, que forma advébios a partir de adjetivos.

2. Conforme dito acima, foi alterado o algoritmo de etiquetagem inicial de tal forma que as palavras são etiquetadas inicialmente como substantivo comum no singular $(\mathrm{N})$ se têm inicial minúscula, e substantivo próprio no singular (NPR) se têm inicial maiúscula. 


\subsubsection{O Etiquetador Final}

Trata-se do módulo do sistema que implementa o algoritmo de etiquetagem de Brill mostrado na Seção 2.3.1, responsável por aplicar as regras contextuais aprendidas pelo sistema de forma a alterar as etiquetas do texto marcado inicialmente. Não foram feitas alterações significantes nesse componente do sistema.

\subsection{O Refinador}

É o módulo do sistema responsável por completar os núcleos das etiquetas quando este for o caso. Os detalhes dos critérios utilizados no refinamento das etiquetas do corpus Tycho Brahe são mostrados em detalhes no próximo capítulo. Ressaltamos, mais uma vez, que esse componente não existe no sistema proposto por Eric Brill.

\subsection{Ferramentas Auxiliares}

Além do sistema propriamente dito, alguns programas auxiliares foram construídos basicamente para que pudéssemos preparar os textos de entrada para serem processados pelo etiquetador. São ferramentas que têm como propósito automatizar tarefas que seriam inviáveis manualmente devido ao tamanho dos textos, como verificação de alguns erros de digitação, formatação, etc.

Tais ferramentas foram implementadas nas linguagens de programação C, padrão ANSI (filter.c) e PERL (todas as demais).

A seguir, descreveremos as funções e as formas de utilização de tais ferramentas.

\subsection{1 checker.prl}

O que faz: Recebe um arquivo com um texto etiquetado formatado e procura os seguintes erros:

- palavras sem etiqueta;

- etiqueta sem palavra (ou seja, o caractere / seguido de alguma string e precedido por um espaço);

- caracteres não permitidos.

Entrada: Um arquivo com um texto em português anotado. 
Saída: Um arquivo com os erros encontrados, indicando a linha e a posição onde eles acontecem.

Utilização: perl checker.prl $\left\langle a r q_{1}\right\rangle\left\langle a r q_{2}\right\rangle$, onde $\operatorname{arq} q_{1}$ é o arquivo de entrada e $\operatorname{arq} q_{2}$ é o arquivo de saída.

\subsection{2 format.prl}

O que faz: Formata um corpus etiquetado de acordo com as normas propostas no Penn Treebank Wall Street Journal Corpus, ou seja, com uma sentença por linha e com todos os itens léxicos (incluindo sinais de pontuação) "tokenizados". Elimina os comentários (tudo o que estiver entre as marcas <comment... $>$ e $</$ comment $>$, incluindo as marcas), as marcas de início e fim de texto (<text $\rangle$ e $\langle/$ text $\rangle$, respectivamente), as marcas de início e fim de título (<heading $>$ e $</$ heading $>$, respectivamente), as informações sobre edição do texto (tudo o que estiver entre as marcas <edition> e </edition>, incluindo as marcas), as informações originais do texto que não puderam ser codificadas ${ }^{7}$ (tudo o que estiver entre as marcas <original> e </original>, incluindo as marcas), as marcas de fim-de-linha $(\langle\mathrm{nl}\rangle)$, além das marcas de início de página $\left(\left\langle\mathrm{P}_{-} \mathrm{xx}\right\rangle\right.$, onde $\mathrm{xx}$ é um número de página).

Entrada: Um corpus etiquetado com comentários, informações sobre a edição do texto, marcas de início e fim de texto, marcas de início de página, etc.

Saída: O corpus de entrada formatado.

Utilização: perl format.prl $\left\langle\operatorname{arq}_{1}\right\rangle\left\langle\operatorname{arq}_{2}\right\rangle$, onde $\operatorname{arq}_{1}$ é o arquivo de entrada e $\operatorname{arq}_{2}$ é o arquivo de saída.

\subsection{3 guessabbrev.prl}

Assim como os textos anotados, os que não são marcados devem estar no formato de uma sentença por linha para que possam ser processadas pelo sistema. Contudo, há o seguinte problema: não há como diferenciar, em princípio, se um ponto (.) encontrado no texto é um ponto final ou um ponto indicador de uma abreviação. Caso não seja feita distinção entre esses casos, o seguinte problema pode acontecer: um ponto indicador de uma abreviação pode ser considerado um terminador de linha e portanto pode ser que uma mesma sentença seja dividida em mais de uma linha. Para resolver este problema, foi criado uma ferramenta que determina quais são as potenciais abreviações para que estas sejam substituidas pelas correspondentes formas completas. Com o objetivo de manter as características do texto original, as abreviações

\footnotetext{
${ }^{7}$ Por problemas de alfabeto, por exemplo.
} 
são desmembradas, mas não são removidas do texto. Para que se possa fazer a distinção entre o que é original e o que foi inserido, utilizamos as marcas <original> e </original>, conforme mostra o exemplo abaixo:

"...Temos bem claro exemplo no cuidado e proteç̧ão paternal com que a Divina Majestade olhou sempre a Igreja de Braga desd'o dia que foi servido fundá-la com a pregação e doutrina do Glorioso Apóstolo e patrão de Espanha, Santiago, e regá-la com o sangue de seu primeiro prelado, São <original> S. </original > Pedro de Rates (sobrenome do lugar do martírio), companheiro e discípulo dos mais amados do mesmo Apóstolo, dando-lhe por todas as idades esclarecidos e valerosos prelados, que com sua virtude e santidade estabeleceram aquela cadeira e primacia de Espanha, muitos dos quais estão hoje honrados por Santos pola Santa Madre Igreja de Roma, $\mathrm{e}<\mathrm{P} \_10>$

provendo-a em nossos tempos de um Arcebispo de tal valor que, não só foi poderoso pera reformar ..."

O que faz: Gera uma lista com as possíveis abreviações em um texto. Uma palavra ${ }^{8}$ é considerada uma possível abreviação se é composta por 1,2 ou 3 letras e termina com o caractere "." (este programa foi escrito de forma que palavras que tenham sub-palavras com as características mencionadas seja consideradas potenciais abreviações. Por exemplo, a palavra "100.000" é uma potencial abreviação nesse contexto).

Entrada: Um texto não etiquetado.

Saída: Uma lista com as potenciais abreviações (esta lista inclui todas as ocorrências de cada uma destas potenciais abreviações, podendo então conter repetições).

Utilização: perl guessabbrev.prl $\left\langle a r q_{1}\right\rangle\left\langle a r q_{2}\right\rangle$, onde $\operatorname{arq} q_{1}$ é o arquivo de entrada e $\operatorname{arq} q_{2}$ é o arquivo de saída.

\subsection{4 filter.c}

O que faz: Recebe uma lista de abreviações e a filtra, gerando uma nova lista onde não há repetições.

Entrada: Uma lista de abreviações.

Saída: Uma nova lista de abreviações sem repetições.

Utilização: filter $\left\langle a r q_{1}\right\rangle\left\langle a r q_{2}\right\rangle$, onde $\operatorname{arq} q_{1}$ é o arquivo de entrada e arq é o arquivo de saída.

\footnotetext{
${ }^{8}$ Novamente, estamos nos referindo a um item léxico.
} 


\subsection{5 generator.prl}

O que faz: Gera um programa em PERL que faz a substituição das abreviações no arquivo de entrada pelas respectivas versões não abreviadas.

Entrada: Uma lista com possíveis abreviações sem repetições e, para cada uma das abreviações, a expressão correspondente por extenso.

Saída: Um programa que substitui as abreviações pelas correspondentes expressões por extenso.

Utilização: perl generator.prl $\left\langle\operatorname{arq}{ }_{1}\right\rangle\left\langle a r q_{2}\right\rangle$, onde $\operatorname{arq}_{1}$ é o arquivo de entrada e $\operatorname{arq} q_{2}$ é o arquivo de saída.

\subsection{6 tokenizer.prl}

O que faz: Formata um texto não etiquetado de forma que este possa ser utilizado no aprendizado de regras de etiquetagem de palavras desconhecidas (removendo inclusive as marcas e as informações extra-lingüísticas mostradas em 4.6.2).

Entrada: Um texto não etiquetado sem abreviações.

Saída: O texto de entrada formatado.

Utilização: perl tokenizer.prl $\left\langle a r q_{1}\right\rangle\left\langle a r q_{2}\right\rangle$, onde $\operatorname{arq} q_{1}$ é o arquivo de entrada e arq é o arquivo de saída.

Este programa manipula "tokens" com o seguinte formato (além dos usuais): (token)..., (token)., (token),, (token) ;, (token)!, (token)?, (token), token)..., token)., token), , token);, token)!, token)?, (token, token), "token',., "token',, "'token"':, "'token",;, "token", " ¡token, "¿token, "token, token",., token",, token"':, token' ';, token' '!, token' '?, token' ', token., token,, token:, token;, token..., token!, token?, ¿token e ¡token, onde token é um item léxico.

\subsection{7 extractcompl.prl}

O que faz: Remove os complementos das etiquetas de um texto anotado com as etiquetas completas (núcleo + complemento).

Entrada: Um texto anotado com as etiquetas completas. 
Saída: O mesmo texto da entrada, só que anotado apenas com os núcleos das etiquetas.

Utilização: perl extractcompl.prl $\left\langle a r q_{1}\right\rangle\left\langle a r q_{2}\right\rangle$, onde $\operatorname{arq} q_{1}$ é o arquivo de entrada e arq é o arquivo de saída.

\subsection{8 statistics.prl}

O que faz: Gera estatísticas sobre a etiquetagem de um texto. Apresenta os seguintes dados:

- o número de palavras do texto que são conhecidas;

- os percentuais de acerto/erro na etiquetagem de palavras conhecidas;

- o número de palavras do texto que são desconhecidas;

- os percentuais de acerto/erro na etiquetagem de palavras desconhecidas;

- o número total de palavras do texto;

- os percentuais de acerto/erro na etiquetagem de todas as palavras;

- uma lista com as palavras etiquetadas corretamente, com o formato 〈palavra〉 $\langle$ etiqueta $\langle$ num $\rangle$, onde num é o número de acertos;

- uma lista com as palavras mal etiquetadas, com o formato 〈palavra〉

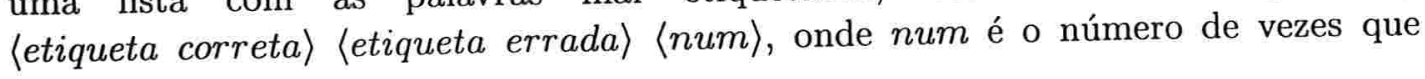
esse erro ocorre;

- uma lista com os erros de etiquetagem, com o formato 〈etiqueta correta〉 $\langle$ etiqueta errada $\langle$ num $\rangle$, onde num é o número de vezes que esse erro ocorre;

- uma lista de verbos com etiquetas múltiplas etiquetados corretamente (ou seja, o refinamento correto é uma das possibilidades apresentadas na etiqueta múltipla);

- os percentuais de acerto/erro na etiquetagem de todas as palavras, incluindo os verbos com etiquetas múltiplas etiquetados corretamente.

Entrada: A referência (texto etiquetado manualmente), o mesmo texto etiquetado automaticamente e o léxico utilizado na etiquetagem.

Saída: Um relatório com as informações mencionadas acima.

Utilização: perl statistics.prl $\left\langle\operatorname{arq}_{1}\right\rangle\left\langle\operatorname{arq}_{2}\right\rangle\left\langle\operatorname{arq}_{3}\right\rangle\left\langle\operatorname{arq}_{4}\right\rangle$ [-verbose], onde $\operatorname{arq}_{1}$ é o arquivo com a referência, $a r q_{2}$ é o arquivo com o texto marcado pelo etiquetador, $\operatorname{arq}_{3}$ é o arquivo com o léxico utilizado na etiquetagem e $\operatorname{arq}_{4}$ é o arquivo de saída. A opção verbose faz com que as listas mencionadas acima sejam incluídas no relatório com as estatísticas. 


\section{Capítulo 5}

\section{Refinando as Etiquetas do Corpus Tycho Brahe}

\subsection{O Refinamento}

Nesse capítulo apresentaremos os critérios utilizados para fazer o refinamento das etiquetas do Corpus Tycho Brahe. Mostraremos, ainda, os problemas que surgiram no decorrer do processo de definição de tais critérios e quais foram as soluções adotadas para resolvê-los (ou contorná-los, quando uma solução definitiva não foi encontrada).

\subsubsection{Comentários Sobre a Notação Utilizada}

1. O símbolo $\nexists$ é utilizado para indicar que um determinado núcleo não possui o referido complemento.

2. O símbolo $\vee$ é utilizado no lugar da palavra ou para indicar múltiplas possibilidades.

3. Cada uma das células da tabela indica os contextos nos quais o referido complemento deve ser acrescentado ao correspondente núcleo. Para apresentar esta informação de forma compreensível e concisa, utilizaremos a seguinte notação:

- pal: $\mathrm{xxx} \equiv \mathrm{a}$ palavra corrente é $\mathrm{xxx}$

- pref: $\mathrm{xxx} \equiv$ a palavra corrente tem prefixo ${ }^{1} \mathrm{xxx}$

\footnotetext{
${ }^{1}$ Nesse contexto, a palavra prefixo está sendo utilizada para indicar as $n$ primeiras letras de uma palavra, independentemente desse prefixo existir ou não na língua portuguesa.
} 
- suf: $\mathrm{xxx} \equiv$ a palavra corrente tem sufixo ${ }^{2} \mathrm{xxx}$

4. Extendendo a notação acima para conjuntos de palavras, sufixos ou prefixos, temos:

- $p a l \in C o n j \equiv$ a palavra corrente pertence ao conjunto Conj

- pref $\in C o n j \equiv$ a palavra corrente tem prefixo contido no conjunto Conj

- $s u f \in C o n j \equiv$ a palavra corrente tem sufixo contido no conjunto Conj

A seguir, mostraremos quais são os critérios propriamente ditos para o refinamento dos núcleos das etiquetas. Por motivo de clareza e concisão, essas informações serão mostradas em tabelas, que devem ser interpretadas como mostra o exemplo abaixo:

\begin{tabular}{|l|l|}
\hline \hline Compl. \ Núcleo & ETIQ \\
\hline \hline COMPL & COND \\
\hline \hline
\end{tabular}

A interpretação dessa tabela deve ser a seguinte: se a etiqueta corrente é ETIQ e a condição COND é satisfeita, então a etiqueta completa deve ser ETIQ-COMPL (ou seja, o núcleo ETIQ deve ser refinada com o complemento COMPL).

Embora as tabelas que serão apresentadas as seguir não exibam explicitamente os significados das etiquetas (por exemplo, temos que a etiqueta SR pode receber o complemento RA, mas não indicamos que SR-RA é uma etiqueta que se refere ao pretérito mais-que-perfeito do modo indicativo do verbo ser), estes podem ser encontrados no Apêndice A. Além disso, mostramos nesse apêndice exemplos da utilização de algumas etiquetas que compõem o Corpus Tycho Brahe e apresentamos alguns esclarecimentos sobre a metodologia de anotação dos textos.

\subsection{Verbos}

Os verbos foram divididos em cinco grandes grupos no projeto do conjunto de etiquetas do Corpus Tycho Brahe: haver, estar, ter, ser e demais verbos. Sendo assim, há cinco núcleos de etiquetas referentes a verbos: HV, ET, TR, SR e VB, respectivamente. A seguir, mostraremos como esses núcleos são refinados.

\footnotetext{
${ }^{2}$ Nesse contexto, a palavra sufixo está sendo utilizada para indicar as $n$ últimas letras de uma palavra, independentemente desse sufixo existir ou não na língua portuguesa.
} 


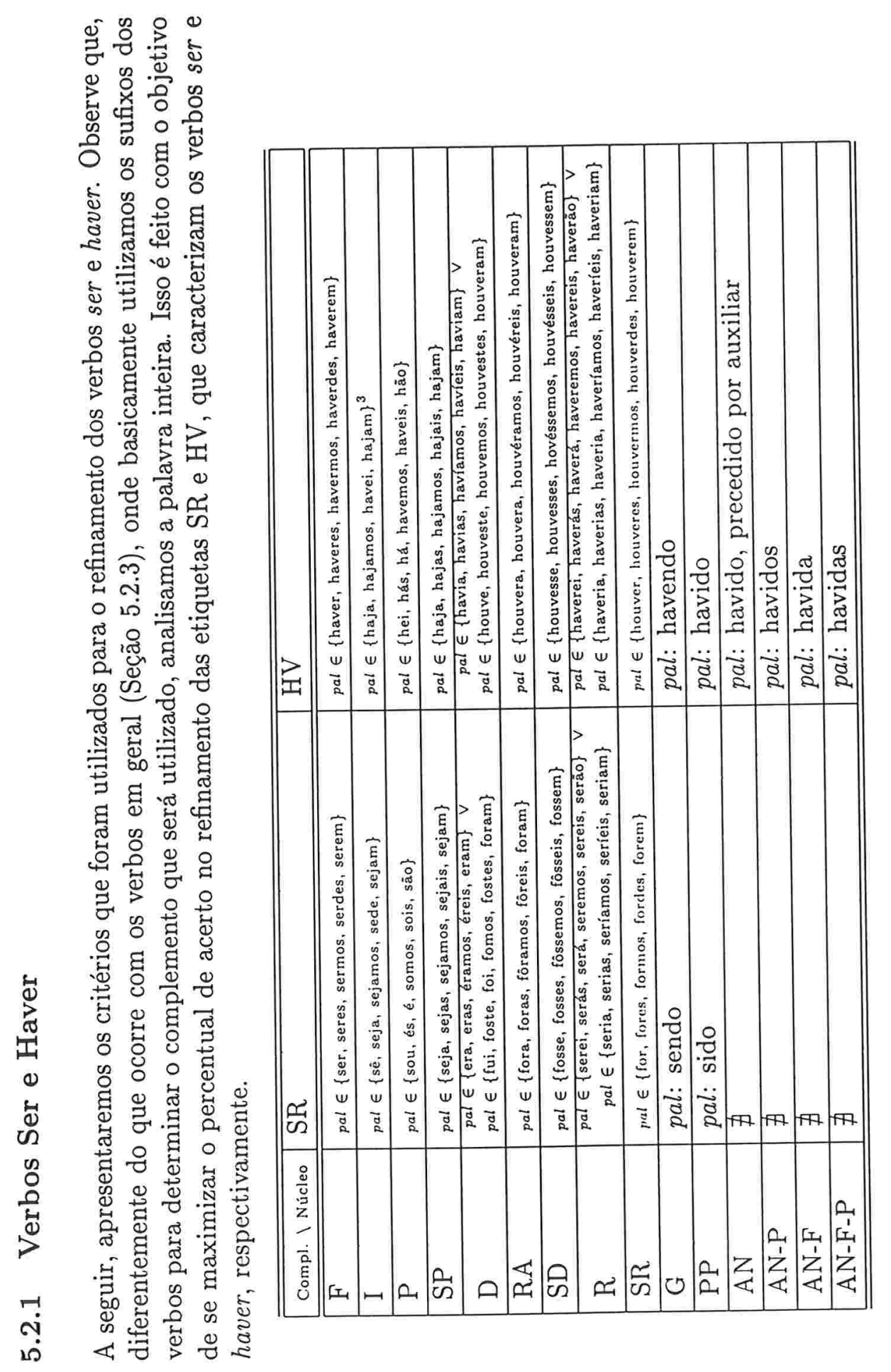

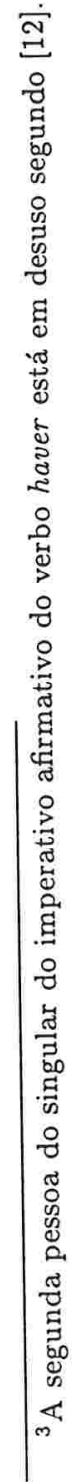




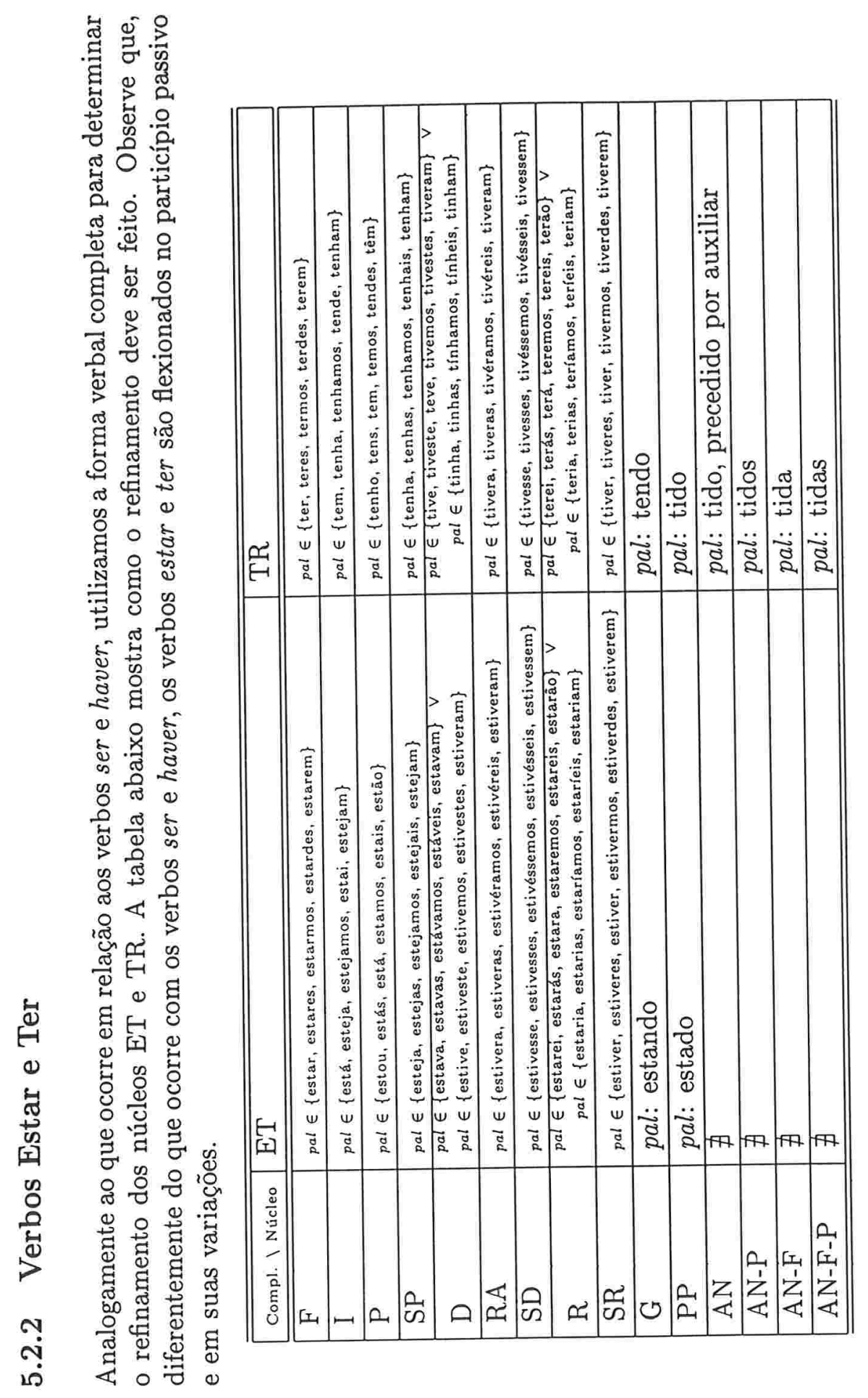




\subsubsection{Demais Verbos}

Mostramos, a seguir, como deve ser feito o refinamento do núcleo VB, que caracteriza os verbos em geral. Note que há sufixos comuns a mais de um tempo verbal, o que introduz ambigüidades no processo de refinamento. Mais detalhes sobre esse problema e as soluções adotadas para resolvê-lo são exibidas na Seção 5.3.

\begin{tabular}{|l|l|}
\hline \hline Compl. \ Núcleo & VB \\
\hline \hline F & suf $\in\{\mathrm{r}$, res, rmos, rdes, rem $\}$ \\
\hline I & suf $\in\{$ a, amos, ai, am, e, emos, ei, em, i\} \\
\hline P & suf $\in\{$ o, as, a, amos, ais, am, es, e, emos, eis, em, imos, is $\}$ \\
\hline SP & suf $\in\{$ e, es, emos, eis, em, a, as, a, amos, ais, am $\}$ \\
\hline Duf $\in\{$ ava, avas, ávamos, áveis, avam, ia, ias, íamos, iam $\}$ \\
D suf $\in\{$ ei, aste, ou, amos, astes, am, i, este, eu, emos, estes $\}$ \\
\hline RA & suf $\in\{$ ra, ras, ramos, reis, ram $\}$ \\
\hline SD & suf $\in\{$ sse, sses, ssemos, sseis, ssem $\}$ \\
\hline R & suf $\in\{$ ei, ás, á, emos, eis, ão, ria, rias, ríamos, ríeis, riam $\}$ \\
\hline SR & suf $\in\{$ r, res, rmos, rdes, rem $\}$ \\
\hline G & suf $\in\{$ ando, endo, indo $\}$ \\
\hline PP & suf $\in\{$ ado, ido $\}$ \\
\hline AN & suf $\in\{$ ado, ido $\}$, precedido por auxiliar \\
\hline AN-P & suf $\in\{$ ados, idos $\}$ \\
\hline AN-F & suf $\in\{$ ada, ida $\}$ \\
\hline AN-F-P & suf $\in\{$ adas, idas $\}$ \\
\hline
\end{tabular}

\subsubsection{Adjetivos}

No Corpus Tycho Brahe, os adjetivos foram divididos em adjetivos comparativos, exclamativos, superlativos e demais adjetivos. Além disso, foram marcadas as flexões de gênero e número. Apresentamos, a seguir, as regras que devem ser seguidas para o refinamento do núcleo ADJ, que caracteriza os adjetivos no nosso corpus. 


\begin{tabular}{|c|c|}
\hline Compl. \ Núcleo & ADJ \\
\hline$\overline{\mathrm{P}}$ & suf: os \\
\hline $\mathrm{F}$ & suf: a \\
\hline F-P & suf: as \\
\hline G & pal $\in\left\{\right.$ amável, tal $\left.^{4}\right\} \vee$ suf $\in\{1, \mathrm{e}\}$ \\
\hline G-P & pal $\in\left\{\right.$ amáveis, demais ${ }^{5}$, mais $\} \vee$ suf $\in\{$ eis, es $\}$ \\
\hline $\mathrm{S}$ & suf : íssimo $\vee$ pal $\in\left\{\right.$ mínimo, máximo ${ }^{6}$, péssimo, ótimo $\}$ \\
\hline S-P & suf: íssimos \\
\hline $\mathrm{S}-\mathrm{F}$ & suf: íssima \\
\hline S-F-P & suf: íssimas \\
\hline $\mathrm{R}$ & pal $\in\{$ tanto, mesmo $\}$ \\
\hline R-P & pal $\in\{$ tantos, mesmos $\}$ \\
\hline $\mathrm{R}-\mathrm{F}$ & pal $\in\{$ tanta, mesma $\}$ \\
\hline R-F-P & pal $\in\{$ tantas, mesmas $\}$ \\
\hline $\mathrm{R}-\mathrm{G}$ & $\begin{array}{l}\text { pal } \in\{\text { melhor, pior, maior, menor, mais, menos, bastante, } \\
\left.\text { demais, } \text { tal }^{7}, \text { mesmo }^{8}\right\}\end{array}$ \\
\hline R-G-P & pal $\in\left\{\right.$ melhores, piores, maiores, menores, bastantes, mesmos $\left.^{9}\right\}$ \\
\hline
\end{tabular}

\subsubsection{Advérbios}

Assim como os adjetivos, os advérbios foram divididos em advérbios comparativos, exclamativos, superlativos e demais advérbios. Além disso, foram marcadas as flexões de gênero e número. Apresentamos, a seguir, as regras que devem ser seguidas para o refinamento do núcleo ADV, que caracteriza os advérbios no Corpus Tycho Brahe. Note que, embora haja palavras que ora são adjetivos e ora são advébios, isso não introduz uma ambigüidade, já que os núcleos das etiquetas das duas formas são diferentes.

\begin{tabular}{|l|l|}
\hline \hline Compl. \Núcleo & $\mathrm{ADV}$ \\
\hline \hline $\mathrm{S}$ & suf: issimamente \\
\hline $\mathrm{R}$ & pal $\in\left\{\right.$ melhor, pior, mais, menos, tão, tanto, bastante, demais, antes $\left.{ }^{10}\right\}$ \\
\hline \hline
\end{tabular}

\footnotetext{
${ }^{4}$ Em uma baía tão formosa, larga e capaz que, por ser tal, deu nome à cidade.

${ }^{5}$ Em as demais ciências.

${ }^{6} \mathrm{Em}$ o máximo/mínimo esforço.

${ }^{7} \mathrm{Em}$ uma tal dificuldade.

${ }^{8} \mathrm{Em}$ comprei o mesmo que você.

${ }^{9} \mathrm{Em}$ comprei os mesmos que você.

${ }^{10} \mathrm{Em}$ morrer antes com honra que ter a vida sem ela.
} 


\subsubsection{Flexão de Gênero}

Mostramos, abaixo, como devem ser complementados os núcleos das etiquetas que caracterizam classes morfo-sintáticas que no Corpus Tycho Brahe são refinadas apenas em relação à flexão de gênero, ou por apresentarem apenas essa flexão ou por uma decisão no projeto das etiquetas utilizadas.

\begin{tabular}{|l|l|}
\hline \hline Compl. \ Núcleo & NUM \\
\hline \hline $\mathrm{F}$ & $p a l \in\{$ uma, duas $\}$ \\
\hline \hline
\end{tabular}

\subsubsection{Flexão de Número}

Mostramos, abaixo, como devem ser complementados os núcleos das etiquetas que caracterizam classes morfo-sintáticas que no Corpus Tycho Brahe são refinadas apenas em relação à flexão de número, ou por apresentarem apenas essa flexão ou por uma decisão no projeto das etiquetas utilizadas.

\begin{tabular}{|l|l|}
\hline \hline Compl. \ Núcleo & N, NPR, WPRO \\
\hline \hline $\mathrm{P}$ & suf: $\mathrm{s}$ \\
\hline \hline
\end{tabular}




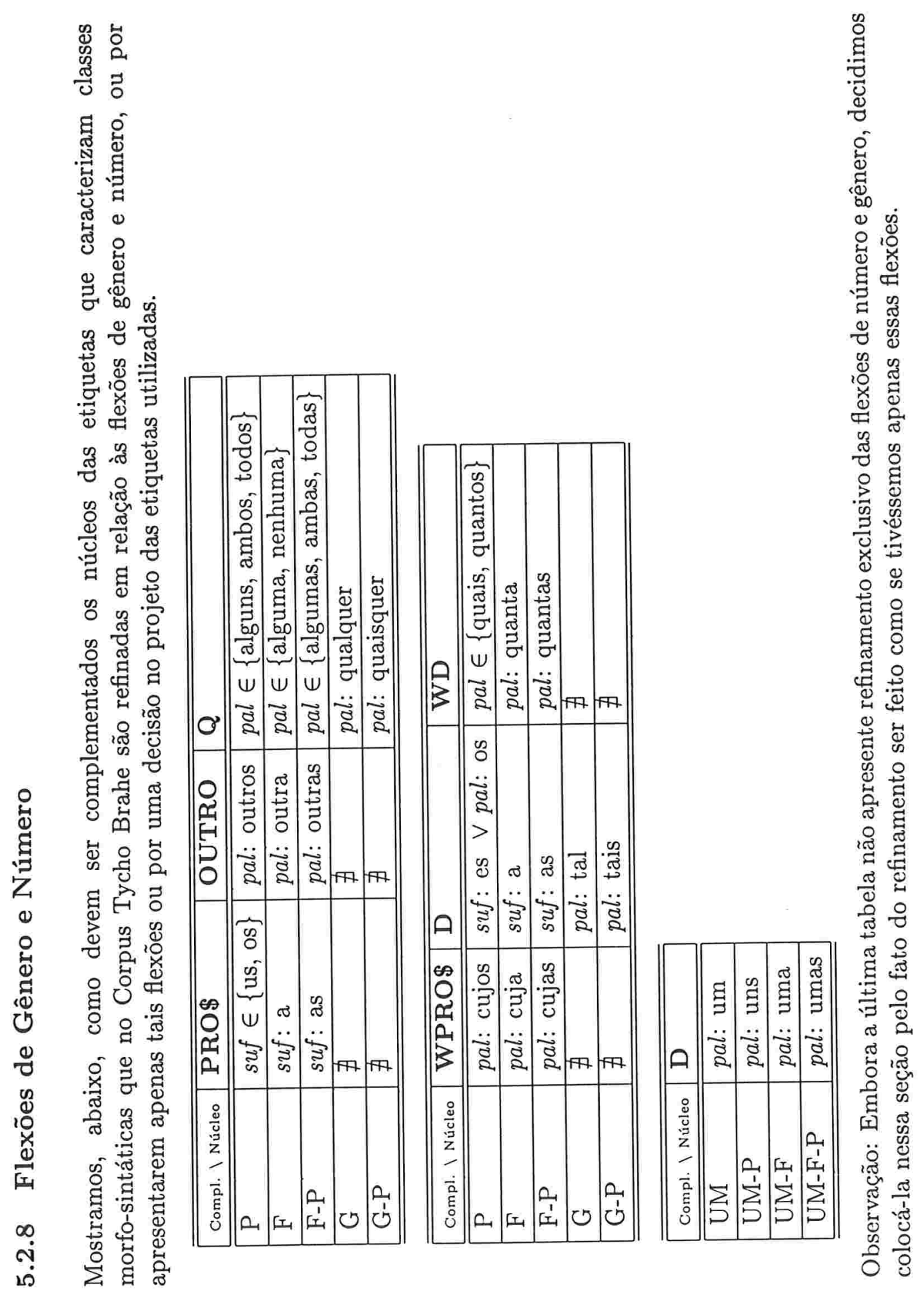




\subsubsection{Contrações}

Apresentamos, a seguir, como devem ser complementados os núcleos das etiquetas relativas às contrações. Note que, diferentemente do que ocorre com os complementos dos demais núcleos, os complementos das contrações são associados ao núcleo $\mathrm{P}$ através dos sinal + (ex.: P+D-F-P).

\begin{tabular}{|l|l|}
\hline \hline Compl. \Núcleo & $\mathbf{P}$ \\
\hline \hline D & pal $\in\{$ ao, no, do, desse, pelo $\}$ \\
\hline D-P & pal $\in\{$ aos, nos, dos, desses, pelos $\}$ \\
\hline D-F & pal $\in\{$ à, na, da, dessa, pela $\}$ \\
\hline D-F-P & pal $\in\{$ às, nas, das, dessas, pelas $\}$ \\
\hline DEM & pal $\in\{$ disso, disto, daquilo $\}$ \\
\hline WADV & pal: donde \\
\hline CL & pal $:$ pela ${ }^{11}$ \\
\hline \hline
\end{tabular}

\subsubsection{Locuções}

O refinamento das locuções prepositivas e conjuntivas será feito da seguinte forma: caso sejam encontradas no texto duas ou mais palavras consecutivas com etiquetas cujos núcleos são P, CONJ ou CONJS, cada uma dessa palavras será marcada da seguinte forma:

$$
\text { palavra/etiqueta- } \mathrm{n}_{1} \mathrm{n}_{2}
$$

onde $\mathrm{n}_{1}$ é o comprimento (número de palavras) da locução e $\mathrm{n}_{2}$ é a posição da palavra dentro da locução. Ex.: no/CONJ-21 entanto/CONJ-22.

\subsubsection{Etiquetas Sem Complemento}

As seguintes etiquetas não possuem complementos: PRO, CL, SE, DEM, CONJ $^{12}$, C, CONJS ${ }^{13}$, WADV, WQ, NEG, SENÃO, INTJ, FW, XX, ., , e (.

\footnotetext{
${ }^{11}$ Em trabalhei pela servir.

${ }^{12} \mathrm{~A}$ menos dos casos de locuções conjuntivas, conforme explicado em 5.2.10.

${ }^{13}$ Ver nota anterior.
} 


\subsection{Tratando as Ambigüidades}

Como pode ser observado na tabela com os refinamentos para os verbos em geral (Seção 5.2.3), há sufixos que caracterizam mais de um tempo verbal. Isso introduz o seguinte problema: como decidir uma determinada palavra pertence a um determinado tempo verbal caso ela seja caracterizada por um tal sufixo? O exemplo abaixo mostra algumas situações onde isto ocorre:

1. (a) Quando você terminar, avisa/VB-I (2 $2^{\underline{a}}$ pessoa do singular, imperativo afirmativo do verbo avisar) ...

(b) Ele avisa/VB-P (3ㅁ pessoa do singular, presente do indicativo do verbo avisar) ...

2. (a) Todo mundo sabe que nós cantamos/VB-P ( $1^{\underline{a}}$ pessoa do plural, presente do indicativo do verbo cantar) ...

(b) Todo mundo sabe que nós cantamos/VB-D (1 $1^{\underline{a}}$ pessoa do plural, passado do indicativo do verbo cantar) ...

3. (a) Quando eu falar/VB-SR (1 $\stackrel{a}{a}$ pessoa do singular, futuro do subjuntivo do verbo falar) ...

(b) Para eu falar/VB (infinitivo do verbo falar) ...

Uma solução definitiva para este problema ainda não foi encontrada. O que fizemos foi o seguinte: caso haja alguma outra informação (diferente do sufixo) que possa determinar em qual tempo verbal o verbo está flexionado, utilizaremos tal informação para fazer o refinamento da etiqueta da palavra em questão. Caso contrário, o refinamento da etiqueta consistirá de uma lista com os possíveis complementos para o núcleo da etiqueta da palavra em questão (nesse caso, teremos classes de equivalência em vez simplesmente classes gramaticais). O próximo exemplo ilustra ambas as situações:

1. Quando você terminar, avisa/VB-(I | P) ...

2. Ele avisa/VB-(I|P) ...

3. Quando eu falar/VB-SR ...

4. Para eu falar/VB ...

Nos casos dos itens 1 e 2 do exemplo, não foi possível determinar qual seria o refinamento correto para o prefixo VB associado à palavra avisa. Já nos casos 3 e 4, a palavra quando foi utilizada como determinante dos refinamentos que deveriam ser utilizados.

Tal solução provavelmente será substituida por outra no futuro, pois: 
(a) esse método dificulta a correção manual dos textos, já que sempre requer correção;

(b) estamos procurando formas para resolver o problema da ambigüidade baseadas na estrutura da oração e em seus componentes.

Embora estejamos pesquisando formas de se discernir entre tempos verbais homógrafos, ainda não conseguimos resultados para todas as situações onde há o problema. Por enquanto, apenas os seguintes conflitos foram solucionados:

- futuro do subjuntivo $\times$ infinitivo: utilizaremos apenas as palavras quando e se para caracterizar o futuro do subjuntivo em oposição ao infinitivo flexionado e a sua forma não flexionada.

- particípio passado $\times$ particípio passivo: quando a forma verbal no particípio terminar em ado ou ido e for precedida pelo verbo ter ou haver, será marcada como particípio passivo. Os outros casos serão marcados como particípio passado.

- adjetivos com gênero duplo $\times$ adjetivos em geral: serão marcados como adjetivos com gênero duplo aqueles que estão listados no manual de etiquetagem, além dos que terminarem com $e$ ou $l$. Analogamente, serão marcados como adjetivos com gênero duplo no plural os que estão no manual e os que terminarem com es ou eis.

Problemas semelhantes acontecem em relação a outras classes morfo-sintáticas. Por exemplo:

1. Pela manhã, ele regou o jardim. $\mathrm{O}$ mesmo/ $\mathrm{N}$ foi feito durante a tarde.

2. Ela virá mesmo/ADV que algo ocorra.

3. O mesmo/ADJ homem saiu.

4. O mesmo/ADJ homem que/WPRO foi ao supermercado acaba de sair.

5. Ele fez o mesmo/ADJ-R trabalho que/C você.

Como pode ser visto, a palavra mesmo pode ser marcada de diversas maneiras. Contudo, apenas duas delas geram problemas, já que apresentam etiquetas com os mesmos núcleos (formas 4 e 5). Para resolver esse problema, verificamos qual é a marca recebida pela palavra que que precede o advérbio mesmo. Se for sucedido por um que marcado com $\mathrm{C}$, será marcado com a etiqueta ADJ-R; caso contrário, será marcado com a etiqueta ADJ.

Está em discussão (pela equipe de lingüistas do projeto) a alteração da função morfo-sintática da palavra mesmo nos casos 2, 3 e 4 mostrados acima para uma partícula de foco. Ou seja, nesse caso, a ambigüidade pode ser desfeita por uma revisão teórica no projeto das etiquetas. 


\section{Capítulo 6}

\section{Os Experimentos Realizados}

Esse capítulo mostra os resultados das experiências que foram realizadas com o etiquetador que implementamos, além de apresentar os dados utilizados e as conclusões obtidas em tais experimentos.

\subsection{Resultados da Etiquetagem}

Apresentaremos, nessa seção, os resultados da marcação dos textos com o etiquetador que desenvolvemos.

\subsubsection{Os Dados Utilizados}

Tanto para o aprendizado quanto para a etiquetagem, foram utilizados textos etiquetados e textos não etiquetados. Esses textos foram divididos da seguinte forma:

- corpus etiquetado com aproximadamente 23.000 palavras para aprendizado de regras para etiquetagem de palavras desconhecidas. Trata-se de uma coleção de textos de Frei Luís de Sousa e Frei Antônio das Chagas, escritos nos séculos XVI e XVII, respectivamente;

- corpus não-etiquetado com aproximadamente 117.000 palavras para aprendizado de regras para etiquetagem de palavras desconhecidas. Trata-se de uma coleção de textos de Frei Luís de Sousa e Frei Antônio das Chagas, escritos nos séculos XVI e XVII, respectivamente; 
- corpus etiquetado com aproximadamente 24.700 palavras para aprendizado de regras contextuais. Trata-se de uma coleção de textos de Frei Luís de Sousa e Frei Antônio das Chagas, escritos nos séculos XVI e XVII, respectivamente;

- dois corpora para testes. Um com aproximadamente 5.000 palavras, escrito por Padre Antônio Vieira no século XVI e outro, com aproximadamente 22.000 palavras, de Almeida Garrett, escrito no século XIX. Os textos não foram agrupados em um único corpus para que fosse possível analisarmos as eventuais diferenças nos resultados obtidos na etiquetagem de textos de diferentes autores e diferentes épocas.

\subsubsection{As Medidas Realizadas}

Foram feitas cinco tipos de medidas em relação à anotação dos textos:

1. utilizando-se apenas o etiquetador inicial. sem regras para etiquetagem de palavras desconhecidas (a marcação utiliza apenas os núcleos das etiquetas);

2. utilizando-se apenas o etiquetador inicial. com regras para etiquetagem de palavras desconhecidas (a marcação utiliza apenas os núcleos das etiquetas);

3. utilizando-se tanto o etiquetador inicial sem regras para etiquetagem de palavras desconhecidas como o etiquetador final, que aplica as regras contextuais (a marcação utiliza apenas os núcleos das etiquetas);

4. utilizando-se tanto o etiquetador inicial com regras para etiquetagem de palavras desconhecidas como o etiquetador final, que aplica as regras contextuais (mais uma vez, apenas os núcleos são utilizados);

5. utilizando-se o etiquetador inicial com regras para etiquetagem de palavras desconhecidas, o etiquetador final e o refinador (as etiquetas completas são utilizadas).

Para cada uma destas medidas, foram analisados os seguintes aspectos:

1. o número de palavras conhecidas (PC);

2. os percentuais de acerto e erro na etiquetagem das palavras conhecidas (PC, EC e PC, $\mathrm{EE}$;

3. o número de palavras desconhecidas (PD); 


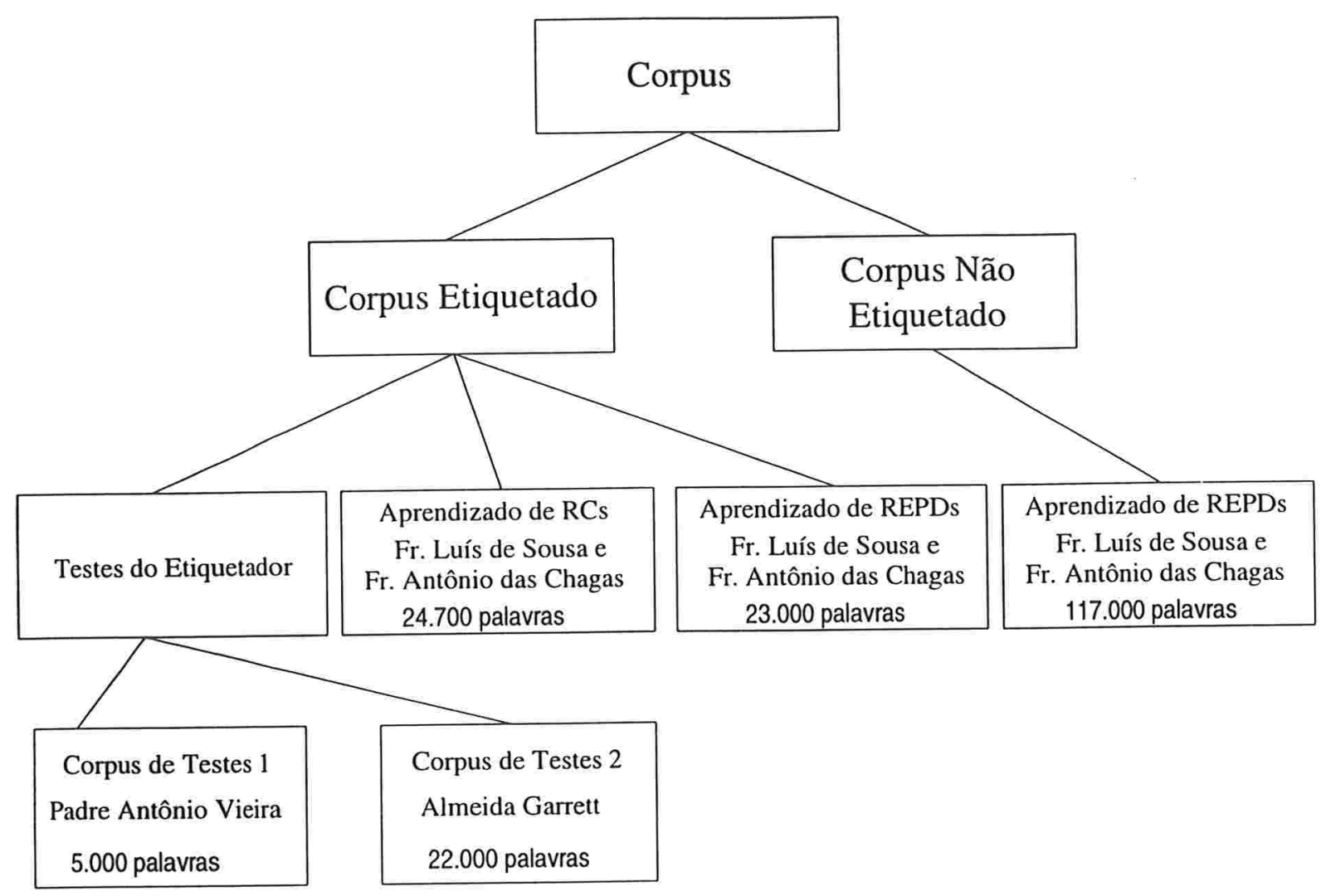

Figura 6.1: Divisão do Corpus para Aprendizado e Experimentos

4. os percentuais de acerto e erro na etiquetagem das palavras desconhecidas (PD, EC e PD, $\mathrm{EE}$;

5. o número total de palavras (TP);

6. os percentuais de acerto e erro na etiquetagem de todas as palavras (TP, EC e TP, EE).

\subsubsection{Os Resultados Obtidos}

Conforme dito na Seção 6.1.2, foram feitos cinco tipos de medidas. Para cada uma das mediadas, foram considerados os seis aspectos citados acima. Os resultados obtidos são apresentados na 
tabela abaixo:

\begin{tabular}{|c|c|c|c|c|c|c|c|c|c|c|}
\hline \hline & \multicolumn{2}{|c|}{ Medida 1 } & \multicolumn{2}{c|}{ Medida 2 } & \multicolumn{2}{c|}{ Medida 3 } & \multicolumn{2}{c|}{ Medida 4 } & \multicolumn{2}{c|}{ Medida 5 } \\
\hline \hline & $5 \mathrm{k}$ & $22 \mathrm{k}$ & $5 \mathrm{k}$ & $22 \mathrm{k}$ & $5 \mathrm{k}$ & $22 \mathrm{k}$ & $5 \mathrm{k}$ & $22 \mathrm{k}$ & $5 \mathrm{k}$ & $22 \mathrm{k}$ \\
\hline PC, EC & 92,34 & 92,05 & 92,34 & 92,05 & 85,67 & 83,75 & 86,67 & 84,70 & 81,76 & 78,86 \\
\hline PC, EE & 7,66 & 7,95 & 7,66 & 7,95 & 14,33 & 16,25 & 13,23 & 15,30 & 18,24 & 21,14 \\
\hline PD, EC & 44,04 & 38,26 & 76,38 & 54,76 & 62,34 & 50,03 & 76,62 & 54,00 & 57,97 & 38,26 \\
\hline PD, EE & 55,96 & 61,74 & 23,62 & 45,24 & 37,66 & 49,97 & 23,38 & 46,00 & 42,03 & 61,74 \\
\hline TP, EC & 84,72 & 80,16 & 89,82 & 83,80 & 81,99 & 76,30 & 85,08 & 77,91 & 78,01 & 69,88 \\
\hline TP, EE & 15,28 & 19,84 & 10,18 & 16,20 & 18,01 & 23,70 & 14,92 & 22,09 & 21,99 & 30,12 \\
\hline \hline
\end{tabular}

\begin{tabular}{|c|c|c|c|c|c|c|}
\hline \hline & \multicolumn{3}{|c|}{$5 \mathrm{k}$} & \multicolumn{3}{c|}{$22 \mathrm{k}$} \\
\hline \hline & s/ Ref & c/ Ref & Acerto Ref & s/ Ref & c/ Ref & Acerto Ref \\
\hline PC, EC & 86,67 & 81,76 & 94,37 & 84,70 & 78,86 & 93,10 \\
\hline PD, EC & 76,62 & 57,97 & 67,04 & 54,00 & 38,26 & 70,85 \\
\hline TP, EC & 85,08 & 78,01 & 91,79 & 77,91 & 69,88 & 89,69 \\
\hline \hline
\end{tabular}

\begin{tabular}{|c|c|c|c|c|}
\hline \hline & \multicolumn{2}{|c|}{$5 \mathrm{k}$} & \multicolumn{2}{c|}{$22 \mathrm{k}$} \\
\hline \hline PC & 4.528 & $81,30 \%$ & 17.203 & $77,89 \%$ \\
\hline PD & 847 & $18,70 \%$ & 4.885 & $22,11 \%$ \\
\hline TP & 5.375 & $100 \%$ & 22.088 & $100 \%$ \\
\hline \hline
\end{tabular}

Nesses experimentos foi utilizado o valor 1 para a constante MÍNIMO no aprendizado de regras contextuais e 0 no o aprendizado de regras para etiquetagem de palavras desconhecidas. Foram geradas 651 regras do primeiro tipo e 1.084 do segundo.

\subsubsection{Conclusões sobre os Resultados}

Comparando os resultados das medidas 1 e 2, podemos observar o papel que as regras para etiquetagem de palavras desconhecidas têm na marcação dos textos. Embora a diferença no percentual de palavras corretamente etiquetadas nas medidas 1 e $2(84,72 \%$ contra $89,82 \%$ e $80,16 \%$ contra $83,80 \%$, para os textos com 5.000 e 22.000 palavras, respectivamente) não seja grande, essa diferença torna-se bastante significativa quando consideramos o percentual de acerto na etiquetagem das palavras desconhecidas ( $76,38 \%$ contra $44,04 \%$ e $54,76 \%$ contra $38,26 \%$, para os textos com 5.000 e 21.000 palavras, respectivamente). Dessa forma, concluimos que, quando 
o texto a ser etiquetado apresenta muitas palavras desconhecidas, ou seja, que não pertencem ao léxico que será utilizado pelo etiquetador, as regras para etiquetagem de palavras desconhecidas têm papel preponderante na obtenção de bons resultados. Por outro lado, se utilizarmos um léxico suficientemente grande para que o número de palavras desconhecidas seja pequeno com relação ao número total de palavras do texto (como é o caso dos experimentos que realizamos), as regras para etiquetagem de palavras desconhecidas não melhoram muito o resultado obtido.

Para avaliar a importância das regras para etiquetagem de palavras desconhecidas na aplicação das regras contextuais, realizamos as medidas 3 e 4 . Observando os resultados obtidos, percebemos que há uma pequena melhora nos resultados quando as regras para etiquetagem de palavras descohecidas são utilizadas, já que os resultados da etiquetagem inicial são melhores (ver comentários acima sobre medidas 1 e 2).

Um fato interessante pode ser notado quando investigamos a importância da aplicação das regras contextuais na etiquetagem dos textos. Comparando os resultados obtidos nas medidas 1 e 3 , percebemos que a aplicação das regras contextuais piora os resultados obtidos pelo etiquetador inicial (sem a utilização de regras para etiquetagem de palavras desconhecidas, apenas marcando as palavras do texto que aparecem no léxico com sua etiqueta mais provável e as demais como nome próprio ou comum). O mesmo pode ser observado quando comparamos os resultados obtidos nas medidas 2 e 4 quando, além de utilizarmos as regras contextuais, aplicamos as regras para etiquetagem de palavras desconhecidas. Explicamos as razões para o acontecimento desse interessante fenômeno na Seção 6.4.

Por fim, investigamos os resultados obtidos pelo refinador que desenvolvemos. Podemos ver que, ao se refinar os núcleos das etiquetas de ambos os textos, houve uma piora de aproximadamente $6 \%$ na etiquetagem (mais precisamente, $4,91 \%$ no caso do texto com 5.000 palavras e $5,84 \%$ no caso do texto com 22.000 palavras). Sendo assim, temos que a precisão do refinador foi de $91,69 \%$ quando aplicado ao texto de 5.000 palavras e $89,70 \%$ quando aplicado ao texto de 22.000 palavras. Embora esses resultados ainda não sejam ideais, são animadores, sobretudo porque que acreditamos que o refinador ainda pode ser melhorado (ver Seção 7.4 para maiores detalhes)..

\subsection{Número de Regras Geradas vs. Número de Etiquetas}

Acreditamos que há uma relação entre o número de regras geradas e o número de etiquetas utilizadas. A idéia é a seguinte: quanto menor o número de etiquetas, menor será o número de regras geradas, já que teremos regras "mais genéricas". Por exemplo, se utilizarmos as etiquetas sem refinamento, ou seja, apenas seus núcleos, teremos possivelmente a geração da seguinte regra: 


\section{N FW NEXT1OR2OR3TAG CONJ}

Por outro lado, caso fossem utilizadas as etiquetas completas, potencialmente teríamos a geração das seguintes regras em vez da regra acima:

\section{N FW NEXT1OR2OR3TAG CONJ N-P FW NEXT1OR2OR3TAG CONJ}

Ou seja, teríamos duas regras em vez de uma única. Contudo, não esperamos que, para cada regra contextual gerada apenas com os núcleos, sejam geradas todas as correspondentes com as etiquetas completas. De qualquer forma, acreditamos que o número de regras geradas utilizando-se apenas os núcleos das etiquetas será significantemente menor do que o número de regras que serão geradas utilizando-se as etiquetas completas. Conseqüentemente, o tempo gasto para o aprendizado de regras (tanto contextuais quanto para etiquetagem de palavras desconhecidas) que manipulam apenas os núcleos das etiquetas será menor que o correspondente para gerar as regras que utilizam etiquetas completas.

\subsubsection{Os Dados Utilizados}

Para confirmar essa intuição, fizemos o aprendizado de regras contextuais utilizando duas versões de um mesmo texto, uma com anotação completa e outra anotada apenas com os núcleos das etiquetas. Foi utilizado um texto com aproximadamente 23.000 palavras etiquetadas e outro com aproximadamente 117.000 palavras não-etiquetadas para o aprendizado de regras para etiquetagem de palavras desconhecidas e um texto com aproximadamente 24.700 palavras para o aprendizado de regras contextuais. Foram medidos os seguintes fatores:

1. o número de regras contextuais geradas que manipulam apenas os núcleos das etiquetas e o tempo para geração de tais regras;

2. o número de regras contextuais geradas que manipulam as etiquetas completas e o tempo para geração de tais regras;

3. o número de regras para etiquetagem de palavras desconhecidas geradas que manipulam apenas os núcleos das etiquetas e o tempo para geração de tais regras;

4. o número de regras para etiquetagem de palavras desconhecidas geradas que manipulam as etiquetas completas e o tempo para geração de tais regras. 


\subsubsection{Os Resultados Obtidos}

Os resultados dos experimentos são apresentados na tabela abaixo:

\begin{tabular}{|l|c|c|c|c|}
\hline \hline & \#REPD & Tempo & \# RC & Tempo \\
\hline \hline Etiquetas Completas & 988 & $120 \mathrm{~h} 22 \mathrm{~m} 47 \mathrm{~s}$ & 1.507 & $26 \mathrm{~h} 26 \mathrm{~m} 33 \mathrm{~s}$ \\
\hline Apenas os Núcleos & 651 & $16 \mathrm{~h} 52 \mathrm{~m} 4 \mathrm{~s}$ & 1.084 & $15 \mathrm{~h} 47 \mathrm{~m} 30 \mathrm{~s}$ \\
\hline \hline
\end{tabular}

Então, temos que:

$$
\begin{gathered}
\frac{\text { Tempo REPD, Etiquetas Completas }}{\text { Tempo REPD, Núcleos }} \approx 7,14 \\
\frac{\text { Tempo RC, Etiquetas Completas }}{\text { Tempo RC, Núcleos }} \approx 1,7 \\
\frac{\text { \#REPD, Etiquetas Completas }}{\text { \#REPD, Núcleos }} \approx 1,52 \\
\frac{\text { \#RC, Etiquetas Completas }}{\text { \#RC, Núcleos }}
\end{gathered}
$$

onde:

- REPD: Regras para etiquetagem de Palavras Desconhecidas,

- RC: Regras Contextuais e

- Tempo: tempo de processamento.

\subsubsection{Conclusões sobre os Resultados}

Conforme esperado, são geradas mais regras quando o corpus de treinamento é marcado com as etiquetas completas. Além disso, o tempo de aprendizado é muito menor quando o corpus de treinamento é marcado apenas com os núcleos. Embora ainda não tenhamos obtidos resultados tão bons quanto os obtidos quando o aprendizado utiliza as etiquetas completas (ver Seção 6.4 para maiores detalhes), acreditamos que, se conseguirmos melhorar o refinador, o nosso 
método será uma boa opção para se etiquetar textos em português. Note que os corpora utilizados no aprendizado das regras são relativamente pequenos quando comparados com os que foram utilizados por Brill nos experimentos reportados em [8]. Esperamos, com base nas estimativas teóricas apresentadas no Capítulo 2 que, quanto maiores forem os textos utilizados no aprendizado das regras, maiores serão as diferenças proporcionais entre os tempos gastos no aprendizado com as etiquetas completas e apenas com seus núcleos. Assim que tivermos textos maiores, faremos novos experimentos para confirmar (ou não) essa expectativa.

\subsection{Distribuição das Regras vs. Valores da Constante MÍNIMO}

Estudamos, ainda, a distribuição das regras contextuais e para etiquetagem de palavras desconhecidas quando são utilizados diferentes valores para a constante MÍNIMO, com o intuito de determinar quantas são as regras relevantes (ou seja, que corrigem um número substancial de erros) e quais são aquelas cujas aplicações praticamente não alteram o percentual de acerto.

Conforme mencionado no Capítulo 2, grandes valores para a constante MÍNIMO possibilitam um aprendizado mais rápido, enquanto valores menores permitem a geração de mais regras, favorecendo, assim, a obtenção e melhores resultados na etiquetagem.

\subsubsection{Os Dados Utilizados}

Nesse experimento, foram utilizados os seguintes conjuntos de regras:

1. regras contextuais, geradas a partir de textos marcados apenas com os núcleos das etiquetas, com 1.084 regras;

2. regras contextuais, geradas a partir de textos marcados com etiquetas completas, com 1.507 regras;

3. regras para etiquetagem de palavras desconhecidas, geradas a partir de textos marcados apenas com os núcleos das etiquetas, com 651 regras;

4. regras para etiquetagem de palavras desconhecidas, geradas a partir de textos marcados com etiquetas completas, com 988 regras. 


\subsubsection{Os Resultados Obtidos}

As Figuras 6.2 e 6.3 mostram as distribuições das regras para etiquetagem de palavras desconhecidas em função de diferentes valores para a constante MíNIMO. Note que a grande maioria das regras têm "scores" menores que 50.

As Figuras 6.4 e 6.5 mostram as distribuições das regras contextuais em função de diferentes valores para a constante MÍNIMO. Observe que, assim como ocorre com relação às regras para etiquetagem de palavras desconhecidas, há uma grande concentração das regras em torno de valores baixos de MíNIMO.

Observação: no canto superior direito de cada um dos gráficos aparece uma pequena cruz. Não se trata de um ponto do gráfico. É apenas uma indicação do tipo de sinal que foi utilizado na "plotagem". Além disso, para melhor visualização do gráfico, foi utilizada escala logarítmica na abscissa (número de regras).

\subsubsection{Conclusões sobre os Resultados}

Claramente, há uma concentração de regras em torno de pequenos valores de MÍNIMO. Isso nos leva a questionar se realmente é vantajoso esperar o tempo necessário para que todas essas regras sejam geradas, já que a grande parte do tempo de aprendizado é gasto com a geração das regras que obtêm baixos "scores" e que, em princípio, podem não trazer benefícios na etiquetagem. A próxima seção discute esse problema e mostra que nem sempre o maior conjunto de regras é o melhor, isto é, produz maior percentual de acerto na etiquetagem dos textos.

\subsection{Acerto na Etiquetagem vs. Valores da Constante MíNIMO}

O tempo gasto no aprendizado das regras contextuais depende diretamente da constante MÍNIMO que é utilizada. Como foi dito anteriormente, valores altos para essa constante fazem com que o aprendizado seja mais rápido, enquanto valores baixos permitem que mais regras sejam aprendidas, que podem eventualmente melhorar a qualidade da etiquetagem. Para verificar se realmente é vantajoso gastar o tempo necessário para que todas (ou pelo menos mais) regras sejam aprendidas, fizemos a seguinte experiência: etiquetamos dois textos,um escrito por Padre Antônio Vieira no século XVI, com aproximadamente 5.000 palavras e outro, escrito por Almeida Garrett no século XIX, com aproximadamente 22.000 palavras. Na etiquetagem, foram utilizados 10 conjuntos de regras. Essas foram divididas em função do número de erros que corrigiam. Os critérios utilizados e os resultados obtidos com um desses conjuntos podem ser conferidos na próxima seção. 


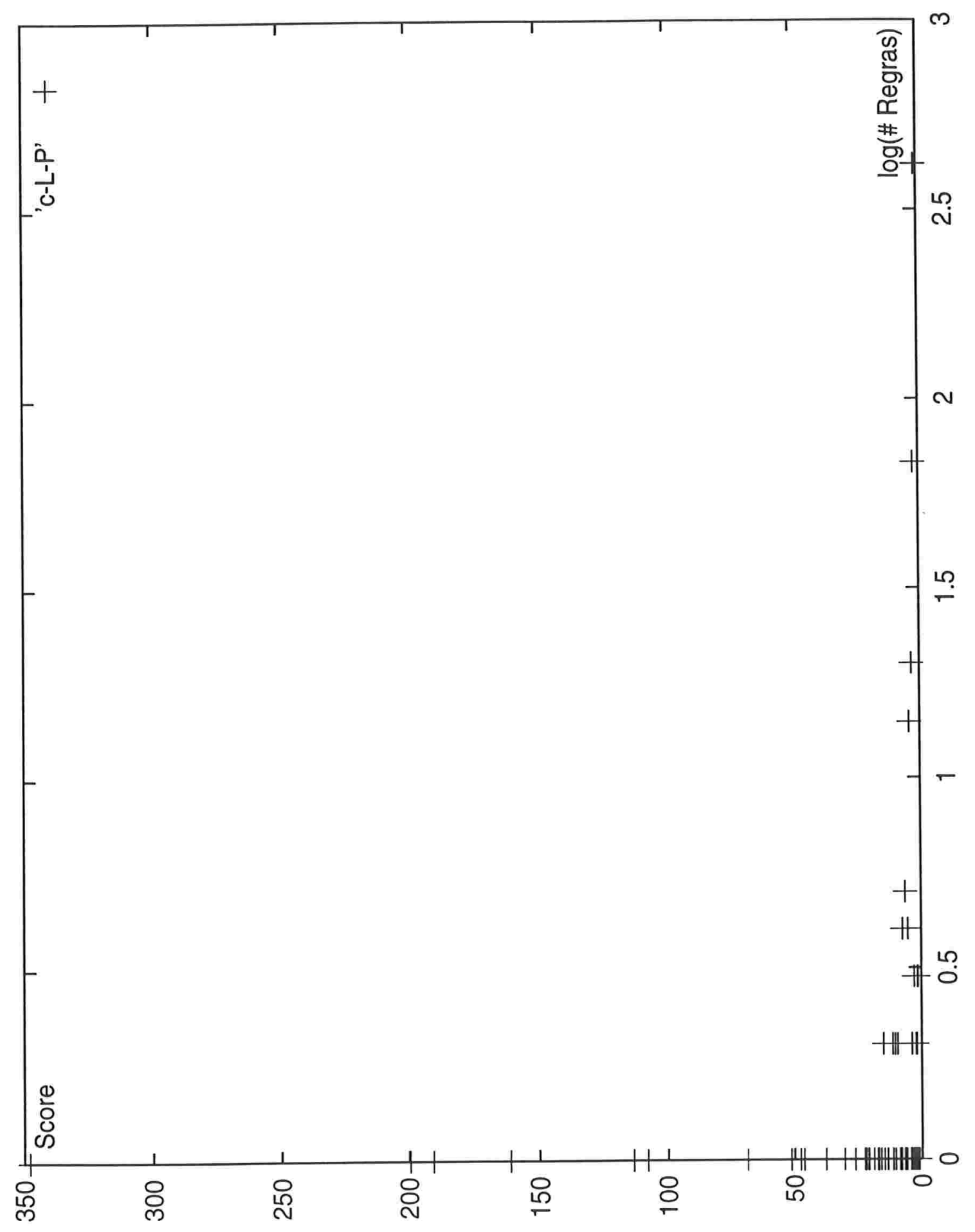

Figura 6.2: Distribuição das REPDs, Núcleos das Etiquetas 


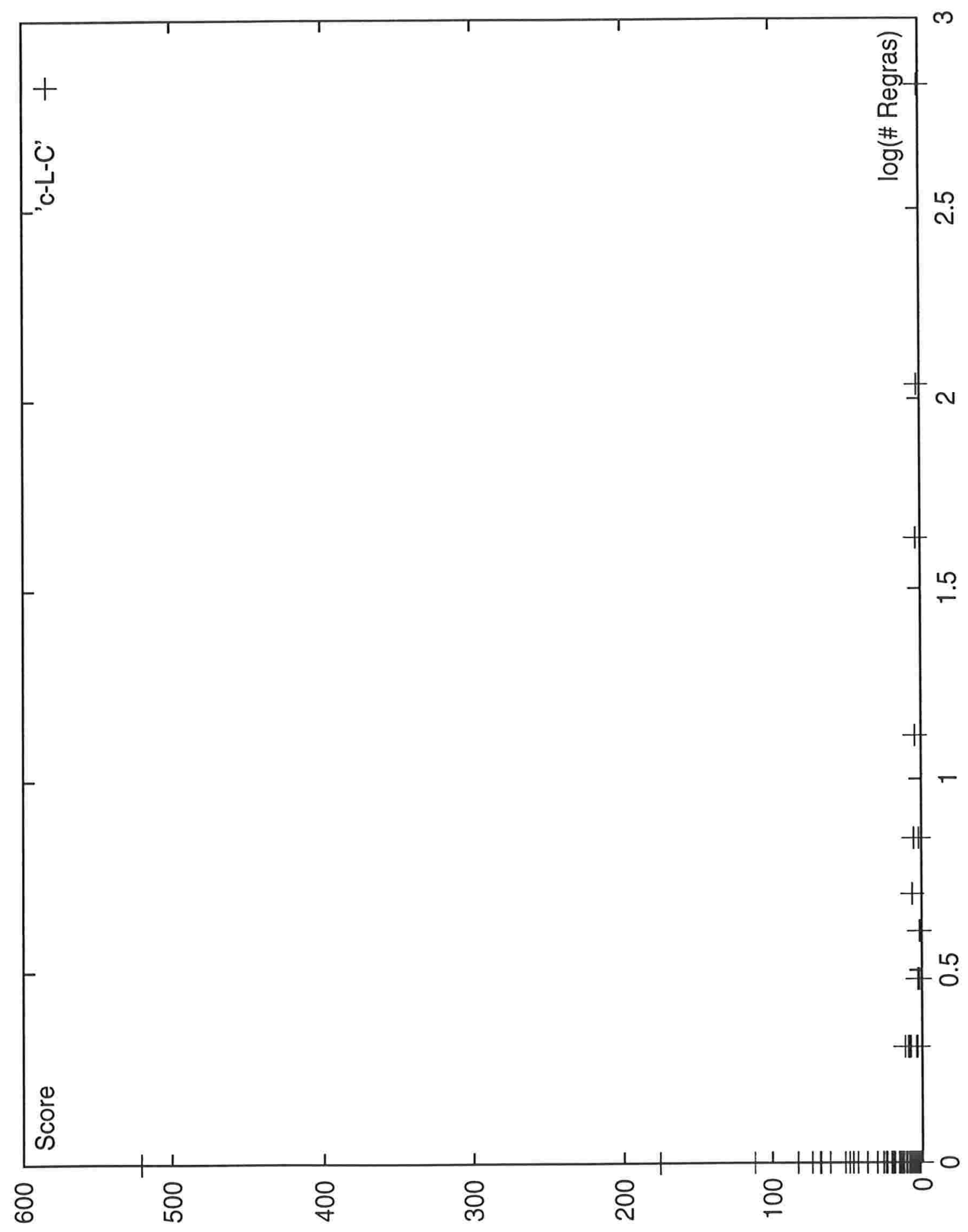

Figura 6.3: Distribuição das REPDs, Etiquetas Completas 


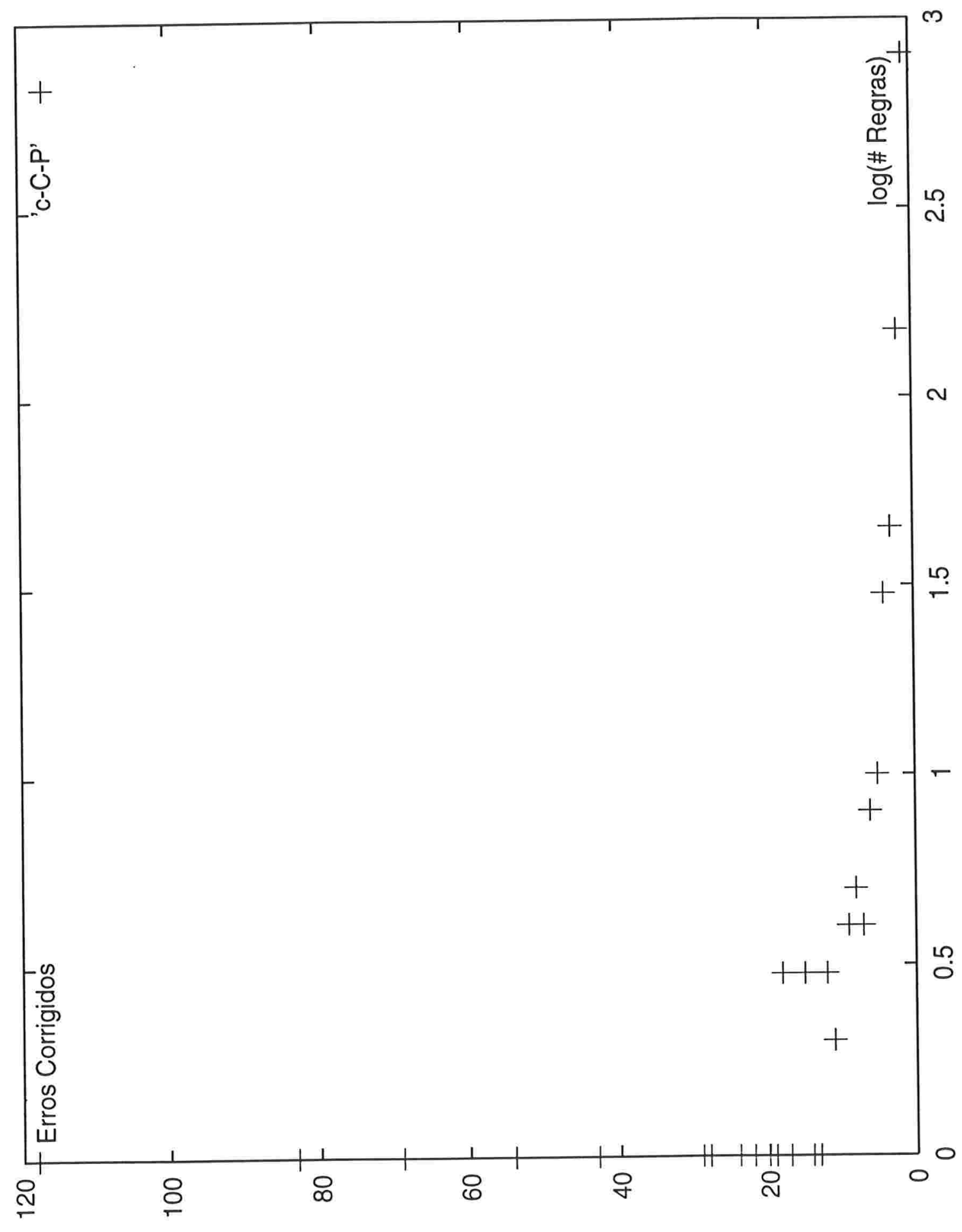

Figura 6.4: Distribuição das RCs, Núcleos das Etiquetas 


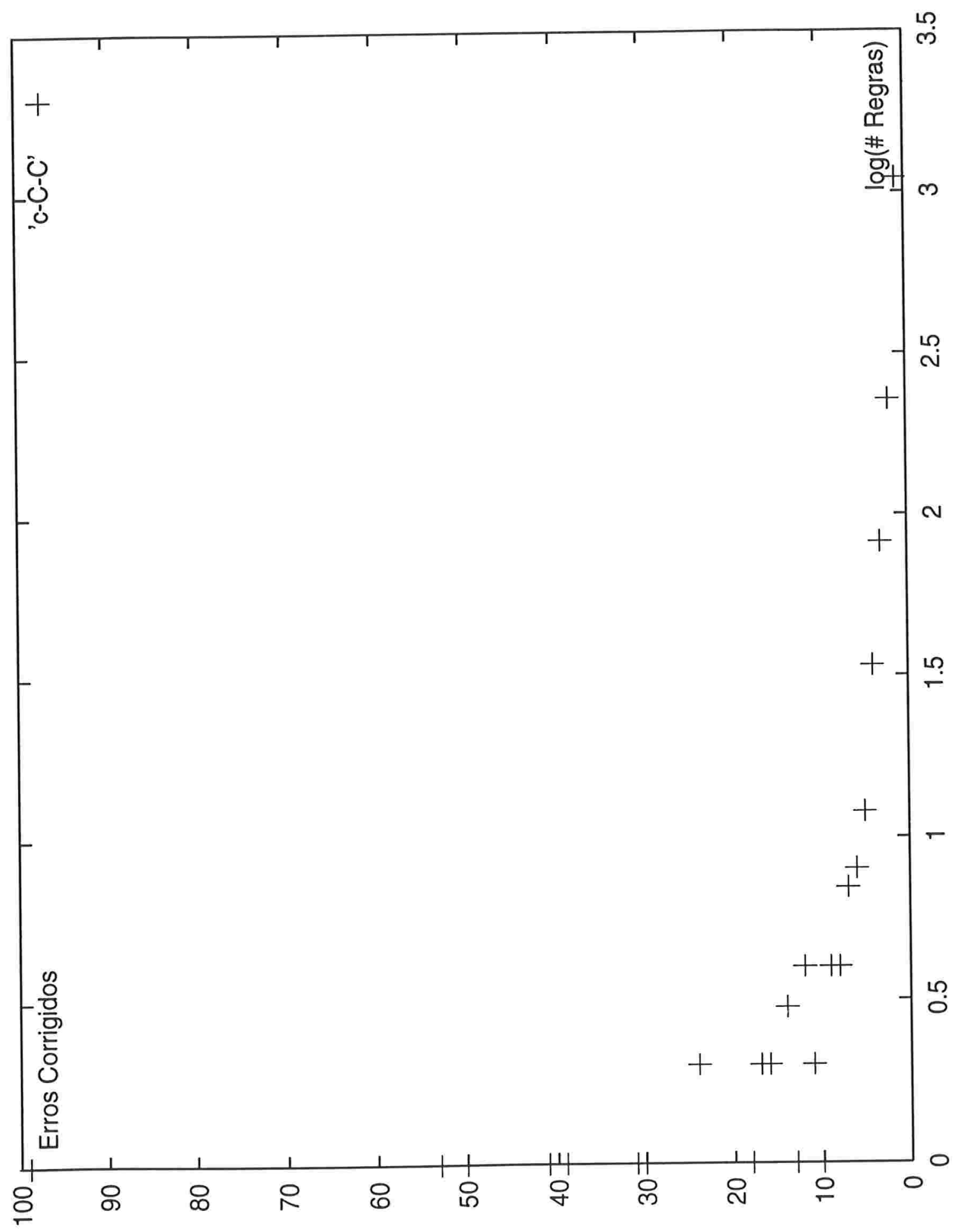

Figura 6.5: Distribuição das RCs. Etiquetas Completas 
Note que existe uma relação direta entre o valor de MíNIMO utilizado no aprendizado e o número de erros corrigidos pelas regras. De acordo com o algoritmo de aprendizado apresentado na Seção 2.2.1, só são geradas regras que corrigem pelo menos MíNIMO erros.

\subsubsection{Os Resultados Obtidos}

Para regras que manipulam apenas os núcleos das etiquetas:

\begin{tabular}{|l|c|c|c|}
\hline \hline \# de Erros Corrigidos & Número de Regras & \multicolumn{2}{|c|}{ Percentual de Acerto } \\
\hline \hline & & $5 \mathrm{k}$ & $22 \mathrm{k}$ \\
\hline$[1 ; \mathrm{MÁX}]$ & 1.084 & 85,08 & 77,91 \\
\hline$[2 ; \mathrm{MÁX}]$ & 274 & 89,08 & 81,81 \\
\hline$[3 ; \mathrm{MÁX}]$ & 125 & 90,68 & 83,35 \\
\hline$[4 ; \mathrm{MÁX}]$ & 84 & 90,88 & 84,02 \\
\hline$[5 ; \mathrm{MÁX}]$ & 55 & 91,29 & 84,53 \\
\hline$[6 ; \mathrm{MÁX}]$ & 46 & 91,18 & 84,54 \\
\hline$[7 ; \mathrm{MÁX}]$ & 38 & 91,59 & 84,94 \\
\hline$[8 ; \mathrm{MÁX}]$ & 34 & 91,55 & 85,22 \\
\hline$[9 ; \mathrm{MÁX}]$ & 27 & 91,40 & 84,99 \\
\hline$[10 ; \mathrm{MÁX}]$ & 24 & 91,33 & 85,05 \\
\hline
\end{tabular}

onde MÁX é o maior número de erros corrigidos por uma regra. Em particular, nessa experiência MÁX $=118$.

Para regras que manipulam etiquetas completas: 


\begin{tabular}{|l|c|c|c|}
\hline \hline \# de Erros Corrigidos & Número de Regras & \multicolumn{2}{|c|}{ Percentual de Acerto } \\
\hline \hline & & $5 \mathrm{k}$ & $22 \mathrm{k}$ \\
\hline$[1 ; \mathrm{MÁX}]$ & 1.508 & 80,09 & 72,75 \\
\hline$[2 ; \mathrm{MÁX}]$ & 394 & 85,04 & 77,70 \\
\hline$[3 ; \mathrm{MÁX}]$ & 173 & 86,70 & 79,49 \\
\hline$[4 ; \mathrm{MÁX}]$ & 93 & 88,45 & 80,92 \\
\hline$[5 ; \mathrm{MÁX}]$ & 60 & 88,46 & 80,98 \\
\hline$[6 ; \mathrm{MÁX}]$ & 48 & 88,50 & 81,11 \\
\hline$[7 ; \mathrm{MÁX}]$ & 40 & 88,48 & 81,14 \\
\hline$[8 ; \mathrm{MÁX}]$ & 34 & 88,48 & 81,11 \\
\hline$[9 ; \mathrm{MÁX}]$ & 30 & 88,41 & 81,06 \\
\hline$[10 ; \mathrm{MÁX}]$ & 26 & 89,95 & 82,22 \\
\hline \hline
\end{tabular}

onde MÁX é o maior número de erros corrigidos por uma regra. Em particular, nessa experiência MÁX $=99$.

\subsubsection{Conclusões sobre os Resultados}

Analisando os resultados obtidos, observamos que o melhor resultado obtido na etiquetagem do texto com aproximadamente 5.000 palavras com os núcleos foi conseguido utilizando-se o conjunto de regras que corrige pelo menos 7 erros. Similarmente, o melhor resultado obtido na etiquetagem do texto com aproximadamente 22.000 palavras com os núcleos foi conseguido utilizando-se o conjunto de regras que corrige pelo menos 8 erros.

Por outro lado, quando a etiquetagem é feita utilizando-se as etiquetas completas, o melhor resultado é obtido quando utilizamos o conjunto de regras que corrige pelo menos 10 erros.

Concluimos, então, que não é vantajoso gastar o tempo necessário para que todas as regras sejam geradas, já que as regras que corrigem poucos erros provavelmente "memorizaram" alguma peculiaridade do corpus de treinamento, ou seja, reproduzem alguma característica do texto utilizado no aprendizado, ocasionando que chamamos de perda de generalidade. Dessa forma, nos deparamos com o seguinte problema: como determinar qual a constante MÍNIMO que deve ser utilizada para o aprendizado de regras para etiquetagem de um determinado tipo de texto? Trata-se de uma questão bastante complexa cuja resposta só pode ser determinada, em princípio, por experimentos com corpora de diferentes estilos e diversos tamanhos.

Além disso, podemos perceber que a etiquetagem do texto com aproximadamente 5.000 palavras sempre obteve resultados superiores do que os obtidos com o texto de 22.000 palavras 
para um mesmo conjunto de regras. Conforme dito anteriormente, o texto de 5.000 palavras foi escrito por Padre Antônio Vieira no século XVI, enquanto o texto de 22.000 palavras foi escrito por Almeida Garrett mais recentemente, no século XIX. Tal resultado é bastante interessante, sobretudo se observarmos que o corpus de treinamento é composto por textos dos séculos XVI e XVII. Podemos, então, interpretar essa diferença nos resultados obtidos como uma evidência de evolução gramatical do português europeu no período que compreende os séculos XVI, XVII, XVIII e XVIII. Caso tivéssemos obtido resultados similares nas etiquetagens de ambos os textos, poderíamos dizer que não houve nenhuma mudança significativa na sintaxe do português no período mencionado. Contudo, há a necessidade de se fazer experimentos com textos maiores para que tenhamos dados mais significativos para confirmar essa intuição.

\subsection{Paralelização das Regras}

Embora o etiquetador produza uma lista de regras que são aplicadas na ordem em que ocorrem em tal lista (ver algoritmo de etiquetagem na Seção 2.3.1), há regras cuja aplicação não depende e nem influencia na aplicação de outras regras. Podemos, então, definir dois conceitos: regras comutáveis e regras confitantes.

Duas regras contextuais $\mathrm{R}_{1}$ e $\mathrm{R}_{2}$ são ditas comutáveis se, para todo texto $\mathrm{T}$, a aplicação de $R_{1}$ seguida por $R_{2}$ produz o mesmo resultado da aplicação de $R_{2}$ seguida por $R_{1}$, ou seja:

$$
\mathrm{T}_{\left(\mathrm{R}_{1}, \mathrm{R}_{2}\right)}=\mathrm{T}_{\left(\mathrm{R}_{2}, \mathrm{R}_{1}\right)}
$$

O seguinte Teorema caracteriza duas regras comutáveis:

Teorema 1 Sejam $R_{1}: A \rightarrow B \mid C O N D_{1}$ e $R_{2}: C \rightarrow D \mid C O N D_{2}$ duas regras contextuais, onde COND $D_{i}$ é a condição associada à regra contextual $i . R_{1}$ e $R_{2}$ são ditas comutáveis se, $e$ só se :

1. $B \neq C, A \neq C, A \neq D$

2. $A \notin \mathrm{COND}_{2}$ e $C \notin \mathrm{COND}_{1}$

3. $B \notin \mathrm{COND}_{2}$ e $D \notin \mathrm{COND}_{1}$

\section{Prova:}

$(\Rightarrow)$ 
1. (a) $B \neq C$ : sejam $R_{1}$ e $R_{2}$ duas regras comutáveis. Suponha, por absurdo, que $B=C$. Considere, ainda, o seguinte fragmento de texto anotado:

$$
p_{1}\left|A \quad p_{2}\right| E_{2} \quad p_{3}\left|E_{3} \quad p_{4}\right| E_{4}
$$

onde $\mathrm{p}_{\mathrm{i}}$ são palavras e $\mathrm{E}_{\mathrm{i}}$ são etiquetas, para $\mathrm{i}=1, \ldots, 4$.

Aplicando $\mathrm{R}_{1}$ e depois $\mathrm{R}_{2}$, temos:

$$
\begin{array}{llll}
p_{1} \mid B & p_{2} \mid E_{2} & p_{3} \mid E_{3} & p_{4} \mid E_{4} \\
p_{1} \mid D & p_{2} \mid E_{2} & p_{3} \mid E_{3} & p_{4} \mid E_{4}
\end{array}
$$

Por outro lado, aplicando $\mathrm{R}_{2}$ e depois $\mathrm{R}_{1}$, temos:

$$
\begin{array}{lllll}
p_{1} \mid A & p_{2} \mid E_{2} & p_{3} \mid E_{3} & p_{4} \mid E_{4} \\
p_{1} \mid B & p_{2} \mid E_{2} & p_{3} \mid E_{3} & p_{4} \mid E_{4}
\end{array}
$$

Portanto, $R_{1}$ e $R_{2}$ não são comutáveis, o que contradiz a hipótese. Logo, $\mathrm{B} \neq \mathrm{C}$. Analogamente, temos que $\mathrm{A} \neq \mathrm{D}$.

(b) $A \neq C$ : sejam $R_{1}$ e $R_{2}$ duas regras comutáveis. Suponha, por absurdo, que $A=C$. Considere, ainda, o seguinte fragmento de texto anotado:

$$
p_{1}\left|A p_{2}\right| E_{2} p_{3}\left|E_{3} \quad p_{4}\right| E_{4}
$$

onde $\mathrm{p}_{\mathrm{i}}$ são palavras e $\mathrm{E}_{\mathrm{i}}$ são etiquetas, para $\mathrm{i}=1, \ldots, 4$.

Aplicando $R_{1}$ e depois $R_{2}$, temos:

$$
\begin{array}{llll}
p_{1} \mid B & p_{2} \mid E_{2} & p_{3} \mid E_{3} & p_{4} \mid E_{4} \\
p_{1} \mid B & p_{2} \mid E_{2} & p_{3} \mid E_{3} & p_{4} \mid E_{4}
\end{array}
$$

Por outro lado, aplicando $\mathrm{R}_{2}$ e depois $\mathrm{R}_{1}$, temos:

$$
\begin{aligned}
& p_{1}\left|D p_{2}\right| E_{2} \quad p_{3}\left|E_{3} \quad p_{4}\right| E_{4} \\
& p_{1}\left|D p_{2}\right| E_{2} \quad p_{3}\left|E_{3} p_{4}\right| E_{4}
\end{aligned}
$$

Portanto, $\mathrm{R}_{1}$ e $\mathrm{R}_{2}$ não são comutáveis, o que contradiz a hipótese. Logo, $\mathrm{A} \neq \mathrm{C}$.

2. $A \notin \mathrm{COND}_{2}$ : sejam $R_{1}$ e $R_{2}$ duas regras comutáveis. Suponha, por absurdo, que $A \in$ $\mathrm{COND}_{2}$. Considere, ainda, o seguinte trecho de texto anotado:

$$
p_{1}\left|A p_{2}\right| E_{2} p_{3}\left|A p_{4}\right| E_{2}
$$


onde $\mathrm{p}_{\mathrm{i}}$ são palavras e $\mathrm{E}_{\mathrm{i}}$ são etiquetas, para $\mathrm{i}=1, \ldots, 4$.

Aplicando $R_{1}$ e depois $R_{2}$, temos:

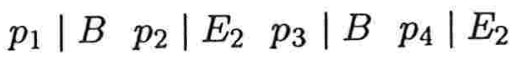

$$
\begin{aligned}
& p_{1}\left|B \quad p_{2}\right| E_{2} \quad p_{3}\left|B \quad p_{4}\right| E_{2}
\end{aligned}
$$

Por outro lado, aplicando $\mathrm{R}_{2}$ e depois $\mathrm{R}_{1}$, temos:

$$
\begin{array}{llll}
p_{1} \mid A & p_{2} \mid D & p_{3} \mid A & p_{4} \mid E_{2} \\
p_{1} \mid A & p_{2} \mid D & p_{3} \mid B & p_{4} \mid E_{2}
\end{array}
$$

Portanto, $\mathrm{R}_{1}$ e $\mathrm{R}_{2}$ não são comutáveis. Logo, $\mathrm{A} \notin \mathrm{COND}_{2}$. Analogamente, temos que $\mathrm{C}$ $\notin \mathrm{COND}_{1}$.

3. $\mathrm{B} \notin C O \mathrm{COND}_{2}$ : sejam $\mathrm{R}_{1}$ e $\mathrm{R}_{2}$ duas regras comutáveis. Suponha, por absurdo, que $A \in$ $\mathrm{COND}_{2}$. Suponha, por absurdo, que $\mathrm{A} \in \mathrm{COND}_{2}$. Considere, ainda, o seguinte trecho de texto anotado:

$$
p_{1}\left|A p_{2}\right| E_{2} \quad p_{3}\left|C \quad p_{4}\right| A \quad p_{5} \mid E_{2}
$$

onde $\mathrm{p}_{\mathrm{i}}$ são palavras e $\mathrm{E}_{\mathrm{i}}$ são etiquetas, para $\mathrm{i}=1, \ldots, 4$.

Aplicando $R_{1}$ e depois $R_{2}$, temos:

$$
\begin{array}{lllll}
p_{1} \mid B & p_{2} \mid E_{2} & p_{3} \mid C & p_{4} \mid B & p_{5} \mid E_{2} \\
p_{1} \mid B & p_{2} \mid E_{2} & p_{3} \mid D & p_{4} \mid B & p_{5} \mid E_{2}
\end{array}
$$

Por outro lado, aplicando $R_{2}$ e depois $R_{1}$, temos:

$$
\begin{array}{llllll}
p_{1} \mid A & p_{2} \mid E_{2} & p_{3} \mid C & p_{4} \mid A & p_{5} \mid E_{2} \\
p_{1} \mid B & p_{2} \mid E_{2} & p_{3} \mid C & p_{4} \mid A & p_{5} \mid E_{2}
\end{array}
$$

Portanto, $\mathrm{R}_{1}$ e $\mathrm{R}_{2}$ não são comutáveis. Logo, $\mathrm{A} \notin \mathrm{COND}_{2}$. Analogamente, temos que $\mathrm{D}$ $\notin \mathrm{COND}_{1}$.

$$
(\Leftarrow)
$$

Antes de demonstrar essa parte do Teorema, vale observar que $\mathrm{R}_{1}$ nunca altera uma etiqueta que foi escrita por $R_{2}$ (e vice-versa).

Suponha, então, por absurdo, que $R_{1}$ e $R_{2}$ não sejam comutáveis. Nesse caso, temos que o resultado da aplicação de $R_{1}$ e $R_{2}$ produz um resultado diferente do que o gerado pela aplicação de $R_{2}$ e $R_{1}$. Há, então 4 possibilidades: 
1. $R_{1}$ altera uma etiqueta de $C \neq E$ para $E$; Isso não acontece pois, por hipótese, $\mathrm{A} \neq \mathrm{C}$.

2. $\mathrm{R}_{1}$ altera uma etiqueta $\mathrm{E} \neq \mathrm{C}$ para $\mathrm{C}$;

Isso não acontece pois, por hipótese, $\mathrm{B} \neq \mathrm{C}$.

3. $\mathrm{R}_{1}$ altera uma etiqueta que pertence a $\mathrm{COND}_{2}$, fazendo com que $\mathrm{COND}_{2}$ se torne falsa em um contexto em que anteriormente seria verdadeira;

Isso não acontece pois, por hipótese, $\mathrm{A} \notin \mathrm{COND}_{2}$.

4. $R_{1}$ altera uma etiqueta, fazendo com que $\mathrm{COND}_{2}$ se torne verdadeira em um contexto em que anteriormente seria falsa.

Isso não acontece pois, por hipótese, $\mathrm{B} \notin \mathrm{COND}_{2}$.

Por outro lado, dizemos que duas regras são conflitantes se elas não são concorrentes.

Para determinar como as regras se comportam em relação a esse critério de concorrência, implementamos um sistema que separa as regras em clusters de regras concorrentes.

\subsubsection{Os Dados Utilizados}

Foi utilizado nesse experimento um conjunto com 1.084 regras contextuais, geradas a partir de um textos de Frei Luís de Sousa e Frei Antônio das Chagas, escritos nos séculos XVI e XVII, com aproximadamente 24.700 palavras.

\subsubsection{Os Resultados Obtidos}

A Figura 6.6 mostra um dos clusters obtidos, enquanto a Figura 6.7 mostra a distribuição dos clusters em função do número de regras que eles contêm.

\begin{tabular}{|l|c|}
\hline \hline Número de Clusters & 256 \\
\hline Maior Cluster & 16 \\
\hline Menor Cluster & 1 \\
\hline Média & 4.23 \\
\hline Moda & 2 \\
\hline \hline
\end{tabular}




\author{
Q NUM NEXTWD anos \\ TR NPR PREVTAG $P$ \\ WQ SE NEXT1OR2TAG P \\ PRO PRO\$ PREVWD Dizia \\ CONJ NEG PREVTAG ADV \\ ADJ OUTRO LBIGRAM e outra \\ $P$ FOC NEXTTAG $P$ \\ CONJS SE NEXTBIGRAM VB P \\ N FW PREV10R20R3TAG FW \\ WPRO C PREVTAG ADV \\ D CL NEXTTAG VB
}

Figura 6.6: Exemplo de Cluster

\title{
6.5.3 Conclusões sobre os Resultados
}

De acordo com os resultados obtidos, percebemos que o "aprendedor" de regras contextuais produz, em vez de uma única lista de regras, um conjunto de listas de regras intercaladas. Contudo, como a maioria dos clusters gerados contém poucas regras (apenas duas no exemplo apresentado) e o processo de etiquetagem é feito de forma eficiente, a aplicação paralela das regras provavelmente não aceleraria muito o processo de marcação dos textos. 


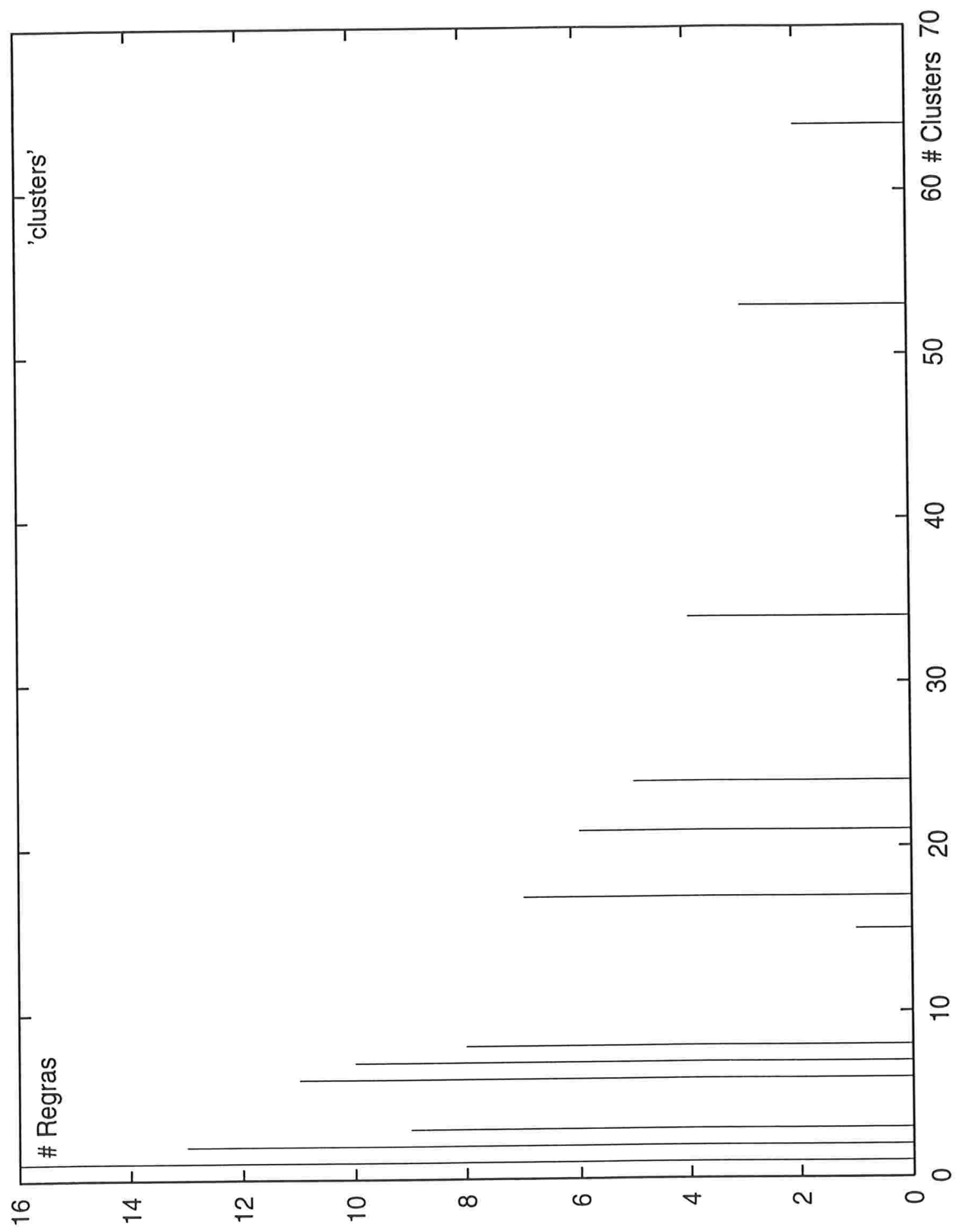

Figura 6.7: Número de Clusters $\times$ Tamanho do Cluster 


\section{Capítulo 7}

\section{Conclusões}

\subsection{Conclusões sobre o Trabalho Realizado}

Nessa dissertação, investigamos como o paradigma proposto por Eric Brill pode ser utilizado para etiquetagem morfo-sintática de textos em português. Concluimos que, devido ao grande número de etiquetas que seria necessário para marcação de tais textos, o método é ineficiente se utilizado sem modificações, ou seja, exatamente da maneira que foi concebido. Sendo assim, propusemos a etiquetagem em fases, onde um texto é marcado em 3 etapas em vez de 2 como sugerido originalmente. Para tanto, acrescentamos uma estrutura às etiquetas, de tal forma que agora elas são compostas por um núcleo e um complemento (refinamento). Durante o processo de construção do refinador (módulo responsável pela complementação dos núcleos das etiquetas), nos deparamos com problemas lingüísticos como o refinamento das etiquetas de palavras homógrafas, a caracterização de algumas classes gramaticais (adjetivos de gênero duplo, por exemplo), etc. Alguns desses problemas foram resolvidos de forma definitiva, enquanto outros foram solucionados apenas parcialmente. Por fim, mostramos os resultados de experimentos feitos com nosso sistema, a partir dos quais concluimos que o método de etiquetagem por fases que propusemos pode vir a ser uma boa alternativa para a etiquetagem de textos em português.

Além das ferramentas para etiquetagem automática de textos, foi desenvolvido nesse trabalho o Corpus Tycho Brahe, que compreende, além de uma metodologia de marcação, textos do português europeu dos séculos XVI, XVII, XVIII e XIX. Atualmente, há duas versões de cada texto: uma não-etiquetada, com informações sobre autor, edição, data em que foi escrito, etc. e outra, contendo apenas o texto etiquetado. No futuro, haverá ainda uma terceira, que consistirá desses mesmos textos com anotação sintática. Esse corpus histórico continua em processo de 
construção, podendo ser encontrado na URL http://www.ime.usp.br/ ${ }^{\sim}$ tycho, assim como informações sobre o processo de escolha dos autores, textos, etc.

\subsection{O Etiquetador como uma Ferramenta para a Construção do Corpus}

A conclusão principal no estágio de trabalho em que nos encontramos é que não estamos construindo um etiquetador em si, mas uma ferramenta de apoio à construção de um corpus etiquetado. Desta forma, nossas preocupações no momento divergem daquelas encontradas por outros que se envolveram no desenvolvimento de tais ferramentas.

Conforme descrevemos na introdução, diferentemente de outros etiquetadores existentes, nosso etiquetador morfo-sintático está sendo desenvolvido em paralelo com a construção do corpus sobre o qual ele será testado. Tal procedimento pode ser descrito como "tentar navegar em um navio enquanto ele é construído". Por outro lado, essa abordagem é crucial para a criação do Corpus Tycho Brahe, que não estaria sendo construído sem as ferramentas automáticas em questão.

Essa abordagem de desenvolvimento paralelo corpus-etiquetador nos tráz problemas interessantes, os quais ainda estamos vivenciando. Esses problemas advém da escassez de palavras etiquetadas para treinarmos nosso etiquetador. Nosso primeiro corpus de treinamento possuia apenas 21.000 palavras etiquetadas à mão. Destas, por motivos metodológicos, apenas 11.000 foram usadas para o aprendizado de regras contextuais; o resto foi utilizado para testar o etiquetador e para o módulo aprendedor de palavras desconhecidas.

Sendo assim, foram construídos vários etiquetadores, cada um treinado com uma versão do corpus. Os resultados produzidos foram melhorando em função do número de palavras que foram utilizadas para o treinamento.

Em sua dissertação, Eric Brill considera que um corpus "muito pequeno" possuiria 40.000 palavras. Desta forma, não é surpreendente que os resultados obtidos na primeira iteração treino-etiquetagem-correção não tenham sido estupendos. No entanto, não sabemos precisar a razão da baixa precisão obtida, que podem ser justificadas de duas maneiras:

(a) O número de palavras (11.000) não é estatisticamente relevante para o treinamento do etiquetador.

(b) O método de Brill, por se basear no aprendizado da etiqueta baseado na vizinhança próxima, não se aplica ao português dos séculos XVI a XIX, que é uma língua com uma ordem de palavras muito mais livre que o inglês moderno. 
O problema com a hipótese (a) é que não sabemos quantas palavras seriam estatisticamente relevantes, nem sabemos como calcular tal valor. Some-se a isso o fato de estarmos tratando com textos históricos, de autores de épocas, convenções ortográficas e estilos distintos, o que nos diferencia muito dos corpora nos quais outros métodos citados foram desenvolvidos.

O problema da hipótese (b) é que absolutamente todos os métodos conhecidos para etiquetagem de palavras fazem uma busca localmente restrita e, portanto, todos os outros métodos estão sujeitos ao mesmo problema.

\subsection{Sobre o Método proposto por Brill}

Uma questão extremamente interessante é o comportamento do método proposto por Brill no que se refere à etiquetagem de diversos textos. Em outras palavras, não há nada que garanta que o método produza bons resultados. Ou seja: o fato de termos obtido um acerto de $90 \%$ na etiquetagem de um determinado texto de um dado tipo/estilo, não implica, em princípio, que conseguiremos esse mesmo resultado na marcação de outros textos desse mesmo tipo/estilo (note que essa observação compara textos de um mesmo gênero; caso um texto de um estilo seja etiquetado utilizando-se um conjunto de regras aprendido a partir de textos de outros estilos, é presumível que os resultados alcançados na marcação de textos desses estilos sejam diferentes. Isso se deve ao fato do método se basear no reconhecimento de padrões morfo-sintáticos no aprendizado das regras.).

Dessa forma, surge a seguinte pergunta: como garantir que um etiquetador produza sempre pelo menos X\% de acerto na anotação dos textos? Trata-se de uma pergunta de difícil resposta. Contudo, antes de respondê-la, devemos investigar se isso realmente é possível, para em seguida estudar como fazê-lo.

\subsection{Investigações Futuras}

A área conhecida como lingüística computacional empírica é muito vasta. Estudamos apenas uma de suas vertentes, a etiquetagem morfo-sintática de palavras de um texto. Há, ainda, muitos tópicos interessantes relacionados com a etiquetagem de textos, que podem ser explorados como continuação desse trabalho. Dentre eles, podemos ressaltar os seguintes:

- resolução do problema de refinamento das etiquetas de palavras homógrafas;

- investigação de novos algoritmos de otimização, que têm como propósito buscar máximos globais em vez de máximos locais; 
- utilização do etiquetador para estudar a evolução da língua portuguesa em diferentes períodos. Para tanto, serão construídos vários etiquetadores, cada um treinado com um texto de um determinado período. Etiquetaremos, então, os textos de uma determinada época com etiquetadores treinados com textos de outras épocas. Caso haja diferenças significativas nos resultados obtidos, teremos bons indícicos de mudança nas normas sintáticas nos períodos estudados.

- estudos de como utilizar o etiquetador morfo-sintático na análise sintática de textos;

- estudo de técnicas de paralelização do aprendizado das regras e etiquetagem dos textos;

- determinação do que é um corpus de treinamento estatisticamente relevante, ou seja, o tamanho do corpus que devemos utilizar para o aprendizado de regras contextuais para que o percentual de acerto na etiquetagem se torne aproximadamente constante;

- melhoria do conhecimento lingüístico codificado no refinador. Pretendemos classificar palavras que pertencem a uma única classe morfo-sintática e que portanto devem ser sempre marcadas com a mesma etiqueta. Tal informação será utilizada para uma pré-etiquetagem dos textos. Procuraremos desenvolver métodos mais precisos para a determinação dos tempos verbais de verbos que apresentem ênclise, além de obter formas de identificar locuções no texto (talvez com o uso de dicionários). 


\section{Apêndice A}

\section{Manual de Etiquetagem do Corpus Tycho Brahe}

\section{A.1 Etiquetas}

Apresentaremos, ness seção, as etiquetas que são utilizadas na marcação do Corpus Tycho Brahe. Essas etiquetas podem ser alteradas ou excluídas no decorrer do processo de construção do corpus, enquanto novas etiquetas podem ser adicionadas por motivos técnicos (lingüísticos e/ou computacionais). A última versão do manual de etiquetagem pode ser encontrada na URL http://www.ime.usp.br/ tycho/corpus/manual. 


\section{A.1.1 Verbos em Geral}

\begin{tabular}{|l|l|}
\hline \hline Etiqueta & Significado \\
\hline \hline VB & Infinitivo \\
\hline VB-F & Infinitivo Flexionado \\
\hline VB-I & Imperativo \\
\hline VB-P & Presente do Indicativo \\
\hline VB-SP & Presente do Subjuntivo \\
\hline VB-D & Passado (perfeito e imperfeito) \\
\hline VB-RA & Pretérito mais-que-perfeito (em todos os seus usos) \\
\hline VB-SD & Passado do Subjuntivo \\
\hline VB-R & Futuro do Indicativo \\
\hline VB-SR & Futuro do Subjuntivo \\
\hline VB-G & Gerúndio \\
\hline VB-PP & Particípio Passado \\
\hline VB-AN & Particípio Passivo, Masculino, Singular \\
\hline VB-AN-P & Particípio Passivo, Masculino, Plural \\
\hline VB-AN-F & Particípio Passivo, Feminino, Singular \\
\hline VB-AN-F-P & Particípio Passivo, Feminino, Plural \\
\hline
\end{tabular}

Os verbos haver, estar, ter e ser são marcados de forma diferente dos demais verbos. A diferença consiste basicamente no núcleo da etiqueta que é utilizada na marcação. Dessa forma, são utilizados os seguintes prefixos na marcação desses verbos: HV, ET, TR e SR, (respectivamente). Além disso, os verbos ser e estar não apresentam nenhuma forma de particípio passivo.

\section{A.1.2 Nomes}

\begin{tabular}{|l|l|}
\hline \hline Etiqueta & Significado \\
\hline \hline $\mathrm{N}$ & Nome Comum, Singular \\
\hline N-P & Nome Comum, Plural \\
\hline NPR & Nome Próprio, Singular \\
\hline NPR-P & Nome Próprio, Plural \\
\hline
\end{tabular}

Observações:

- Coletivos (ex.: multidão) são marcados com N, assim como infinitivos precedidos de determinante ou pronome e acompanhados pelos seus argumentos (ex.: o $a m a r / N$ é 
envolvente, o sofrer $/ N$ é desgastante, etc.). Note que os infinitivos que são precedidos por determinantes que não são acompanhados por argumentos são marcados como verbos no infinitivo (ex.: o $a m a r / V B$ a Deus é bom).

- Nomes que não mudam no plural são marcados de acordo com os determinantes que os acompanham (ex.: o/D lápis/ $N$, os/D-P lápis/N-P).

- Formas de tratamento e títulos são marcados com NPR (ex.: Dom/NPR Frederico).

- Datas e dias da semana são marcados com NPR (ex.: o Natal/NPR, Sexta/NPR Feira/NPR), assim como lugares (ex.: o/D rio/N Amazonas/NPR).

- Palavras com inicial maiúscula são marcadas com NPR (ex.: o Rio/NPR Amazonas/NPR).

Note que não é marcada a flexão de gênero dos nomes próprios e comuns.

\section{A.1.3 Pronomes}

\begin{tabular}{|l|l|}
\hline \hline Etiqueta & Significado \\
\hline \hline PRO & Pronomes Pessoais do Caso Reto e alguns Oblíquos Tônicos \\
\hline P+PRO & Alguns Pronomes Pessoais Oblíquos Tônicos \\
\hline PRO\$ & Pronomes Possessivos Masculinos, Singular \\
\hline PRO\$-P & Pronomes Possessivos Masculinos, Plural $^{4}$ \\
\hline PRO\$-F & Pronomes Possessivos Femininos, Singular $^{5}$ \\
\hline PRO\$-F-P & Pronomes Possessivos Femininos, Plural $^{6}$ \\
\hline
\end{tabular}

Note que não há flexão de gênero e número para os pronomes oblíquos átonos.

Observação: a gente será marcado como $a / D-F$ gente/N.

\footnotetext{
${ }^{1}$ Exemplos: eu, tu, ele, ela, você, nos, vós, eles, elas, vocês, mim, ti, si

${ }^{2}$ Exemplos: comigo, contigo, consigo, conosco, convosco.

${ }^{3}$ Exemplos: meu, teu, seu, nosso, vosso.

${ }^{4}$ Exemplos: meus, teus, seus, nossos, vossos.

${ }^{5}$ Exemplos: minha, tua, sua, nossa, vossa.

${ }^{6}$ Exemplos: minhas, tuas, suas, nossas, vossas.
} 


\section{A.1.4 Clíticos}

\begin{tabular}{|l|l|}
\hline \hline Etiqueta & Significado \\
\hline \hline CL & Pronomes Oblíquos Átonos \\
\hline SE & Clítico $s e$ \\
\hline \hline
\end{tabular}

Observações:

- No caso de ênclise, a marcação será feita como no exemplo: comê-lo/VB+CL.

- Verbos no futuro do presente e no futuro do pretérito admitem mesóclise. Nesse caso, a marcação será feita da seguinte forma: dar-lhe-ei/VB-R!CL.

- Quando não há hífen, o clítico e o verbo são considerados duas palavras isoladas (ex.: lhe/CL emprestei/VB-D).

\section{A.1.5 Determinantes}

\begin{tabular}{|l|l|}
\hline \hline Etiqueta & Significado \\
\hline \hline D & o, esse, este, aquele \\
\hline D-F & a, essa, esta, aquela \\
\hline D-P & os, esses, estes, aqueles \\
\hline D-F-P & as, essas, estas, aquelas \\
\hline D-G & tal \\
\hline D-G-P & tais \\
\hline D-UM & um \\
\hline D-UM-F & uma \\
\hline D-UM-P & uns \\
\hline D-UM-F-P & umas \\
\hline OUTRO & outro \\
\hline OUTRO-F & outra \\
\hline OUTRO-P & outros \\
\hline OUTRO-F-P & outras \\
\hline DEM & isto, isso, aquilo, tal \\
\hline \hline
\end{tabular}

${ }^{7}$ Exemplos: o, a, os, as, me, te, se, the. 


\section{A.1.6 Adjetivos}

\begin{tabular}{|l|l|}
\hline \hline Etiqueta & Significado \\
\hline \hline ADJ & Adjetivo Masculino, Singular \\
\hline ADJ-P & Adjetivo Masculino, Plural \\
\hline ADJ-F & Adjetivo Feminino, Singular \\
\hline ADJ-F-P & Adjetivo Feminino, Plural \\
\hline ADJ-G & Adjetivo com Gênero Duplo, Singular \\
\hline ADJ-G-P & Adjetivo com Gênero Duplo, Plural \\
\hline ADJ-S & Adjetivo Superlativo, Masculino, Singular \\
\hline ADJ-S-P & Adetivo Superlativo Masculino, Plural \\
\hline ADJ-S-F & Adjetivo Superlativo, Feminino, Singular \\
\hline ADJ-S-F-P & Adjetivo Superlativo, Feminino, Plural \\
\hline ADJ-S-G & Adjetivo Superlativo, Gênero Duplo \\
\hline ADJ-R & Adjetivo Comparativo, Masculino, Singular \\
\hline ADJ-R-P & Adjetivo Comparativo, Masculino, Plural \\
\hline ADJ-R-F & Adjetivo Comparativo, Feminino, Singular \\
\hline ADJ-R-F-P & Adjetivo Comparativo, Feminino, Plural \\
\hline ADJ-R-G & Adjetivo Comparativo, Gênero Duplo, Singular \\
\hline ADJ-R-G-P & Adjetivo Comparativo, Gênero Duplo, Plural \\
\hline \hline
\end{tabular}

\section{A.1.7 Advérbios}

\begin{tabular}{|l|l|}
\hline \hline Etiqueta & Significado \\
\hline \hline ADV & Advérbios terminados em mente, Advérbios de Lugar e Advérbios de Tempo \\
\hline ADV-S & Advérbios Superlativos \\
\hline ADV-R & Advérbios Comparativos \\
\hline \hline
\end{tabular}




\section{A.1.8 Quantificadores}

\begin{tabular}{|l|l|}
\hline \hline Etiqueta & Significado \\
\hline \hline Q & Quantificadores Masculinos em Geral, Singular \\
\hline Q-P & Quantificadores Masculinos em Geral, Plural \\
\hline Q-F & Quantificadores Femininos em Geral, Singular ${ }^{10}$ \\
\hline Q-F-P & Quantificadores Femininos em Geral, Plural \\
\hline Q-G & Quantificadores com Gênero Duplo, Singular ${ }^{12}$ \\
\hline Q-G-P & Quantificadores com Gênero Duplo, Plural \\
\hline
\end{tabular}

\section{A.1.9 Conjunções Coordenativas e Subordinativas}

\begin{tabular}{|l|l|}
\hline \hline Etiqueta & Significado \\
\hline \hline CONJ & $\begin{array}{l}\text { Conjunções Coordenativas Aditivas, Adversativas, Alternativas } \\
\text { Conclusivas, Explicativas }\end{array}$ \\
\hline C & Conjunção Subordinativa Integrante ${ }^{15}$ \\
\hline CONJS & $\begin{array}{l}\text { Conjunções Subordinativas Causais, Concessivas, Condicionais } \\
\text { Finais, Temporais, Consecutivas, Comparativas }\end{array}$ \\
\hline \hline
\end{tabular}

\footnotetext{
${ }^{8}$ Exemplos: algum, nenhum, tudo, nada, muito, pouco, todo, etc.

${ }^{9}$ Exemplos: alguns, ambos, todos.

${ }^{10}$ Exemplos: alguma, nenhuma, etc.

${ }^{11}$ Exemplos: algumas, ambas, todas.

${ }^{12}$ Exemplos: cada, ninguém, alguém, qualquer.

${ }^{13}$ Exemplo: quaisquer.

${ }^{14}$ Exemplos: $e$, nem, ou ... ou, tanto ... quanto, logo, pois, etc.

${ }^{15}$ Exemplo: que.

${ }^{16}$ Exemplos: porque, embora, quando, enquanto, segundo, etc.
} 


\section{A.1.10 Interrogativas Diretas e Indiretas/Relativas/Exclamativas}

\begin{tabular}{|c|c|}
\hline Etiqueta & Significado \\
\hline WPRO & "algum, nenhum, tudo, nada, muito, pouco \\
\hline WPRO-P & alguma, nenhuma \\
\hline WPRO\$ & alguns, ambos, todos \\
\hline WPRO\$-F & algumas, ambas, todas \\
\hline WPRO\$-P & cada, ninguém, alguém, qualquer \\
\hline WPRO\$-F-P & quaisquer \\
\hline WADV & onde, quando, como, quanto, quem \\
\hline WQ & $s e^{17}$ \\
\hline WD & que, qual $^{18}$ \\
\hline WD-P & 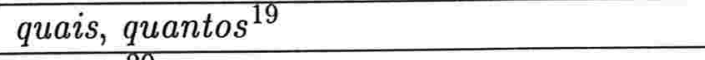 \\
\hline WD-F & quanta $^{20}$ \\
\hline WD-F-P & quantas 21 \\
\hline
\end{tabular}

\section{A.1.11 Preposições e Contrações}

\begin{tabular}{|l|l|}
\hline \hline Etiqueta & Significado \\
\hline \hline $\mathrm{P}$ & $a$, de, com, em, para, até, desde, sobre, exceto, salvo \\
\hline $\mathrm{P}+\mathrm{D}$ & $a o$, no, do, desse, pelo \\
\hline $\mathrm{P}+\mathrm{D}-\mathrm{P}$ & $a o s$, nos, dos, desses, pelos \\
\hline $\mathrm{P}+\mathrm{D}-\mathrm{F}$ & $\grave{a}$, na, da, dessa, pela \\
\hline $\mathrm{P}+\mathrm{D}-\mathrm{F}-\mathrm{P}$ & $\grave{a} s$, nas, das, dessas, pelas \\
\hline $\mathrm{P}+\mathrm{DEM}$ & disto, disso, daquilo \\
\hline $\mathrm{P}+\mathrm{WADV}$ & donde $^{2}$ \\
\hline $\mathrm{P}+\mathrm{CL}$ & pela $^{22}$ \\
\hline
\end{tabular}

\section{A.1.12 Locuções}

Serão considerados locuções os conjuntos de palavras que:

\footnotetext{
${ }^{17} \mathrm{Em}$ interrogativas indiretas.

${ }^{18} \mathrm{Em}$ que/qual livro.

${ }^{19} \mathrm{Em}$ os quais livros.

${ }^{20} \mathrm{Em}$ Quanta desesperança encontrastes, quando ...?

${ }^{21} \mathrm{Em}$ Quantas esperanças você me deu!

${ }^{22} \mathrm{Em}$ trabalhei pela servir.
} 
1. recebem uma interpretação de conjunto que não pode ser derivada da composição das categorias que os compõem;

2. contêm palavras de categoria duvidosa.

A marcação é feita da seginte forma:

[P | CONJ | CONJS]-complemento- $\mathrm{n}_{1} \mathrm{n}_{2}$

onde $\mathrm{n}_{1}$ é o comprimento da locução e $\mathrm{n}_{2}$ é a posição da palavra na locução. Note que podem ocorrer contações em uma locução. Ex.: apesar/P-21 de/P-22, no/CONJ-21 entanto/CONJ-22, apesar/P-21 disso/P+DEM-22, etc.

\section{A.1.13 Numerais}

\begin{tabular}{|l|l|}
\hline \hline Etiqueta & Significado \\
\hline \hline NUM & Numeral Cardinal Masculino \\
\hline NUM-F & Numeral Cardinal Feminino \\
\hline ADJ & Numeral Ordinal Masculino, Singular \\
\hline ADJ-F & Numeral Ordinal Feminino, Singular \\
\hline ADJ-P & Numeral Ordinal Masculino, Plural $^{27}$ \\
\hline ADJ-F-P & Numeral Ordinal Feminino, Plural $^{28}$ \\
\hline \hline
\end{tabular}

\section{A.1.14 Negações}

\begin{tabular}{|l|l|}
\hline \hline Etiqueta & Significado \\
\hline \hline NEG & $n \tilde{a} o^{29}, n e m^{30}$ \\
\hline SENAO & senão $^{31}$ \\
\hline \hline
\end{tabular}

\footnotetext{
${ }^{23}$ Exemplos: um, dois, três, etc.

${ }^{24}$ Exemplos: uma, duas.

${ }^{25}$ Exemplos: primeiro, segundo, terceiro, etc.

${ }^{26}$ Exemplos: primeira, segunda, terceira, etc.

${ }^{27}$ Exemplo: os primeiros pacientes.

${ }^{28}$ Exemplo: as primeiras páginas.

${ }^{29} \mathrm{Em}$ não saia sem levar um agasalho.

${ }^{30} \mathrm{Em}$ nem só de pão vive o homem.

${ }^{31} \mathrm{Em}$ não respira senão pode se intoxicar.
} 


\section{A.1.15 Interjeições}

\begin{tabular}{|l|l|}
\hline \hline Etiqueta & Significado \\
\hline \hline INTJ & olá, adeus, tchau \\
\hline \hline
\end{tabular}

Observação:

- até amanhã ou até logo são analisados como duas palavras: até/P manhã $/ A D V$, até/P logo/ADV.

\section{A.1.16 Palavras Estrangeiras e Palavras Desconhecidas}

\begin{tabular}{|l|l|}
\hline \hline Etiqueta & Significado \\
\hline \hline FW & Palavras Estrangeiras \\
\hline XX & Palavras Desconhecidas \\
\hline \hline
\end{tabular}

\section{A.1.17 Sinais de Pontuação}

\begin{tabular}{|l|l|}
\hline \hline Etiqueta & Significado \\
\hline \hline. & $\begin{array}{l}\text { Ponto Final (.), Pontos de Interrogação ( } \\
\text { Reticências (...) ?), Pontos de Exclamação ( } i \text { e !), }\end{array}$ \\
\hline, & Vírgula (,) \\
\hline " & Aspas Iniciais (") ou Finais (") \\
\hline( & Parênteses Iniciais(() ou Finais ()), Travessão (-) \\
\hline \hline
\end{tabular}

\section{A.2 Marcações Extra-lingüísticas}

Além das etiquetas que descrevem as classes gramaticais propriamente ditas, há outros tipos de marcações. São elas:

- Marcações de início de página. Ex.: 〈P_01〉.

- Marcações de início e fim de texto, <text $\rangle$ e $\langle/$ text $\rangle$, respectivamente.

- Marcações de início e fim de comentários, <comment> e </comment>, respectivamente. 
- Marcações de início e fim de título, <heading > e </heading>, respectivamente.

- Marcações de início e fim de informações sobre a edição (data, editor, editora, etc.), <edition> e </edition>, respectivamente.

- Há caracteres que não fazem parte do alfabeto iso-latin1 (também conhecido como iso-8859-1), definido como padrão para armazenamento do Corpus Tycho Brahe. Um exemplo é o caractere $\tilde{u}$. Contudo, é importante que haja pelo menos uma versão do texto que preserve suas características originais. Para tanto, utilizamos as marcações <original> e </original>, que identificam que há alguma informação presente no texto original que não pode ser codificada diretamente no corpus. Por exemplo, para o caractere mencionado, teremos <original> ũa </original>. Essas marcas também são utilizadas para preservação de abreviações que foram encontradas no texto original e que não aparecem na versão etiquetada.

- Em alguns textos, o autor inicia uma nova sentença sem finalizar a anterior, ou seja, sem utilizar uma marca apropriada (ponto final, ponto de exclamação, etc.) Nesses casos, utilizamos a marca $\langle\mathrm{nl}\rangle$ para indicar que a sentença termina. 


\section{Apêndice B}

\section{Manual do Sistema}

\section{B.1 O Aprendizado de Regras para Etiquetagem de Palavras Desconhecidas}

Para iniciar o aprendizado de regras para etiquetagem de palavras desconhecidas, deve-se utilizar o seguinte comando:

perl unknown-lexical-learn.prl WORDLIST SMALLWORDTAGLIST BIGRAMLIST n LEXRULEOUTFILE

onde:

WORDLIST é um arquivo com o formato $\langle p a l\rangle$, onde pal são palavras conhecidas (que ocorrem no corpus de treinamento).

Exemplo de fragmento de um arquivo desse tipo:

que
a
se
com
os
Vossa
Excelência


para

do

SMALLWORDTAGLIST é um arquivo com o formato $\langle p a l\rangle\langle e t i q\rangle\langle$ freq $\rangle$, onde freq é a freqüência com que a palavra pal aparece marcada com a etiqueta etiq no corpus de treinamento.

Exemplo de fragmento de um arquivo desse tipo:
, 1569
e CONJ 801
que WPRO 476
a D 385
que C 338
não NEG 252
se $\mathrm{SE} 179$
da $P 170$
; . 140
me CL 131

Observe que este arquivo é ordenado pelas freqüências, com os pares 〈palavra〉 〈etiqueta〉 mais freqüentes aparecendo antes dos menos freqüentes.

BIGRAMLIST é um arquivo com o formato $\left\langle p a l_{1}\right\rangle\left\langle p a l_{2}\right\rangle$, onde $\mathrm{pal}_{1}$ e $\mathrm{pal}_{2}$ são palavras que aparecem no corpus de treinamento adjascentemente (ou seja, pal $_{1}$ aparece à esquerda de $\mathrm{pal}_{2}$ ).

Exemplo de fragmento de um arquivo desse tipo:

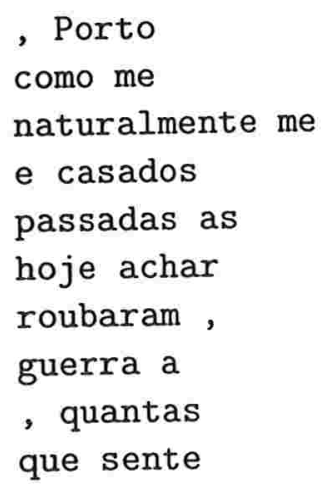


n é um número utilizado para indicar ao sistema que deverão ser utilizados apenas os bigramas onde pelo menos uma das palavras está na lista das $n$ palavras mais freqüentes no corpus de treinamento. Aumentando-se esse número, o "aprendedor" potencialmente irá aumentar o número de regras aprendidas, gastando mais tempo e espaço de armazenamento. Por outro lado, diminuindo-se o valor de $n$, o aprendizado potencialmente será mais rápido e irá utilizar menos memória.

LEXRULEOUTFILE é o arquivo onde as regras aprendidas serão armazenadas.

\section{B.2 O Aprendizado de Regras Contextuais}

Para iniciar o aprendizado de regras contextuais, deve-se utilizar o seguinte comando:

crl TAGGEDCORPUS DUMMYTAGGEDCORPUS CONTEXTRULEFILE TRAININGLEXICON INFO

onde:

TAGGEDCORPUS é o arquivo com a referência, ou seja, o texto etiquetado manualmente e portanto sem erros. Este texto deve estar no formato de uma sentença por linha e com todos os itens léxicos "tokenizados".

DUMMYTAGGEDCORPUS é o arquivo com a marcação inicial. Note que o texto no arquivo TAGGEDCORPUS é o mesmo deste arquivo. Assim como o texto em TAGGEDCORPUS, o texto nesse arquivo deve estar no formato de uma sentença por linha e com todos os itens léxicos "tokenizados".

CONTEXTRULEFILE é o arquivo onde as regras aprendidas serão armazenadas.

TRAININGLEXICON é o arquivo com o léxico, onde para cada palavra do corpus de treinamento etiquetado, há uma lista com suas possíveis etiquetas (em relação ao corpus de treinamento; nada impede que uma determinada palavra apareça marcada com uma etiqueta que não aparece na lista em algum outro corpus).

Exemplo de fragmento de um arquivo desse tipo:

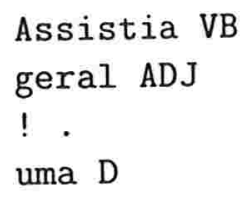




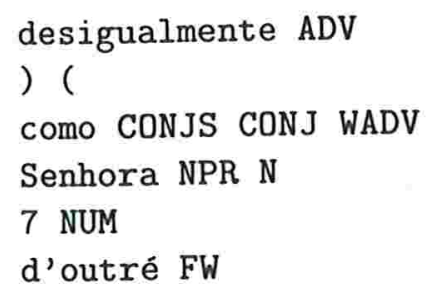

A primeira etiqueta da lista é a etiqueta mais freqüentemente associada à palavra em questão.

INFO é um arquivo onde será armazenado o resultado de cada uma regra no formato 〈regra) 〈número de erros corrigidos〉.

\section{B.3 Etiquetagem dos Textos}

Para etiquetar um texto, deve-se utilizar o seguinte comando:

tagger LEXICON CORPUS BIGRAMS LEXRULEOUTFILE CONTEXTUALRULEFILE

onde:

LEXICON é o arquivo com o léxico que será utilizado na etiquetagem.

CORPUS é o arquivo com o texto que se deseja etiquetar. O etiquetador supõe que há uma única sentença por linha e que os sinais de pontuação estejam "tokenizados". As palavras do texto que se deseja etiquetar podem estar pré-etiquetadas, desde que a etiqueta esteja separada da palavra por duas barras, conforme mostra exemplo abaixo:

$$
\text { O garoto//N disse : "eu estou aqui." " }
$$

(Observe que as aspas, os dois pontos e o ponto final são elementos do léxico da linguagem que serão etiquetados da mesma forma que as palavras, e portanto aparecem "tokenizados").

BIGRAMS é um arquivo que contém pares de palavras que aparecem de forma adjascente no corpus de treinamento, que são usados para aplicação de regras como altere a etiqueta corrente de etiq $q_{1}$ para etiq $q_{2}$ se a palavra pal sempre aparece à direita da palavra corrente. 
LEXRULEOUTFILE é um arquivo que contém as regras de etiquetagem de palavras desconhecidas.

Exemplo de fragmento de um arquivo desse tipo:

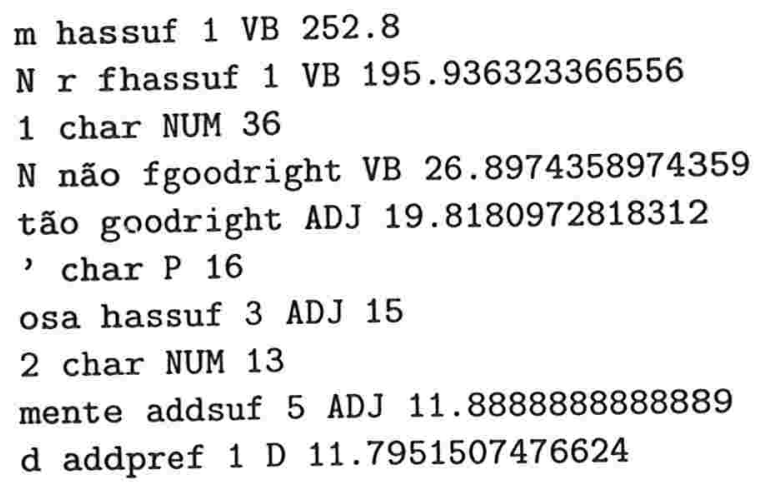

CONTEXTUALRULEFILE é um arquivo que contém as regras de etiquetagem que foram aprendidas e que serão utilizadas no etiquetador.

Exemplo de um fragmento de um arquivo desse tipo:

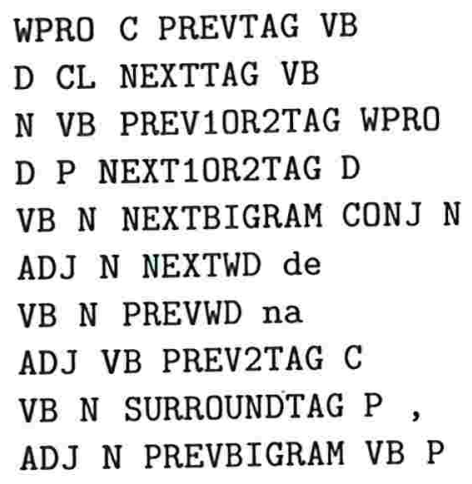

As opções de linha de comando disponíveis são as seguintes:

-? Exibe o formato da linha de comando que deve ser utilizada para executar o etiquetador.

-h Exibe auxílio (help) ao usuário. 
-w wordlist Faz com que seja utilizado um arquivo que contém palavras que não são encontradas em LEXICON. Tais palavras são utilizadas na etiquetagem de palavras desconhecidas, em regras como: altere a etiqueta de um palavra desconhecida para advérbio se adicionando o sufixo "mente" temos em uma palavra conhecida. Para verificar se a "nova palavra" pertence ou não ao léxico, verificamos se ela esta em LEXICON ou em WORDLIST (observe que o fato da palavra não se encontrar em nenhum desses arquivos não implica no fato de não pertencer ao léxico da língua analisada; em contrapartida, se ele está em algum desses arquivos, ela certamente é uma palavra conhecida da linguagem).

-i arq Faz com que resultados intermediários da etiquetagem sejam armazenados no arquivo arq.

-s num Processa o corpus a ser etiquetado em blocos de num linhas por vez. Tal opção é útil quando se deseja etiquetar textos muito grandes em sistemas que não dispõem de memória suficiente para processar o texto de uma única vez.

-S Se esta opção for acionada, apenas o etiquetador inicial será utilizado.

-F Se esta opção for acionada, apenas o etiquetador final será utilizado. Nesse caso, CORPUS deve ser um texto previamente etiquetado, cujas etiquetas serão alteradas pelo etiquetador final segundo as regras de etiquetagem contidas no arquivo CONTEXTUALRULEFILE.

\section{B.4 Refinamento das Etiquetas}

Para refinar as etiquetar de um texto, deve-se utilizar o seguinte comando:

ref CORPUS-IN CORPUS-OUT

onde:

CORPUS-IN é o arquivo e entrada, com o texto marcado apenas com os núcleos das etiquetas.

CORPUS-OUT é o arquivo de saída, que armazenará o texto marcado com as etiquetas completas. 


\section{B.5 Ferramentas Auxiliares}

São ferramentas construídas para automatizar algumas tarefas que manualmente seriam impossíveis ou inviáveis de serem feitas devido à quantidade de dados manipulada pelos programas. Muitos dos arquivos mencionados anteriormente que fazem parte da entrada dos programas de aprendizado e etiquetagem são gerados por tais utilitários. Além disso, há programas para geração de estatísticas sobre os resultados da etiquetagem, remoção das etiquetas de um texto anotado, etc.

\section{B.5.1 divide-in-two-rand.prl}

Entrada: Um texto etiquetado.

Saída: Dois arquivos com textos etiquetados.

O que faz: Divide o arquivo com o texto de entrada aleatoriamente em dois outros textos com aproximadamente o mesmo tamanho (número de linhas).

Utilização: perl divide-in-two-rand.prl $\left\langle\right.$ texto $\left._{1}\right\rangle\left\langle\right.$ texto $\left._{2}\right\rangle\left\langle\right.$ texto $\left._{3}\right\rangle$, onde texto ${ }_{1}$ é o arquivo com a entrada e texto $\mathrm{e}_{2}$ e texto $\mathrm{o}_{3}$ são os arquivos com a saída.

\section{B.5.2 wordlist-make.prl}

Entrada: Um texto não-etiquetado.

Saída: Uma lista com todas as palavras do texto de entrada ordenadas decrescentemente em relação às freqüências com que ocorrem no texto.

Utilização: cat 〈texto-não-etiquetado) | perl wordlist-make.prl | sort +1 -rn | awk ' $\{$ print $\$ 1\}$ ' > BIGWORDLIST, onde texto-não-etiquetado é o arquivo com a entrada e BIGWORDLIST é o arquivo com a saída.

\section{B.5.3 word-tag-count.prl}

Entrada: Um texto etiquetado.

Saída: Uma lista com entradas do tipo $\langle p a l\rangle\langle e t i q\rangle\langle f r e q\rangle$, onde freq é a freqüência com que a palavra pal aparece marcada com a etiqueta $e t i q$ no texto de entrada. 
Utilização: cat 〈texto-etiquetado) | perl word-tag-count.prl | sort +2 -rn > SMALLWORDTAGLIST, onde texto-etiquetado é o arquivo com a entrada e SMALLWORDTAGLIST é o arquivo com a saída.

\section{B.5.4 bigram-generate.prl}

Entrada: Um texto não-etiquetado.

Saída: Uma lista de todos os pares de palavras que aparecem no texto de entrada.

Utilização: cat 〈texto-não-etiquetado〉 | perl bigram-generate.prl awk ' $\{$ print $\$ 1, \$ 2\}$ ' > BIGBIGRAMLIST, onde texto-não-etiquetado é o arquivo com a entrada e BIGBIGRAMLIST é o arquivo com a saída.

\section{B.5.5 make-restricted-lexicon.prl}

Entrada: Um texto etiquetado.

Saída: Uma lista com as palavras do texto de entrada, cada uma delas seguida pela lista de etiquetas que aparecem associadas a ela no texto, sendo que a primeira etiqueta desta lista é a mais freqüente.

Utilização: perl make-restricted-lexicon.prl (texto-etiquetado) LEXICON, onde texto-etiquetado é o arquivo com a entrada LEXICON é o arquivo com a saída.

\section{B.5.6 tagged-to-untagged.prl}

Entrada: Um texto etiquetado.

Saída: O texto de entrada sem as etiquetas.

Utilização: perl tagged-to-untagged.prl (texto-etiquetado) (texto-não-etiquetado), onde texto-etiquetado é o arquivo com a entrada e texto-não-etiquetado é o arquivo com a saída.

\section{B.5.7 comparitor.prl}

Entrada: A referência (texto etiquetado manualmente), o mesmo texto etiquetado automaticamente e o léxico utilizado na etiquetagem. 
Saída: Estatísticas sobre a etiquetagem do texto etiquetado automaticamente.

Utilização: perl comparitor.prl 〈referência〉 〈texto-etiquetado〉 〈léxico〉, onde referência, texto-etiquetado e léxico são os arquivos de entrada.

Para uma descrição das ferramentas checker.prl, format.prl, textttfilter.c, guessabbrev.prl, tokenizer.prl, extractcompl.prl, generator.prl e statistics.prl, ver o Capítulo 4. 


\section{Referências Bibliográficas}

Essa seção foi dividida em duas partes. A primeira, que chamamos de Bibliografia, compreende todos os textos que compõem as citações que se encontram nessa dissertação. A segunda, intitulada Outras Referências, contém outros textos que, apesar de não fazerem parte das citações, foram utilizados nos estudos que culminaram nesse trabalho e são fontes de pesquisa para quem deseja obter informações sobre o assunto.

\section{Bibliografia}

[1] Brill, E. Unsupervised Learning of Desambiguation Rules for Part of Speech Tagging. Artigo obtido na URL http://www.cs.jhu.edu/ “brill, 1993.

Nesse artigo o autor apresenta um etiquetador morfo-sintático baseado em regras não-supervisionado, ou seja, que não utiliza textos etiquetados na fase de aprendizado das regras contextuais. Mostra também diferenças de um etiquetador desse tipo em relação a um etiquetador supervisionado, maneiras de se combinar o aprendizado supervisionado com o não-supervisionado, além de apresentar os resultados comparativos da etiquetagem quando é utilizado um etiquetador supervisionado e um que combina os dois tipos de aprendizado. Brill também compara o algoritmo de aprendizado baseado em regras não-supervisionado com o algoritmo Baum-Welsh, utilizado por etiquetadores estocásticos não-supervisionados.

[2] Brill, E. Transformation-Based Error Driven Parsing. Third Workshop on Parsing Technologies, Netherlands, 1993.

Nesse artigo o autor apresenta uma técnica de etiquetagem sintática que se baseia no aprendizado automático de uma gramática de transformações (o termo é utilizado com um sentido diferente do usual). Tal gramática é capaz de fazer a análise sintática de um texto através de sua representação em árvores sintáticas binárias. 
[3] Brill, E. A Corpus-Based Approach to Language Learning. Ph.D. Dissertation, University of Pennsylvania, 1993.

Dissertação de doutorado de Eric Brill onde ele apresenta o método de aprendizado de trannsformações dirigido por erros e mostra sua aplicação na etiquetagem morfológica de palavras e na etiquetagem sintática de textos.

[4] Brill, E. README.TRAINING. Arquivo pertencente ao etiquetador, obtido na URL http://www.cs.jhu.edu/“brill, 1993.

Arquivo com documentação sobre a fase de treinamento encontrado no diretório Docs, que faz parte da distribuição do etiquetador morfológico implementado por Eric Brill, disponível na URL http://www.cs.jhu.edu/ " brill.

[5] Brill, E. Automatic Grammar Induction and Parsing Free Text: A Transformation-Based Approach. Artigo obtido na URL http://www.cs.jhu.edu/ brill, 1993.

Artigo onde o autor apresenta a técnica de análise sintática baseada no aprendizado de regras de transformação, assim como em [2].

[6] Brill, E. Some advances in transformation-based part-of-speech tagging. In Proceedings of the 12th National Conference on Artificial Intelligence (AAAI-94), 1994.

Artigo no qual o autor faz um apanhado geral de como a técnica de aprendizado de transformações dirigido por erros pode ser utilizada na etiquetagem morfo-sintática de palavras de um texto. Ele mostra, em linhas gerais, como funciona um etiquetador que implementa tal paradigma, como fazer com que esse etiquetador utilize regras que manipulem palavras da língua em questão (em outras palavras, como construir um etiquetador lexicalizado), como resolver o problema de etiquetagem de palavras desconhecidas e como etiquetar um texto com conjuntos de etiquetas ao invés de uma única etiqueta.

[7] Brill, E., Resnik, P. A Rule-Based Approach to Prepositional Phrase Attachment Disambiguation. Artigo obtido na URL http://www.cs.jhu.edu/〜brill, 1994.

Artigo no qual o autor apresenta uma técnica para resolver o problema de ambigüidade causado pelas preposições na língua inglesa através da utilização do paradigma de aprendizado de regras dirigido por erros.

[8] Brill, E. Transformation-Based Error Driven Learning and Natural Language. A case Study in Part of Speech Tagging. Computational Linguistics, 21(4):543-565, 1995.

Artigo no qual o autor mostra como a técnica de aprendizado de transformações dirigida por erros pode ser utilizada na etiquetagem morfo-sintática de palavras de um texto. Além disso, ele apresenta as principais características de etiquetadores lexicalizados e não lexicalizados, a técnica de etiquetagem por conjuntos de etiquetas e a técnica de etiquetagem de palavras desconhecidas. Por fim, ele faz uma comparação entre etiquetadores que implementam o 
paradigma estocástico e o por ele proposto a partir da utilização de corpora de treinamento de diversos tamanhos.

[9] Brill, E. Unsupervised Learning of Disambiguation Rules for Part of Speech Tagging. Artigo obtido no, disponível na URL http://www.cs.jhu.edu/〜brill, 1995.

Neste artigo o autor descreve um algoritmo de aprendizado para treinamento de um etiquetador morfo-sintático que dispensa a utilização de um corpus etiquetado manualmente. Apresenta também uma comparação deste algoritmo com o algoritmo Baum-Welch, utilizado para treinamento de etiquetadores estocásticos. Por fim, mostra como combinar algoritmos de treinamento supervisionados (ou seja, que utilizam textos anotados manualmente) e não supervisionados para construção de um etiquetador que obtém alta performance com a utilização de uma pequena quantidade de textos etiquetados manualmente.

[10] Brill, E., Mooney, R. J. (editores). AI Magazine, volume 18, número 4. American Association for Artificial Intelligence, Inverno 1997.

Edição especial da revista Artificial Intelligence Magazine sobre lingüística computacional empírica que, além de trazer uma introdução histórica sobre o assunto, trata de problemas como reconhecimento de fala, etiquetagem sintática de textos, tradução automática, análise semântica, etc.

[11] Charniak, E. Statistical Language Learning. MIT Press, Primeira Impressão, 1993.

Livro no qual o autor explora o processamento de linguagem natural sob o ponto de vista estatístico, mostrando as vantagens deste em relação à abordagem tradicional, sob o enfoque da inteligência artificial. São apresentados, entre outras coisas, algoritmos baseados em hidden markov models, gramáticas livres de contexto probabilísticas e aplicações para solucionar o problema de ambigüidade entre sentenças.

[12] Cunha, C., Cintra, L. Nova Gramática do Português Contemporâneo. Editora Nova Fronteira, Segunda Edição, 35a. Reimpressão, 1985.

Gramática da língua portuguesa.

[13] Garside, R., Leech, G., McEnery, A. Corpus Annotation: Linguistic Information form Computer Text Corpora. Longman, Primeira Edição, 1997.

Livro que trata de diversos aspectos da (relativamente nova) área de pesquisa dentro da lingǘstica computacional, conhecida como anotação ou enriquecimento de Corpus. Abrange áreas como etiquetagem morfológica de palavras, etiquetagem sintática de sentenças, construção de etiquetadores, anotação semântica, etc.

[14] Mangu, L., Brill, E. Automatic Rule Acquisition for Spelling Correction. Artigo obtido na URL http://www.cs.jhu.edu/brill, 1997. 
Artigo no qual os autores utilizam a técnica de aprendizado de transformações dirigida por erros para correção de erros de grafia que não resultam em erros léxicos, ou seja, erros de grafia que produzem palavras pertencentes ao vocabulário da língua em questão.

[15] McEnery, T., Wilson, A. Corpus Linguistics. Edinburg University Press, Primeira Edição, 1996.

Livro que descreve a área da lingüística que utiliza textos como base para extração de conhecimento. Traz uma boa introdução histórica na qual mostra as razões que fizeram com que a área fosse esquecida por tanto tempo até que fosse retomada há alguns anos. Assim como [13], traz uma visão geral sobre as diversas frentes de pesquisa dentro da área.

[16] Satta, G., Brill, E. Efficient Transformation-Based Parsing. 34th Annual Meeting of the Association for Computational Linguistics, 1996.

Artigo onde os autores utilizam a técnica de aprendizado de transformações dirigido por erros para etiquetagem sintática de textos. É apresentada uma teoria que utiliza, entre outras coisas, autômatos, árvores sintáticas, etc. para representação das regras de etiquetagem sintática. O principal resultado desse artigo é o desenvolvimento de um algoritmo de etiquetagem sintática que apresenta limitante superior de complexidade $O(\rho \cdot t \cdot \log (t))$, onde $\rho$ é o custo de matching de uma regra e $t$ é o número total de regras aplicadas a uma sentença (entrada).

[17] Villavicencio, A., Marques, N. M. C., Lopes, J. G. P., Villavicencio, F. Part-of-Speech Tagging for Portuguese Texts. Lecture notes in Proceedings of the 12th Brazilian Conference on Artificial Intelligence (SBIA'95), 1995.

Artigo no qual os autores apresentam técnicas de etiquetagem morfo-sintática baseados em métodos estatísticos, como hidden markov models. Além de fazerem uma breve descrição da teoria utilizada para construção do modelo, eles mostram alguns resultados obtidos para textos em português contemporâneo.

[18] Home-page do projeto Rythimic Patterns, Parameter Setting \& Language Change, disponível na URL http://www.ime.usp.br/ tycho.

Página do projeto do qual este trabalho faz parte. Esta página contém, entre outras coisas, o manual com as etiquetas que serão utilizadas no corpus Tycho Brahe, os artigos relacionados com o projeto e o corpus propriamente dito.

\section{Outras Referências}

[19] Allen, J. Natural Language Understanding. The Benjamin/Cummings Publishing Company, Inc., Segunda Edição, 1995. 
Livro no qual o autor apresenta desde técnicas clássicas até técnicas recentes para processamento de linguagem natural. É dividido em três partes: a primeira se refere á técnicas de análise sintática, trazendo uma breve introdução à sintaxe da língua inglesa, teorias sobre gramáticas e como implementá-las em um analisador sintático (parser). A segunda lida com aspectos referentes à semântica, como o problema de ambigüidade de sentenças. A terceira e última trata da questão de como se representar o conhecimento, em particular informações sobre o contexto onde a comunicação está ocorrendo.

[20] Alves, C. D. C. Etiquetagem do Português baseada em Corpus. Texto apresentado como um dos requisitos do Exame de Qualificação para o Mestrado em Matemática Aplicada Ênfase em Ciência da Computação, 1997.

Nesse texto é apresentada uma introdução histórica da lingüística empírica, além do algoritmo proposto por Brill para o aprendizado de regras e uma comparação entre os paradigmas estocástico e baseado no aprendizado de regras dirigido por erros.

[21] Alves, C. D. C. Notas sobre o Etiquetador de Eric Brill. Manuscrito, Universidade de São Paulo, 1998.

Descrição do sistema de etiquetagem morfo-sintática implementado por Eric Brill, que compreende comentários sobre as estruturas de dados utilizadas, o conteúdo dos principais módulos, etc.

[22] Brill, E. A Report of Recent Progress in Transformation-Based Error-Driven Learning. In Proceedings of ARPA Human Language Technology Workshop, 1994.

Artigo no qual o autor descreve o paradigma de aprendizado de transformaçóes dirigido por erros e mostra sua aplicação na etiquetagem morfo-sintática de palavras de um texto.

[23] Deitel, H. M., Deitel P. J. C How to Program. Prentice Hall, Segunda Edição, 1994.

Livro sobre a linguagem de programação C.

[24] Finger, M. Tagging a Morphologically Rich Language - The Construction of the Tycho Brahe Parsed Corpus of Historical Portuguese. In Proceedings of First Workshop of Text, Speech and Dialogue, 1998.

Artigo no qual o autor mostra os problemas de se utilizar o método proposto por Brill para etiquetagem morfo-sintática de textos. Apresenta a solução de etiquetagem em fases e comenta algumas possíveis utilizações de etiquetadores em estudos de lingüística.

[25] Husain, K., Breedlove, R. F. PERL 5: Unleashed. SAMS Publishing, Primeira Edição, 1996.

Livro sobre a linguagem de programação PERL 5. 
[26] Kernigham, B., Ritchie, D. C: A Linguagem de Programação - Padrão ANSI. Editora Atlas, 1990.

Livro sobre a linguagem de programação C, padrão ANSI.

[27] Santorini, B. Part of Speech Tagging Guidelines for the Penn Treebank Project. 3rd revision, Segunda Impressão, 1990 (esta versão foi atualizada em 1995 por Robert MacIntyre).

Manual de etiquetagem do Penn Treebank Wall Street Journal Corpus, com o conjunto de etiquetas (morfológicas e sintáticas), os casos problemáticos (geradores de confusões e ambigüidades) e as convenções de etiquetagem (notação, abreviações, etc.).

[28] Wall, L., Christiansen, T. e Schwartz, R. L. Programming Perl. O'Reilly \& Associates, Inc., Segunda Edição, 1996.

Livro sobre a linguagem de programação PERL 5. 